University of Rhode Island

DigitalCommons@URI

Open Access Dissertations

1999

\title{
THE APPLICATION OF THE POPULATION APPROACH TO \\ PHARMACOKINETICS IN DRUG DEVELOPMENT
}

Kimberley Anne Jackson

University of Rhode Island

Follow this and additional works at: https://digitalcommons.uri.edu/oa_diss

\section{Recommended Citation}

Jackson, Kimberley Anne, "THE APPLICATION OF THE POPULATION APPROACH TO

PHARMACOKINETICS IN DRUG DEVELOPMENT" (1999). Open Access Dissertations. Paper 179.

https://digitalcommons.uri.edu/oa_diss/179

This Dissertation is brought to you for free and open access by DigitalCommons@URI. It has been accepted for inclusion in Open Access Dissertations by an authorized administrator of DigitalCommons@URI. For more information, please contact digitalcommons-group@uri.edu. 
THE APPLICATION OF THE POPULATION APPROACH TO PHARMACOKINETICS IN DRUG DEVELOPMENT.

BY

KIMBERLEY JACKSON

A DISSERTATION SUBMITTED IN PARTIAL FULFILLMENT OF THE REQUIREMENTS FOR THE DEGREE OF DOCTOR OF PHILOSOPHY

IN

APPLIED PHARMACEUTICAL SCIENCES

UNIVERSITY OF RHODE ISLAND

1999 
PHARMACOKINETICS IN DRUG DEVELOPMENT. 
DOCTOR OF PHILOSOPHY DISSERTATION

OF

KIMBERLEY JACKSON

APPROVED:

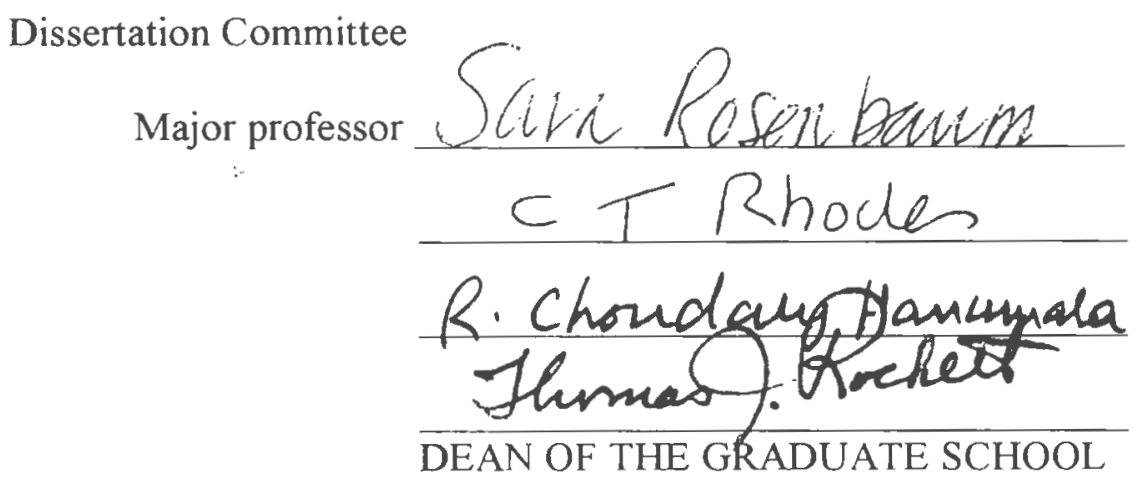

UNIVERSITY OF RHODE ISLAND

1999 


\begin{abstract}
The population approach to pharmacokinetic involves the estimation of mean pharmacokinetic parameters and their variability within a study population. Advantages of this approach include the ability to i) utilize sparse data, ii) analyze data from large, heterogeneous populations to obtain realistic and relevant estimates of variability and iii) evaluate the influence of patient characteristics on pharmacokinetic estimation.
\end{abstract}

Sparse data from a phase III clinical trial of the protease inhibitor, nelfinavir, were used to obtain estimates of the pharmacokinetic parameters and their variability. The effects of patient covariates on the pharmacokinetic parameters of nelfinavir were evaluated. Clearance, estimated from data in the latter part of a dosing interval, was estimated well due to random spread of the data in this part of the concentration-time profile. Only the influence of concomitant administration of the azole antifungal agent, fluconazole was statistically significant resulting in a reduction in clearance of $30 \%$. Problems arose in the estimation of volume of distribution and the absorption rate constant and their variability. The lack of early samples and the lack of variability in the timing of these samples contributed to the difficulty in estimating these parameters.

A simulation study was designed to investigate design issues including the ability to detect a sub-population with a $30 \%$ reduction in clearance. A one-compartment model with intravenous input was employed. Different designs consisting of 2 samples per individual in 100 individuals were evaluated at two levels of interindividual variability 
$(30 \%$ and $60 \%$ ). When interindividual variability was $30 \%$, a sub-population of 20 individuals could consistently be identified and the pharmacokinetic parameters of the model could be accurately estimated. Estimates of the variability parameters were less accurate but acceptable using some designs. When interindividual variability was $60 \%$, no design could consistently identify the sub-population even when the sub-population was 30 , and no design provided accurate estimates of all of the parameters. Overall, the performance of one design, which consisted of three sampling windows covering the whole dosing interval, proved superior to the other designs investigated. Increasing the total sample size and using the FOCE method in NONMEM improved the ability of this design. 


\section{ACKNOWLEDGEMENTS}

I would like to thank my major professor, Dr. Sara Rosenbaum, for her support, guidance and encouragement and the endless amount of time she spent with me throughout my studies. I extend a thank you to the other members of my doctoral committee, Dr. Christopher Rhodes and Dr. Choudary Hanumara, for their support and advice. In addition, I greatly appreciate the extra time that Dr. Rhodes spent in giving me help and the lively discussions that were involved in this. A special thank you to Dean Joan Lausier for her endless gems of advice and for providing motivation when it was needed. Also I would like to thank the chairman of my oral examining committee, Dr. Raymond Panzica, for giving his time and encouragement during my latter times at URI.

My thanks also to Dr. Ene Ette of Vertex Pharmaceuticals who managed to find the time in a very busy schedule to help me and share his expert knowledge of the field. And thank you to Dr. Michael Dudley of Microcide Pharmaceuticals for his continual support and for the opportunity to work in the industry which was a valuable experience.

I would like to thank Denise Gorenski whose friendship and support during my studies has meant a great deal to me. And thank you to Kathy Hayes for her friendship and help in navigating the system at URI - which was no mean feat!

Finally a thank you to my family and my friends without whose encouragement and support I could not have seen this through to the end. 


\section{PREFACE}

This document was prepared in the format of the manuscript plan in accordance to section 11-3 of the Graduate School Manual at the University of Rhode Island. The dissertation is divided into three sections.

Section I contains a general introduction to the objectives of the research. Section II consists of the main body of this dissertation. This section is composed of three manuscripts written in the format required for each scientific journal to which they are, or will be, submitted. A statement of overall conclusions for the entire dissertation is also included in this section. Section III contains 1 appendix that includes additional information and experimental details useful to the understanding of the work in section II. A bibliography follows section III in which all sources used as references in this document are cited. 


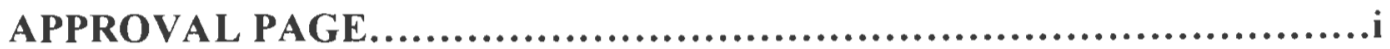

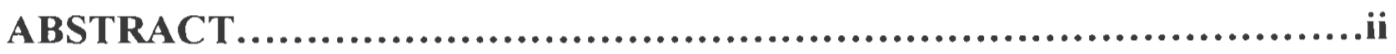

ACKNOWLEDGEMENTS...................................................

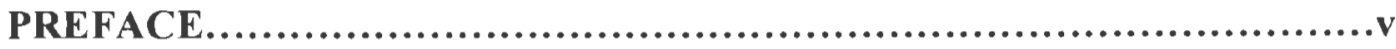

LIST OF PUBLICATIONS.................................................ii

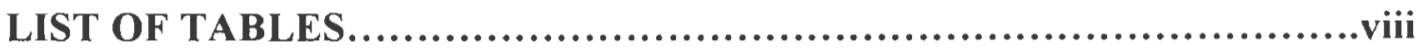

LIST OF FIGURES..........................................................

\section{SECTION I}

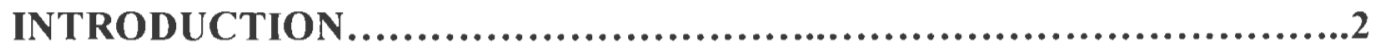

HYPOTHESES TESTED................................................

OBJECTIVES.............................................................

SECTION II

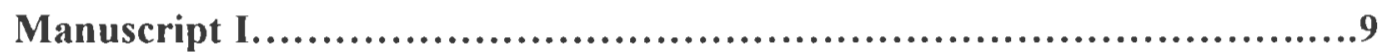

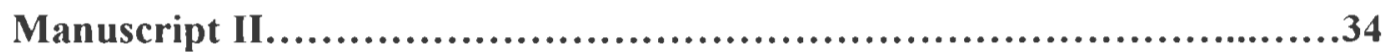

Manuscript III..............................................................64

SUMMARY OF CONCLUSIONS.........................................121

\section{SECTION III}

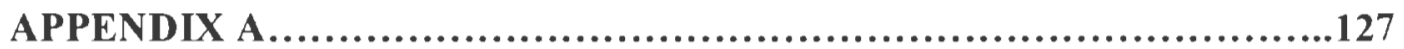

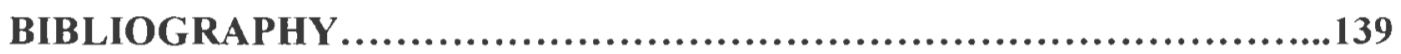




\title{
LIST OF PUBLICATIONS
}

The following is a list of journals and scientific meetings for which the manuscripts were prepared for and their current publication status.

\section{Manuscript I}

APPLICATION OF POPULATION PHARMACOKINETICS IN THE DRUG DEVELOPMENT PROCESS

Published in Drug Development and Industrial Pharmacy 24(12) 1155-1162 (1998).

\author{
Manuscript II \\ POPULATION PHARMACOKINETIC ANALYSIS OF VIRACEPTTM(NELFINAVIR \\ MESYLATE) IN HIV-RNFECTED PATIENTS ENROLLED IN A PHASE III \\ CLINICAL TRIAL. \\ Presented at $12^{\text {th }}$ World AIDS Conference, Geneva, July 1998.
}

Manuscript III DESIGN OF POPULATION PHARMACOKINETIC STUDIES UTILIZING SPARSE DATA.

Presented at AAPS $13^{\text {th }}$ Annual Meeting, San Francisco, November 1998. 


\section{LIST OF TABLES}

\section{MANUSCRIPT II}

Table 1: $\quad$ Characteristics of 174 Patients Evaluated in the Population

Pharmacokinetic Analysis of Nelfinavir .............................60

Table 2: $\quad$ Summary of Analyses of Significant Effects of Patient Covariates

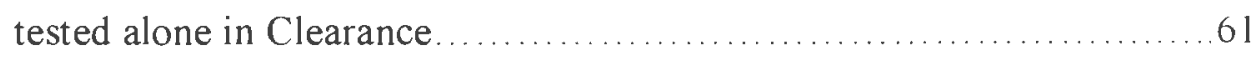

Table 3: Final Population Pharmacokinetic Parameters for Model 1 and

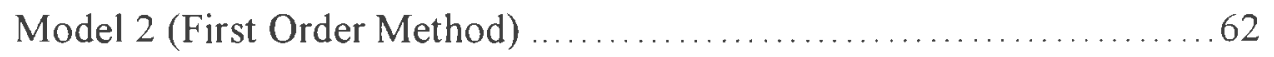

Table 4: $\quad$ Final Population Pharmacokinetic Parameters for Model 1 and

Model 2 (First Order Conditional Estimation Method) ...............63

\section{MANUSCRIPT III}

Table 1: $\quad$ Sampling Windows for Designs 1 to 3

Table 2: $\quad$ Number of NONMEM Runs in Which Group B was Successfully identified when Interindividual Variability was $30 \%$

Table 3: Number of NONMEM Runs in Which Group B was Successfully

identified when Interindividual Variability was $60 \%$

Table 4: $\quad$ Percent Bias of Parameter Estimates using all Three Designs

when Interindividual Variability in Clearance and Volume of

Distribution were $30 \%$

102 
Table 5: $\quad$ Percent Precision of Parameter Estimates using all Three Designs when Interindividual Variability in Clearance and Volume of

Distribution were $30 \%$ 103

Table 6: $\quad$ Percent Bias of Parameter Estimates using all Three Designs when Interindividual Variability in Clearance and Volume of

Distribution were $60 \%$ 104

Table 7: $\quad$ Percent Precision of Parameter Estimates using all Three Designs when Interindividual Variability in Clearance and Volume of

Distribution were $60 \%$ 105

Table 8: $\quad$ Percent Bias and Precision of Parameter Estimates using

Different Levels of Intraindividual Variability 106

Table 9: $\quad$ Percent Bias and Precision of Parameter Estimates using

Different Total Numbers of Individuals

Table 10: $\quad$ Percent Bias and Precision of Parameter Estimates obtained

when the FO Method was compared to the FOCE Method 108

\section{APPENDIX A}

Table 1: $\quad$ Parameter Estimates of the Basic Models of the Different Data Sets..... 128

Table 2: $\quad$ Basic Model Parameter Estimates using Four Different Models

Table 3: Results of Covariates that are found to be statistically Significant

In Clearance using Four Different Models

Table 4: $\quad$ Results of Covariates tested for an effect on Clearance using Model 1 and Model 2 (FO Method) 
Table 5: $\quad$ Results of Covariates tested for an effect on Clearance using Model 1 and Model 2 (FOCE Method) .................................... 132 


\section{LIST OF FIGURES}

\section{MANUSCRIPT III}

Figure la-b: Percent Runs in which Group B was Successfully Identified ... 109

Figure 2a-c: Percent Bias in Pharmacokinetic Parameter Estimates when

Interindividual Variability is set at $30 \%$

Figure 3a-c: Percent Precision in Pharmacokinetic Parameter Estimates when

Interindividual Variability is set at $30 \%$

Figure 4a-c: Percent Bias in Pharmacokinetic Parameter Estimates when

Interindividual Variability is set at $60 \%$

Figure 5a-c: Percent Precision in Pharmacokinetic Parameter Estimates when

Interindividual Variability is set at $60 \%$

Figure 6a-c: Percent Bias in Variability Parameter Estimates when

Interindividual Variability is set at $30 \%$

Figure 7a-c: Percent Precision in Variability Parameter Estimates when

Interindividual Variability is set at $30 \%$

Figure 8a-c: Percent Bias in Variability Parameter Estimates when

Interindividual Variability is set at $60 \%$

Figure 9a-c: Percent Precision in Variability Parameter Estimates when

Interindividual Variability is set at $60 \%$

Figure 10a-b: Percent Bias and Precision in Parameter Estimates

Comparing Design 3 to Design 4 
Figure $11 \mathrm{a}-\mathrm{b}$ : Percent Bias and Precision in Parameter Estimates

Comparing Design 3 to Design 5

Figure 12a-b: Percent Bias and Precision in Parameter Estimates

Comparing Design 3 to Design 6

\section{APPENDIX A}

Figure 1: Concentration versus time for patients who received a dose of $500 \mathrm{mg}$ three times a day

Figure 2: Concentration versus time for patients who received a dose of $750 \mathrm{mg}$ three times a day

Figure 3: $\quad$ NONMEM Control File for the Final Model (Model 1 and FO Method).

Figure 4: $\quad$ NONMEM Control File for the Final Model (Model 1 and FOCE Method) 136

Figure 5: $\quad$ NONMEM Control File for the Final Model (Model 2 and FO Method).

Figure 6: NONMEM Control File for the Final Model (Model 2 and FOCE Method). 
SECTION I 


\section{INTRODUCTION}

Pharmacokinetics is the study of the relationship between a given dose of a drug and the plasma concentrations achieved over time. Traditionally pharmacokinetic studies are usually conducted in a small, homogeneous group of individuals ( 1 - 3). After administration of the study drug each individual provides an extensive number of plasma samples that are then used to obtain estimates of that individual's pharmacokinetic parameters. Summary statistics of the parameter values within that group can then be calculated using standard methods. There are many advantages to this approach such as the statistics are straightforward and familiar to scientists and there are many years of experience using this methodology. However, there are also limitations e.g. only a small number of individuals can be studied and subjects tend to be either healthy volunteers or patients with a mild form of the disease and thus are not representative of the true population to be treated.

An alternative method to traditional pharmacokinetic analysis is the population approach to pharmacokinetic analysis (1-4). A major difference between the two methods is that the population approach can use data consisting of only a few samples per patient $(2,3)$. The unit of analysis is the study population. The population approach is used in a single step to obtain point estimates of the mean pharmacokinetic parameters and their variability within the population under investigation (2). As population pharmacokinetic studies tend to be conducted in a large, heterogeneous population the influence of demographic and physiological characteristics on the pharmacokinetics of the drug can 
be assessed. This method, like the traditional approach, has many potential benefits such as the ability to utilize sparse data and the ability to study larger populations more representative of the true population to be treated. There are also limitations to the approach that need to be recognized e.g. the unfamiliar and complex statistics and computer software and the lack of use of this technique to date.

One of the major advantages of the population approach is the ability to utilize only a few (even as little as one) samples per individual $(2,3)$. However the method can equally be applied to data that is rich or a combination of both rich and sparse data (1). Historically in phase III trials, random trough samples may be taken from some individuals to monitor compliance (5), which in many cases has been the only use of this data. The population approach is ideally suited to the analysis of this kind of data. By using the population approach useful information can be obtained on the pharmacokinetics of a new drug using data that already exists. This can be accomplished for little additional cost except for the cost of the actual analysis itself.

However a note of caution is necessary. It must be realized that the quality of an analysis is highly dependent on the design of the study and the quality of the data obtained. Thus, in order for the population approach to be implemented effectively, the design of the study and the collection of the data must be given careful consideration $(5,6)$.

Important aspects of study design to be considered include the number of individuals to include in the study, the number of samples per individual (e.g. a fixed number per 
individual or variable numbers) and the timing of sampling (e.g. optimal times, sampling windows or sampling completely at random). All levels of these factors must be chosen so that sufficient information is available to estimate the pharmacokinetic and variability parameters of interest. If the effect of a patient characteristic on a pharmacokinetic parameter is to be evaluated then it is important to ensure that the size of the subpopulation possessing that characteristic is adequate to detect the effect. In terms of the data itself, accurate dosing and sampling records and the documentation of covariate information are important considerations.

In short, the population approach to pharmacokinetic analysis has the potential to provide high quality, relevant information on a drug's pharmacokinetics from sparsely sampled data if the study is conducted in an appropriate manner. 


\section{HYPOTHESIS TESTED IN THIS PROJECT}

Design of population pharmacokinetic studies is an area of active investigation. Several simulation studies investigating issues such as the number of samples per individual, the timing of samples and the number of total individuals in the study necessary to produce accurate parameter estimates have been reported in the literature. As this approach is intended for use in situations when only sparse data is available such as a phase III clinical trial, then consideration must be given to these issues. In particular, the information available on pharmacokinetic parameters and their variability is highly dependent on the number of samples obtained per individual and the timing of these samples.

The influence of the size of a sub-population possessing a characteristic that significantly influences a pharmacokinetic parameter on the ability to detect that population in an analysis has received little attention. There are no formal studies in the literature that specifically address this issue and in instances when this design consideration is mentioned, the authors have chosen the size of the sub-population based upon their own experiences $(7,8)$.

The hypothesis to be tested in this research is that the population approach to pharmacokinetic analysis can be applied to sparsely sampled data to obtain precise and unbiased estimates of pharmacokinetic parameters and their variability and to distinguish significant covariate effects. 


\section{REFERENCES}

1. Aarons L. Sparse Data Analysis. European Journal of Drug Metabolism and Pharmacokinetics, 18 (1):97-100 (1993).

2. McLachlan A. J. Sparse Concentration Data Analysis using a Population approach: a valuable tool in clinical pharmacology. Clinical and Experimental Pharmacology and Physiology, 23: 995-999 (1996).

3. Samara E. and Granneman R. Role of population pharmacokinetics in drug development. A pharmaceutical industry perspective. Clinical Pharmacokinetics, 32 (4): 294-312 (1997).

4. Sheiner L. B. and Ludden T. M. Population Pharmacokinetics/Dynamics. Annual Review of Pharmacology and Toxicology, 32: 185-209 (1992).

5. Antal E. J., Grasela T. H. and Smith R. B. An Evaluation of Population Pharmacokinetics in Therapeutic Trials. Part III. Prospective Data Collection versus Retrospective Data Assembly. Clinical Pharmacology and Therapeutics, 46: 552-559 (1989).

6. Vozeh S., Steimer J. L., Rowland M., Morselli P., Mentre F., Balant L. P. and Aarons L. The use of population pharmacokinetics in drug development. Clinical Pharmacokinetics. 30 (2): $81-93$ (1996).

7. Sheiner L. B. and Benet L. Z. Premarketing Observational Studies of Population Pharmacokinetics of New Drugs. Clinical Pharmacology and Therapeutics, 38(5): 481-487 (1985).

8. Aarons L., Balant L. P., Mentre F.. Morselli P. L., Rowland M., Steimer J-L. and Vozeh S. Practical Experience and issues in designing and performing population pharmacokinetic / pharmacodynamic studies. European Journal of Clinical Pharmacology, 49: 251 - 254 (1996). 


\section{OBJECTIVES}

The objectives of this research project are:

1. To determine the pharmacokinetic parameters of a marketed drug using a sparse sampling design (observational data).

2. To determine if the study design is adequate to accurately determine these parameters.

3. To evaluate the influence of patient covariates on the pharmacokinetics of this drug.

Using simulated data:

4. To evaluate the ability to accurately measure the pharmacokinetic parameters of an intravenously administered drug using a sparsely sampled study design consisting of only two samples per individual.

5. To determine the influence of the size of a sub-population possessing different pharmacokinetic characteristics on the ability to detect that sub-population.

6. To assess the ability to estimate the value of the pharmacokinetic parameter in the sub-population. 
SECTION II 


\title{
MANUSCRIPT I
}

\author{
Application of Population Pharmacokinetics to the Drug Development Process \\ * published in Drug Development and Industrial Pharmacy 24(12) $1155-1162$ (1998).
}

\begin{abstract}
Population pharmacokinetics is playing an increasing role in clinical drug development. An overview of the population approach, including software and the advantages and limitations of the approach compared to the traditional approach to pharmacokinetic studies, is given. This paper also documents how the area has evolved over the past 15 years and addresses some of the issues that have arisen over the design and conduct of population studies. Finally, some alternative applications of the population approach are given for areas other than clinical drug development.
\end{abstract}




\section{INTRODUCTION}

Pharmacokinetics is the study of the relationship between the dose of a drug and the manner in which its plasma concentrations change over time. A pharmacokinetic model provides a mathematical representation of this relationship and relates the independent variables of time and dose to the dependent variable, plasma concentration, using pharmacokinetic parameters such as clearance $(\mathrm{CL})$ and volume of distribution $(\mathrm{Vd})$ Pharmacodynamics is the study of the relationship between concentrations of the drug at the site of action and its physiological effect.

The traditional approach to pharmacokinetic studies involves taking intensive samples, up to 10 or 20 per individual, from a small group of subjects or patients. The data from each subject are individually fitted to a pharmacokinetic model (e.g., a one- or twocompartment model) to obtain that individual's pharmacokinetic parameters. Then, summary statistics such as the mean and the variance of the group are calculated based on each individual's pharmacokinetic parameters. Initially, these studies are often performed on healthy volunteers, especially in phase I clinical studies.

The population approach to the analysis of pharmacokinetic data also provides estimates of the average value of pharmacokinetic parameters in a study population and gives a measure of the variability of these parameters within that population (1). In contrast to the traditional approach, the population approach is based on only a few samples from each subject in a larger number of subjects. In addition, the population approach provides parameter estimates from the population of individuals in a single step. A population 
model generally consists of two components: a pharmacokinetic or structural model and a pharmacostatistical model. As a result, the term mixed effects modeling is often used to describe the modeling process since two types of parameters are estimated: the fixed effect parameters associated with the pharmacokinetic model and the random effect parameters that describe the pharmacostatistical model (2)

Fixed effect parameters describe the relationship between the plasma concentration and the fixed effects. Fixed effects include the dose, physiological factors such as age, weight and creatinine clearance and other factors such as concomitant medications. Fixed effect parameters include typical pharmacokinetic parameters such as volume of distribution (Vd) and clearance (CL) and proportionality constants that quantify the relationship between a pharmacokinetic parameter such as clearance and a fixed effect such as creatinine clearance (1-3).

Random-effect parameters are used to quantify variability in pharmacokinetic parameter estimates that arise due to interindividual (between subjects) and intraindividual (within subject) variations (1). Interindividual variability is the random between subject variability that cannot be explained in terms of fixed effects. It is important to obtain an estimate of unexplainable variability for a new drug because the safety and efficacy of a drug tends to decrease as unexplainable variability increases (4). Intraindividual variability is the variability that occurs within an individual. It includes errors that arise from the measurement of drug concentrations, model misspecification due to 
oversimplification of the model, and random variation in a patient's pharmacokinetic parameters that can occur over time $(1,2,4,5)$.

There are numerous articles in the literature that can be consulted to provide a more comprehensive review of the theory and methodology underlying the population approach to pharmacokinetic analysis (1-3,5-8).

\section{COMPUTER SOFTWARE}

Software development for population analyses is an active area of investigation, and a number of programs are currently available. A meeting of experts was held in 1994 to discuss software issues associated with the analysis of population pharmacokinetic and pharmacodynamic data. The participants concluded that programs need to be userfriendly with good graphical interfaces, have the ability to specify complex pharmacokinetic and pharmacodynamic models, and be able to handle sparse data (9). NONMEM (Nonlinear Mixed Effects Modeling) (10) is the software most often used and tested for these analyses $(9,11)$. Other currently available software includes NPML (NonParametric Maximum Likelihood) (12), NPEM (Non-Parametric Expectation Maximization) (13) and the programs that implement the Bayesian approach using Gibbs sampling (14)

Each method of applying the population approach has its own assumptions and limitations. Some researchers have advocated using several methods to analyze one dataset as a means of confirming results and of highlighting problems in methodology 
$(9,15)$. A comparative study carried out in 1992 under the initiative of the American Statistical Association compared four population modeling methods: NONMEM, Gibbs sampling, SPML (semi-parametric maximum likelihood) and NPML. They showed that the different methods gave similar results, with only minor discrepancies observed (9). In 1997, the Population Pharmacokinetic Modeling Workgroup formed by the Biopharmaceutical Section of the American Statistical Association compared population methods using two simulated data sets (11). Their report included analyses performed using seven different modeling programs: NONMEM, a conditional first-order method implemented in S-Plus (16), two alternative first-order methods implemented in SAS (1719), the Bayesian approach using Gibbs sampling (14), a semi-non-parametric approach (20) and NPML (12). The statistical theory and methodology underlying these software programs can be found in the literature $(5,7,12-14,16-20)$. The group observed differences in some parameter estimates when the different approaches were compared Thus, there appears to be conflicting evidence regarding the comparability of some methods of implementing the population approach and this subject requires further investigation.

\section{ADVANTAGES AND LIMITATIONS OF THE POPULATION APPROACH}

In contrast to traditional studies, the population approach to pharmacokinetic studies requires fewer samples per patient. Thus, these designs are more suited to the study of sub-populations such as pediatrics, geriatrics and the very ill (e.g. AIDS and cancer patients or patients with renal and hepatic impairment), for whom there are ethical constraints to taking many blood samples per patient $(3,5,7)$. 
Traditional pharmacokinetic studies often involve volunteers or patients with mild forms of the disease of interest, and inclusion and exclusion criteria are often very strict. Thus, these patients/subjects are not very representative of the population to be treated, and the pharmacokinetics of the study drug for these patients may differ significantly from the pharmacokinetics of patients who receive the drug in clinical practice (21). As fewer samples are required per patient in a population study, it is feasible to study a greater number of patients. For example, if a population pharmacokinetic study is incorporated into a phase III clinical trial, patients under study are more representative of the population for which the drug will eventually be used; thus the results of the analysis are of more relevance to the population of interest. Also, as the patient population is generally more heterogeneous, it becomes possible to examine the effect of various patient characteristics (e.g., age, weight, renal function, concomitant medications) on the pharmacokinetics of the drug. Thus, if a population analysis is incorporated into a phase II or III trial, then drug disposition can be evaluated early in the development process, and the results used to guide dosage recommendations in different sub-populations (4).

Traditional studies are expensive to conduct due to their strict scientific design, so only a small number of individuals can be studied, which can result in poor estimates of interindividual variability. In contrast, a population study can be done using observational data, that is, data collected under less-restrictive conditions, such as in clinical practice, than in a traditional study. The requirement for fewer samples per individual and the use of routine data enables a population study to be conducted less expensively. Plasma 
samples are often obtained periodically from subjects enrolled in phase III trials to monitor compliance. Therefore, if these samples were used in a population pharmacokinetic study, there would be minimal additional cost to the sponsor.

A limitation to the use of population pharmacokinetic methods is the complex data analysis techniques involved. In contrast, the analysis of traditional pharmacokinetic data is relatively straightforward and is performed using common, simple statistical methods (3). The observational design of a population study does not provide as convincing evidence for causation as the rigid scientific control of a traditional pharmacokinetic study. However, traditional studies are done in patients often not representative of the population of interest, which makes the relevance of the results questionable.

\section{INTEGRATION OF POPULATION PHARMACOKINETICS IN THE DRUG DEVELOPMENT PROCESS}

In 1983, a discussion paper on the testing of drugs in the elderly was issued by the Food and Drug Administration (FDA). It advocated the inclusion of population pharmacokinetic studies as part of phase III clinical trials (22). Initially, there was a negative reaction from the pharmaceutical industry to this suggestion for a number of reasons (4). First, the method of data analysis was unfamiliar to most scientists, and the complex nature of the analytical technique demanded specialized expertise. There was the belief that identification of a factor influencing the pharmacokinetics of the drug during drug development could result in the FDA requiring a prospective study to investigate this possible influence. Some believed that incorporating a population 
pharmacokinetic study into a trial protocol could result in additional cost and reduced compliance with the study protocol. Finally, there were questions regarding the quality of the data used in such an analysis $(3,4,23,24)$.

By the late 1980s to early 1990s, a number of applications of the population approach had appeared in the literature, they were summarized by Sheiner and Ludden in 1992 (7). However, the majority were carried out in a clinical setting after marketing of the drug and were not performed in the pre-approval process (25).

At this time, Grasela and colleagues published a series of articles in which they evaluated the use of population pharmacokinetics in clinical drug development $(21,26-28)$. They applied the population approach in four different scenarios: a phase III clinical trial of patients who contributed only a few plasma samples each, a phase III clinical trial designed to detect a drug-drug interaction, a prospectively designed clinical trial that included forms designed to collect and record information relating to plasma sampling and dosing specifically for determining population pharmacokinetics, and finally, a postmarketing surveillance study that had limited control of design issues. They found that parameter estimates obtained using the population approach in all situations were comparable to estimates obtained in traditional pharmacokinetic studies and thus confirmed the potential use of this methodology in phase III and IV studies.

An interdisciplinary conference was held in April 1991 to discuss the integration of pharmacokinetics in rational drug development (29). The report from the conference 
advocated the use of population approaches in phase III trials to identify those patient characteristics that influence the pharmacokinetics of a drug in different subpopulations and to use this information in drug labeling. It was accepted that a population pharmacokinetic analysis was not the primary objective of phase II, III and IV trials; thus, the methods for a population pharmacokinetic study, which must be incorporated into the efficacy protocol, should be as simple as possible and not have an impact on the major goals of the study $(30,31)$

In March 1995, a meeting of experts was held to discuss design issues associated with conducting population pharmacokinetic and pharmacodynamic studies (30). The experiences of the committee were that the population approach had frequently been implemented successfully in phase II and phase III studies. The consensus was that population pharmacokinetics should be included in clinical trials, and the discussion focused on design issues associated with the inclusion of a population pharmacokinetic study in a phase II or phase III efficacy trial

A report published in 1996 on the implementation of the population approach in clinical drug development proposed many instances in which the population approach could successfully be employed in the drug development process from the preclinical stage to postmarketing studies (15). Phase 1 studies provide initial information on the pharmacokinetics and pharmacodynamics of a drug in human subjects, usually healthy volunteers (29). Intensive sampling, as employed in traditional pharmacokinetic studies, is advocated at this stage to establish an initial pharmacokinetic profile for the drug (15). 
However, if data from sufficient patients can be pooled, then the population approach can be applied at this stage. An advantage in doing this is that the data from all patients can be fit to the same pharmacokinetic model (i.e., a one- or two-compartment model) whereas in traditional studies, different models may sometimes be fit to data from different patients (15).

Phase 11 studies are used to determine initial efficacy data in relatively small groups of patients with the disease to be treated and to investigate the dose-response relationship (29). A more rational design of subsequent clinical studies can be undertaken if the population approach is applied at this stage to investigate variability in response and relationships with covariates $(15)$.

Phase III clinical trials are designed to confirm the efficacy of a drug and to establish a toxicity profile (29). It is often the nature of these studies to exclude patients with diverse characteristics (e.g., patients with renal or hepatic disease) to increase the statistical power of the study. It is these patients whose pharmacokinetic profile is most likely to differ and whose dosage regimen may need to be individualized. As a solution to this problem, Vozeh et al. proposed that these patients be included in the study as a satellite group whose data would be excluded from the efficacy assessment, but included in the population pharmacokinetic analysis (15).

In September 1997, the FDA issued proposed guidelines to govern the conduct and analysis of population pharmacokinetic studies in the drug development process (32). 
Design issues associated with these studies were discussed in the guidelines. Obviously, the issues depend to some extent on what stage in the drug development process (preclinical, phase I - III or postmarketing) in which the analysis is being conducted as this drives the kind of data collected. The new regulations proposed by the FDA, which are to require companies to conduct extensive clinical studies in the pediatric population during drug development, provide an opportunity for the wide application of the population approach (33)

\section{ISSUES ASSOCIATED WITH THE DESIGN AND CONDUCT OF A POPULATION PHARMACOKINETIC STUDY}

There are a number of fundamental requirements to fulfill in order to conduct a good population pharmacokinetic study. A sensitive and specific assay is needed to measure plasma concentrations of parent drug and clinically relevant metabolites; confirmation from preliminary studies is required to demonstrate a correlation between drug or metabolite concentrations and clinically relevant effects; and last, preliminary pharmacokinetic studies should have established the basic pharmacokinetic model to describe the drug's disposition, although population analyses of sparse data may use less complex structural models than are required in data-rich situations $(2,4,9)$.

The draft documentation issued by the FDA governing the conduct of population pharmacokinetic studies discussed some of the issues involved in designing a population pharmacokinetic study. These include the number of subjects required for a population 
analysis, the number of samples required per subject, and the optimum time of sampling (32). Simulation studies and real data sets are being used to investigate these issues.

In the early 1980 s, Sheiner and Beal conducted three simulation studies with designs that were based on three experiments, each consisting of 10 subjects who were extensively sampled. They found that estimates of interindividual variability were imprecise as a result of the small number of individuals, even though each individual provided many samples (34). In another study, they used a one-compartment intravenous model to simulate data. They found that when the total number of samples were fixed at approximately 100 , the bias and precision of pharmacokinetic and variability parameters were comparable when the data consisted of three samples from 33 patients or two samples from 50 patients. However, estimates were less precise and more biased when the data consisted of four samples from 25 patients (35).

One study investigated the number of samples per patient and the total number of samples necessary to provide accurate pharmacokinetic parameter estimates of cyclosporine in liver transplant patients (36). The data consisted of 203 samples from 42 individuals and was analyzed using a one-compartment model implemented in NPEM. Estimates of clearance and volume of distribution converged and showed very little variation once there were two levels per patient and the total number of patients in the analysis reached 15-20. Others found that analyses using either two or three samples per patient provided estimates that were not significantly biased or imprecise when compared with the intense sampling strategy (37). 
A simulation study using a two-compartment model with intravenous input found that pharmacokinetic parameter estimates were accurate using from four to six samples per subject for 100 subjects, but interindividual variabilities were biased using the foursample design (38). Also in this study, the effect of the number of subjects was assessed using a six-sample design. They evaluated seven levels from 20 to 100 subjects and found that all pharmacokinetic parameters were comparable irrespective of the sample size, but estimates of interindividual variability became less biased as the number of subjects increased.

Another group used simulated data to mimic sparsely sampled data for 100 patients from a phase III clinical trial in which either one or two blood samples were taken per patient on two occasions (39). They compared various sampling strategies for bias and precision of population parameter estimates and found that parameter estimates were often more precise and less biased when patients provided two samples per visit as compared to only one.

Thus, it appears that two samples per individual for 30 to 50 individuals can provide accurate estimates of population average parameters. However, more individuals and more samples per patient may be required to obtain unbiased estimates of interindividual variability (40). Obviously, the specific pharmacokinetic model used to fit the data and the number of parameters to be estimated has an impact on the number of samples required per individual 
Some researchers have advocated the use of random sampling of plasma concentrations within the population $(21,30)$. However, it is likely that the quality of information obtained will increase if informative sampling times are selected. Samples obtained at the time of peak serum concentrations usually contain the most information about the volume of distribution, whereas samples obtained in the middle of a dosing interval are informative about clearance (2). Others have employed Optimal Sampling Theory (OST) to reduce the number of samples required per subject $(41,42)$. This method ensures that data are collected at informative times for estimation of pharmacokinetic parameters $(37,43-47)$. These studies investigated various sampling schedules and pharmacokinetic models; in all cases, the optimally sampled, reduced data sets provided accurate estimates of clearance, often the parameter of most interest. In some, but not all, cases, other pharmacokinetic parameters were also accurately estimated.

The quality of the data used in a population analysis is of paramount importance. Ette, Sun, and Ludden investigated the use of balanced (i.e., equal number of samples per patient) versus unbalanced data and found that the precision of parameter estimates, but not accuracy, was affected by missing data (48). Sun et, al. conducted a simulation study to investigate the effect of misrecorded sample times on parameter estimation in NONMEM (49). Obviously a well designed study may not provide good results if sample times are not recorded accurately. Sun, Ette, and Ludden found that estimates of clearance tended to be unbiased when errors were random or systematically positive whereas the estimate of clearance was biased when there was a negative systematic error. 
One study compared prospectively and retrospectively collected data (27). Specific forms were designed to collect and record information related to plasma sampling and dosing in the prospective study. Patient records were used to obtain information in the retrospective study. The prospective study was found to produce pharmacokinetic estimates comparable to previously reported estimates from traditional studies, whereas the retrospective study yielded biased estimates. The results from these studies demonstrate the need for good quality data in order to conduct a meaningful population pharmacokinetic analysis.

Validation of population pharmacokinetic models (i.e., if the parameter estimates and covariates included in a model based on one set of data can be reproduced with another set of data) is an area of current interest (32). The various approaches that have been used to date, such as data splitting and the bootstrap resampling technique, have recently been discussed (50).

In summary, there are many ongoing issues in the design and conduct of population pharmacokinetic analyses. It appears that two samples per patient for 100 patients would be a reasonable minimum number of patients and samples required to develop a population pharmacokinetic model. It should be noted that the number of samples obtained from each subject depends on the number of pharmacokinetic parameters to be estimated (21). Thus, care should be taken when extrapolating results from specific situations that use particular pharmacokinetic models to other situations. A well-planned 
study protocol which describes the objectives and methodology for conducting a population pharmacokinetic analysis is required. It should include a specific form that is simple in design to record sample times and dosing history. Education of clinical investigators is also essential to ensure that good quality data is obtained.

\section{OTHER APPLICATIONS OF POPULATION PHARMACOKINETICS}

Although the majority of discussion has involved the implementation of the population approach in clinical drug development, there is interest in using these methods in preclinical development, although application of the population approach in preclinical studies is still relatively sparse $(15,51-54)$. Two examples can be found in the literature that investigate the use of the population approach in one animal species only $(53,54)$

Both studies used a one sample per animal design, which is often the case in preclinical studies. The first study showed that variability in volume of distribution could be partially explained due to gender differences, and the second study produced unbiased and precise estimates of the pharmacokinetic parameters. However, both studies were unable to separate interindividual from intraindividual variability and thus did not provide good estimates of variability.

The use of the population approach to investigate the pharmacokinetics and influence of covariates in a single species requires further study to show that it is a meaningful and cost-effective analysis to undertake. A potential application of the population approach in 
preclinical studies is to analyze data from a number of animal species in order to investigate allometric relationships using weight as a covariate (15).

Therapeutic drug monitoring (TDM) is applied in clinical practice to monitor the plasma concentrations of drugs that have a narrow therapeutic range. TDM is used to individualize the dose in order to avoid subtherapeutic levels of the drug or unwanted toxic effects (55). Relevant prior pharmacokinetic parameter estimates are required in order to implement TDM (56). Population pharmacokinetic studies can be used to provide these a priori estimates, and there are many examples in the literature where pharmacokinetic parameters that have been derived from population analyses to be used in this manner (see the summary by Thomson and Whiting, Ref. 56).

\section{CONCLUSIONS}

The population approach to pharmacokinetic studies is a new field that is rapidly growing and gaining acceptance in the pharmaceutical arena. The population approach can be used to analyze data that consists of only a few samples per individual. Thus, it is ideally suited to analyze observational data that is collected during clinical studies to monitor compliance, data pooled from early phase traditional pharmacokinetic studies, and data collected through routine clinical practice in postmarketing studies.

The population approach provides estimates of the mean population pharmacokinetic parameters within a population and variability of these estimates within that population. This method partitions the variability into between variability and within variability, and 
it can be used to explain the variability in pharmacokinetic parameter estimates in terms of physiological fixed effects. In doing so, this method can provide information on possible patient subgroups at risk of excessive drug accumulation or subtherapeutic levels, and it can be used to develop guidelines for drug dosage individualization $(2,4)$

The advent of proposed guidelines from the FDA that govern the design and conduct of population pharmacokinetic studies supports the use of these studies in the drug development process. 


\section{REFERENCES}

1. B. Whiting, A. W. Kelman, and J. Grevel, Population pharmacokinetics: Theory and clinical application, Clin. Pharmacokinet., 11,387-401 (1986).

2. T. M. Ludden, Population pharmacokinetics, J. Clin. Pharmacol, 28, 1059-1063 $(1988)$

3. L. B. Sheiner and T. H. Grasela, An introduction to mixed effect modeling: Concepts, definitions and justification, J. Pharmacokinet. Biopharm., 19 (3), 11 S - 24S (1991).

4. L. B. Sheiner and L. Z. Benet, Premarketing observational studies of population pharmacokinetics of new drugs, Clin. Pharmacol. Ther., 38 (5), 481-487 (1985).

5. S. E. Rosenbaum, A. A. Carter, and M. N. Dudley, Population pharmacokinetics: Fundamentals, methods and applications, Drug Dev. Ind. Pharm., 21(9), $1115-1141$ $(1995)$

6. L. Aarons, Sparse data analysis, Eur. J. Drug Met. Pharmacokinet, 18(1), 97-100 (1993).

7. L. B. Sheiner and T. M. Ludden, Population pharmacokinetics/pharmacodynamics Annu. Rev. Pharmacol. Toxicol., 32, 185-209 (1992)

8. S. L. Beal and L. B. Sheiner, Estimating population kinetics, CRC Crit. Rev. Biomed. Eng., 8 (3), 195-222 (1982).

9. L. Aarons, L. P. Balant, F. Mentre et al, Population approaches in drug development: Report on an expert meeting to discuss population pharmacokinetic/pharmacodynamic software, Eur. J. Clin. Pharmacol., 46, 389-391 (1994). 
10. S. L. Beal and L. B. Sheiner (eds.), NONMEM (Isers Guides, NONMEM Project Group, University of California at San Francisco, San Francisco, CA. (1992).

11. D. J. Roe. Comparison of population pharmacokinetic modeling methods using simulated data: Results from the Population Modeling Workgroup, Stat. Med., 16, $1241-1262$ (1997).

12. A. Mallet, A maximum likelihood estimation method for random coefficient regression models, Biometrika, 73, 645-656 (1986).

13. A. Schumitzky, Nonparametric EM algorithms for estimating prior distributions. Applied Mathematics and Computation, 45, 141-157 (1991).

14. J. Wakefield, A. F. M. Smith, A. Racine-Poon, and A. Gelfand, Bayesian analysis of linear and nonlinear population models using the Gibbs sampler, Applied Statistics, $43,201-221(1994)$.

15. S. Vozeh, J. L. Steimer, M. Rowland et al, The use of population pharmacokinetics in drug development, Clin. Pharmacokinet. 30 (2), 81-93 (1996).

16. M. J. Lindstrom and D. M. Bates, Nonlinear mixed effects models for repeated measures data, Biometrics, 46, 673-687 (1990).

17. E. F. Vonesh and R. L. Carter, Mixed-effects nonlinear regression for unbalanced repeated measures, Biometrics, 48, 1-17 (1992).

18. E. F Vonesh, Non-linear models for the analysis of longitudinal data. Stat. Med., 11 , 1929-1954 (1992)

19. R. D. Wolfinger, Laplace's approximation for nonlinear mixed effects models, Biometrika, 80, 791-795 (1993). 
20. M. Davidian and A. R. Gallant, The nonlinear mixed effects model with a smooth random effects density, Biometrika, 80, 475-488 (1993).

21. T. H. Grasela, E. J. Antal, R. J. Townsend, and R. B. Smith, An evaluation of population pharmacokinetics in therapeutic trials. Part 1. Comparison of methodologies, Clin. Pharmacol. Ther., 39 (6), 605-612 (1986)

22. R. Temple, Discussion paper on the testing of drugs in the elderly, Memorandum of the Food and Drug Administration of DHHS, Washington, DC, (1983)

23. E. Samara and R. Granneman, Role of population pharmacokinetics in drug development. A pharmaceutical industry perspective, Clin. Pharmacokinet., 32 (4), 294-3 12 (1997).

24. W. A. Colburn, Controversy IV: Population Pharmacokinetics, NONMEM and the Pharmacokinetic Screen; Academic, Industrial and Regulatory Perspectives. J. Clin. Pharmacol., 29, 1-6 (1989).

25. L. Aarons, Population pharmacokinetics: Theory and practice. Br. J. Clin. Pharmacol., 32, 669-670 (1991).

26. T. H. Grasela, E. J. Antal, and R. B. Smith, An evaluation of population pharmacokinetics in therapeutic trials. Part II. Detection of a drug-drug interaction, Clin. Pharmacol. Ther., 42, 433-441 (1987).

27. E. J. Antal, T. H. Grasela, and R. B. Smith, An evaluation of population pharmacokinetics in therapeutic trials. Part III. Prospective data collection versus retrospective data assembly, Clin. Pharmacol. Ther., 46, 552-559 (1989). 
28. C. L. DeVane, T. H. Grasela, E. J. Antal, and R. L. Miller, An evaluation of population pharmacokinetics in therapeutic trials. Part IV. Application to postmarketing surveillance, Clin. Pharmacol. Ther., 53, 521-528 (1993).

29. C. C. Peck, W. H. Barr, L. Z. Benet et al., Conference Report: Opportunities for integration of pharmacokinetics, pharmacodynamics and toxicokinetics in rational drug development, Clin. Pharmacol. Ther., 51, 465-473 (1992).

30. L Aarons, L. P. Balant, F Mentre et al., Practical Experience and issues in designing and performing population pharmacokinetic/ pharmacodynamic studies, Eur. J. Clin. Pharmacol., 49, 251 - 254 (1996)

31. E. J. Antal, T. H. Grasela and R. B. Smith, The application of population pharmacokinetic analyses to large scale clinical efficacy trials, J. Pharmacokinet. Biopharm., 19 (3), 37S - 46S (1991).

32. Guidance for Industry: Population Pharmacokinetics (Draft Guidance), U.S. Department of Health and Human Services, Food and Drug Administration, Center for Drug Evaluation (CDER) (September 1997).

33. Proceedings from the Public Meeting on FDA 's Proposed Regulation to Increase Pediatric Use Information for I)rugs and Biologics, U.S. Department of Health and Human Services, Food and Drug Administration, Center for Drug Evaluation (CDER) (October 27 1997).

34. L. B. Sheiner and S. L. Beal, Evaluation of methods for estimating population pharmacokinetic parameters II. Biexponential model and experimental pharmacokinetic data, J. Pharmacokinet. Biopharm., 9 (5), 635-651 (1981). 
35. L. B. Sheiner and S. L. Beal, Evaluation of methods for estimating population pharmacokinetic parameters III. Monoexponential model: Routine clinical pharmacokinetic data, J. Pharmacokinet. Biopharm., 11 (3), 303-319 (1983).

36. V Breant, B Charpiat, J. M. Sab et al., How many patients and blood levels are necessary for population pharmacokinetic analysis? A study of a one compartment model applied to cyclosporine, Eur. J. Clin. Pharmacol., 51, 283 - 288 (1996).

37. G. L. Drusano, A. Forrest, G. Yuen et al., Optimal Sampling Theory: Effect of error in a nominal parameter value in bias and precision of parameter estimation, Clin. Pharmacol., 34, 967-974 (1994).

38. E. I. Ette, H. Sun and T. M. Ludden, Design of population pharmacokinetic studies, Proc. Am. Stat. Assoc, 487-492 (1994).

39. E. N. Jonsson, J. R. Wade and M. O. Karlsson, Comparison of some practical sampling strategies for population pharmacokinetic studies, J. Pharmacokinet. Biopharm., 24 (2), 245-263 (1996)

40. M. K. Al-Banna, A. W. Kelman and B Whiting, Experimental design and efficient parameter estimation in population pharmacokinetics, J. Pharmacokinet. Biopharm., $18(4), 347-360(1990)$

41. J. J. DiStephano III, Optimized blood sampling protocols and sequential design of kinetic experiments, Am. J. Physiol., 240, R259-R265 (1981).

42. D. Z. D'Argenio, Optimal sampling times for pharmacokinetic experiments, J. Pharmacokinet. Biopharm., 9 (6), 739-756 (1981). 
43. A. Forrest, C. H. Ballow, D. E. Nix et al., Development of a population pharmacokinetic model and optimal sampling strategies for intravenous ciprofloxacin, Antimicrob. Agents and Chemother., : 1065-1072 (1993).

44. G. L. Drusano, A. Forrest, K. I. Plaisance and J. C. Wade, A prospective evaluation of optimal sampling theory in the determination of the steady-state pharmacokinetics of piperacillin in febrile neutropenic patients, Clin Pharmacol. Ther., 45, 635-641 $(1989)$.

45. G. J. Yuen, G. L. Drusano, A. Forrest et al., Prospective use of optimal sampling theory: Steady-state ciprofloxacin pharmacokinetics in critically ill trauma patients, Clin Pharmacol Ther., 46, 451-457 (1989).

46. G. L. Drusano, A. Forrest, M. J. Snyder et al., An evaluation of optimal sampling strategy and adaptive study design, Clin. Pharmacol. Ther., 44, 232-238 (1988)

47. A. H. Burstein, P Gal and A. Forrest, Evaluation of a sparse sampling strategy for determining vancomycin pharmacokinetics in preterm neonates: application of optimal sampling theory, Ann. Pharmacother., 31, 980-3 (1997)

48. E. I. Ette, H. Sun and T. M. Ludden, Ignorability and parameter estimation in longitudinal pharmacokinetic studies, J. Clin. Pharmacol., 38, 221-226 (1998).

49. H. Sun, E. I. Ette and T. M. Ludden, On the recording of sample times and parameter estimation from repeated measures pharmacokinetic data, J. Pharmacokinet.

Biopharm., 24 (6), 637 - 650 (1996).

50. E. I. Ette, Stability and performance of a population pharmacokinetic model, J. Clin. Pharmacol, , 37, 486-495 (1997). 
51. L. Aarons, J. W. Mandema and M. Danhof, A population analysis of the pharmacokinetics and pharmacodynamics of midazolam in the rat, J. Pharmacokinet Biopharm., 19 (5), 485-496 (1991).

52. I. F. Troconiz, L. G. Lopez-Bustamante and D. Fos, Tenoxicam Pharmacokinetics in rats: A population model, J. Pharm. Sci., 84 (12), 1482- 1487 (1995).

53. E. I. Ette, A. W. Kelman, C. A. Howie and B. Whiting, An application of the population approach to animal pharmacokinetics during drug development, Clin. Res. Regul. Affairs, 11 (3 and 4), 243-255 (1994).

54. E. I. Ette, A. W. Kelman, C. A. Howie and B. Whiting, Influence of inter-animal variability on the estimation of population pharmacokinetic parameters in pre-clinical studies, Clin. Res. Regul. Affairs, 11(2), 121-139 (1994).

55. R. W. Jelliffe, A. Schumitsky, D. Bayard et al,, Model-based, goal-oriented, individualized drug therapy, Clin. Pharmacokinet., 34 (1), 57-77 (1998).

56. A. H. Thomson and B. Whiting, Bayesian parameter estimation and population pharmacokinetics, Clin. Pharmacokinet., 22 (6), 447-467 (1992). 


\title{
MANUSCRIPT II
}

\author{
A Population Pharmacokinetic Analysis of the Protease Inhibitor, Nelfinavir \\ Mesylate in Human Immunodeficiency Virus (HIV) Infected Patients Enrolled in a \\ Phase III Clinical Trial. \\ *presented at the $12^{\text {th }}$ World AIDS Conference, Geneva, 1998.
}

\begin{abstract}
A population pharmacokinetic analysis was conducted on nelfinavir in patients infected with Human Immunodeficiency Virus (HIV), who were enrolled in a phase III clinical trial. The data consisted of 509 plasma concentrations from 174 patients who received nelfinavir at a dose of $500 \mathrm{mg}$ or $750 \mathrm{mg}$ three times a day. The analysis was performed using NONMEM. A one-compartment model with first-order absorption best described the data. The timing and number of early post dose blood levels did not allow accurate estimation of volume of distribution $(\mathrm{Vd} / \mathrm{F})$ and the absorption rate constant $(\mathrm{ka})$. As a result, two models were used to analyze the data, Model 1 in which oral clearance $(\mathrm{CL} / \mathrm{F}), \mathrm{Vd} / \mathrm{F}$ and ka were estimated and Model 2 in which $\mathrm{Vd} / \mathrm{F}$ and ka were fixed and only $\mathrm{CL} / \mathrm{F}$ was estimated. The values of $\mathrm{Vd} / \mathrm{F}$ and $\mathrm{ka}$ were fixed to those obtained from analysis of data from 19 intensely sampled HIV patients enrolled in a traditional pharmacokinetic study. Estimates of CL/F ranged from $41.9-45.1 \mathrm{~L} / \mathrm{h}$, values in close agreement with previous studies. Neither body weight, age, gender, race, dose level, baseline viral load, CYP2C19 metabolizing status, history of liver disease nor raised liver
\end{abstract}


function tests appeared to be significant covariates for clearance. A low CD4 count and concomitant use of a macrolide antibiotic or fluconazole were significant when tested alone. However once concomitant use of fluconazole was incorporated into the model as a covariate for $\mathrm{CL} / \mathrm{F}$, the other covariates no longer achieved statistical significance. Patients who received concomitant therapy with fluconazole experienced a statistically significant reduction in $\mathrm{CL} / \mathrm{F}$ of $26-30 \%$. This is unlikely to be of clinical significance. Addition of this covariate to the model resulted in a modest reduction in interindividual variability of $\mathrm{CL} / \mathrm{F}$. Only a small fraction of patients (5/174) were taking concomitant rifabutin and it was not possible to obtain conclusive results for the effect of this drug on the $\mathrm{CL} / \mathrm{F}$ of nelfinavir. 


\section{INTRODUCTION}

Nelfinavir mesylate (Viracept ${ }^{\mathrm{TM}}$ ) is a protease inhibitor approved for the treatment of Human Immunodeficiency Virus (HIV) infection. The viral protease enzyme plays an essential role in the replicative cycle of HIV by catalyzing the cleavage of genetically encoded polyprotein precursors to yield mature, viral proteins $(12,21)$. Inhibition of the protease enzyme by nelfinavir results in the formation of immature, non-infectious virions.

Nelfinavir was approved by the Food and Drug Administration (FDA) in March 1997. The currently recommended adult dose is $750 \mathrm{mg}$ three times a day (tid) taken with or after food (1). Pharmacokinetic studies of nelfinavir have previously been conducted in phase I/II of clinical drug development $(18,20)$. When nelfinavir was administered at a dose of $500 \mathrm{mg}$ or $750 \mathrm{mg}$ tid the peak plasma concentration $\left(\mathrm{C}_{\mathrm{max}}\right)$ at steady-state was in the range of $3-4 \mu \mathrm{g} / \mathrm{ml}$ and the time to peak concentration $\left(\mathrm{T}_{\max }\right)$ in the range of $2.5-3$ hours (18). The half-life of nelfinavir has been reported in these studies as 3 - 5 hours $(18,20)$.

Nelfinavir, like the other currently available protease inhibitors, ritonavir, indinavir and saquinavir, is metabolized by the cytochrome P450 system $(13-16,19,20,25,29,31)$. In vitro studies have shown that CYP3A4 and CYP2C19 are the predominant isozymes involved $(16,29,31)$. Other isozymes, CYP2D6 and CYP2C9 are involved to a lesser extent $(11,13,25,29)$. Nelfinavir has one major metabolite, the M8 metabolite (nelfinavir hydroxy-t-butylamide), which is exclusively catalyzed by CYP2C19 (10,16,29). The M8 
metabolite has been shown to have an antiviral potency in vitro similar to nelfinavir itself $(1,15,16,1825,31)$. Studies have demonstrated that CYP2C19 exhibits genetic polymorphism (17) and that $2-6 \%$ of Caucasians and $18-22 \%$ of Asians are poor metabolizers of CYP2C19 (15). In addition to being a substrate, nelfinavir is also an inhibitor of some CYP450 isozymes, namely CYP3A4, CYP2C19, CYP2D6 and CYP1 A2 $(13,15)$. Only inhibition of CYP3A4 appears to be of clinical significance $(13,15)$ and it seems that nelfinavir is a less potent inhibitor of CYP3 A4 than indinavir and ritonavir $(14,15,19,20)$. It has also been suggested that nelfinavir may induce as well as inhibit CYP3A4, however, the net effect of nelfinavir on this isozyme appears to be inhibition rather than induction $(15,20)$.

On the basis of nelfinavir's involvement with the cytochrome P450 enzyme system, there is the potential for drug interactions to occur especially as patients with HIV disease are often taking multiple concomitant medications.

The development of resistance to protease inhibitors, like other antiretroviral therapies, is of major concern. It has been observed that resistance is more likely to develop when plasma concentrations of protease inhibitors are subtherapeutic (6). Therefore it is important to characterize the pharmacokinetics of nelfinavir in a representative patient population and to try and identify variables that may lead to lower plasma concentrations which in turn may increase the risk of therapeutic failure. 
Thus, the objectives of this study were to determine the population pharmacokinetic parameters of nelfinavir and their variability in an HIV infected patient population, to determine the influence of patient characteristics on the pharmacokinetic parameters of nelfinavir and to investigate potential drug interactions for an effect upon the pharmacokinetics of nelfinavir.

\section{METHODS}

Concentration-time data were obtained from patients enrolled in a phase III clinical study, which was primarily designed to evaluate the safety and efficacy of nelfinavir in HIV infected patients. A secondary objective of the study was to determine the population pharmacokinetic parameters of nelfinavir. Safety and efficacy results have been reported elsewhere $(5,24)$. This paper deals only with the pharmacokinetic aspects of the study.

\section{Study Population}

The study population included patients aged 13 years or older who had received either no prior antiretroviral therapy or less than 1 month of treatment with zidovudine (AZT). Patients were required to have a baseline plasma HIV RNA titer $\geq 15,000$ copies $/ \mathrm{ml}$. Participants in the trial were randomized to receive nelfinavir $500 \mathrm{mg}$ three times a day, nelfinavir $750 \mathrm{mg}$ three times a day or placebo. In order to balance treatment groups, patients' CD4 counts (less than 100 cells per $\mu 1,100$ to 300 cells per $\mu 1$ or greater than 300 cells per $\mu \mathrm{l}$ ) were used in a dynamic randomization procedure. All patients received concomitant therapy with AZT $200 \mathrm{mg}$ three times a day and lamivudine (3TC) $150 \mathrm{mg}$ 
twice a day. Concentration-time data were obtained from 174 participants who received one of the nelfinavir dosage regimens. These patients were enrolled at 27 investigative sites.

Exclusion criteria at baseline examination included: prior antiretroviral therapy; therapy with immune modulators or vaccines within one month of baseline; patients of procreative potential who were not practicing double-barrier contraception; elevated LFTs, hemoglobin or bilirubin levels; decreased neutrophil or platelet counts; renal insufficiency; acute pancreatitis or hepatitis; significant fever or diarrhea; malabsorption syndrome; severe intermittent medical conditions including opportunistic infections; active substance abuse; neoplastic disease requiring radiation or cytotoxic therapy and lastly, females taking oral contraceptives. The appropriate institutional review boards approved the study and written informed consent was obtained from all participants.

\section{Plasma Samples}

The pharmacokinetic study was designed such that patients had blood samples drawn for analysis of nelfinavir concentrations during clinical follow-up visits. In general, each individual provided two blood samples per visit: a pre-dose trough level and a post-dose level taken approximately two hours after a dose. The majority of individuals were sampled at week 2 and week 8 of the study hence all concentrations were considered to be at steady state. Ultimately, 509 samples from 174 patients were used in the pharmacokinetic analysis. This was an average of approximately 3 samples per patient with a range of 1 to 6 . Plasina samples were analyzed for nelfinavir and M8 
concentrations using a modified version of a previously published HPLC assay (28). This assay was modified to include analysis of the M8 metabolite.

\section{Data Preparation and Pharmacokinetic Analysis}

Clinical, pharmacokinetic and demographic data relevant to the population pharmacokinetic analysis were extracted from the raw data and merged and formatted using SAS (version 6.09) on an IBM ES-9000 computer. The pharmacokinetic analysis was performed using NONMEM (version 4.0, double precision) (3) on an IBM ES-9000 computer. There are several statistical methods that can be implemented in NONMEM to calculate parameter estimates (3). Initially, the analyses were performed using the first order (FO) method and subsequently confirmed using the first order conditional estimation (FOCE) method.

\section{Pharmacokinetic Model}

Several models were used to fit the data. A one-compartment and a two-compartment open model with first-order absorption and first-order elimination were tested. A zeroorder input to a one-compartment model was also tested using an input period of 3 hours (the average value of the time taken to reach the maximum concentration previously reported as 2-4 hours (1)). The first-order input to the one-compartment model was parameterized as the first order absorption rate constant $(\mathrm{ka})$, oral clearance $(\mathrm{CL} / \mathrm{F})$ and volume of distribution $(\mathrm{V} / \mathrm{F})$ and the zero-order input to the one-compartment model was parameterized as oral clearance $(\mathrm{CL} / \mathrm{F})$ and volume of distribution $(\mathrm{V} / \mathrm{F})$. The twocompartment model was parameterized as the first-order absorption rate constant $(\mathrm{ka})$, 
oral clearance $(\mathrm{CL} / \mathrm{F})$, volume of the central compartment $(\mathrm{Vc} / \mathrm{F})$, volume of distribution at steady state (Vss/F) and intercompartmental clearance (Q). The model that best fit the data was selected for further analyses.

\section{Statistical Model}

An exponential error model and a proportional error model were evaluated to describe interindividual variability. The models were as follows:

$$
\begin{gathered}
\theta_{\mathrm{j}}=\theta^{\prime} \exp \left(\eta_{\theta_{\mathrm{j}}}\right)-\operatorname{exponential~error~model,~and~} \\
\theta_{\mathrm{j}}=\theta^{\prime *}\left(1+\left(\eta_{\theta_{\mathrm{j}}}\right)\right) \text { - proportional error model }
\end{gathered}
$$

where $\theta_{j}$ is the estimate for a pharmacokinetic parameter in the $\mathrm{j}^{\text {th }}$ individual as predicted by the regression model, $\theta^{\prime}$ is the population mean of the pharmacokinetic parameter, and $\eta_{\theta_{j}}$ represents the random variable with zero mean and variance $\omega^{2}$, that

distinguishes the $\mathrm{j}^{\text {th }}$ individual pharmacokinetic parameter from the population mean value predicted by the regression model. Terms for interindividual variability were included in $\mathrm{CL} / \mathrm{F}, \mathrm{Vd} / \mathrm{F}$ and $\mathrm{ka}$.

Intraindividual (residual) variability was modeled using either a proportional error model or a combined proportional and additive error model. The following equations were used:

$$
\begin{gathered}
\mathrm{C}_{\mathrm{ij}}=\mathrm{C}_{\mathrm{ij}}^{\prime *}\left(1+\varepsilon 1_{\mathrm{ij}}\right) \text { and } \\
\mathrm{C}_{\mathrm{ij}}=\left[\mathrm{C}_{\mathrm{ij}}^{\prime}\left(1+\varepsilon 1_{\mathrm{ij}}\right)\right]+\varepsilon 2_{\mathrm{ij}} ;
\end{gathered}
$$


where $C_{i j}$ is the observed serum concentration for the $j^{\text {th }}$ individual at time $i, C_{i j}^{\prime}$ is the model predicted serum concentration for the $j^{\text {th }}$ individual at time $i$, and $\varepsilon 1_{i j}$ and $\varepsilon 2_{i j}$ are the components of proportional and additive error (with zero mean and variance $\sigma^{2}$ ), respectively.

\section{Data Analysis Strategy}

The pharmacokinetic and statistical models were evaluated to determine the basic model that best fit the data. A statistically significant decrease in the minimum value of the objective function (as measured by the Log Likelihood Difference) when comparing reduced models to fuller models, visual inspection of the data and precision of pharmacokinetic parameter and variability estimates were used as criteria to determine the best basic model.

After the basic model was constructed, a model building process was employed to examine the influence of patient covariates on the estimates of the pharmacokinetic parameters. The effect of the following patient covariates were evaluated: age, weight, gender, ethnic origin, dose, baseline HIV disease status, history of liver disease, raised liver function tests (LFTs), CYP2C19 metabolizing status of the patient and concomitant medications.

Age and weight were examined as continuous variables. Gender, dose, ethnic origin and history of liver disease were examined as categorical variables. The effect of an increase in LFTs was examined as a dichotomous variable, either grade two and higher or less 
than grade two. The HIV disease status of the patient at entry into the study was characterized by baseline CD4 count and baseline viral load. The CD4 count was categorized into 3 groups as follows: less than 100 cells per $\mu l, 100$ to 300 cells per $\mu$ l or greater than 300 cells per $\mu$ l. Viral load measurements were also split into 3 categories: greater than 100000 copies $/ \mathrm{ml}, 50000$ to 100000 copies $/ \mathrm{ml}$ or less than 50000 copies/ml. The ability of an individual to metabolize nelfinavir to the M8 metabolite was investigated as a potential covariate both as a continuous variable and as a categorical variable. The CYP2C19 metabolizing status of the patient was determined, where possible, from the M8 to nelfinavir peak concentration ratios and categorized into 3 groups. An individual with a ratio of less than 0.1 was classed as a poor metabolizer, an individual with a ratio of 0.1 to 0.3 as an intermediate metabolizer and an individual with a ratio greater than 0.3 as an extensive metabolizer (16). As CYP3A4 and CYP2C19 play an important role in the elimination of nelfinavir $(11,13,31)$ concomitant medications known to inhibit or induce these isozymes were examined as potential covariates. The effects of macrolide antibiotics and quinolone antibiotics were examined as a class rather than on an individual basis to increase the number of patients in each group. In this study, patients taking an azole antifungal consisted mainly of patients taking fluconazole, thus, the effect of fluconazole alone was investigated as was the effect of concomitant therapy with rifabutin.

A decrease in the minimum value of the objective function of 3.8 or greater following introduction of a single covariate into the model was considered statistically significant ( $p=0.05$ ) using the $\chi^{2}$ distribution if the $95 \%$ confidence intervals $(\mathrm{CI}$ ) for the estimate 
did not include the null value. If the change in the objective function was 3.8 or greater but the $95 \% \mathrm{CI}$ for the estimate included the null value, the effect of the variable was considered to be of borderline significance and that covariate was not included in the full model. All significant variables were included in the full model.

A backward elimination process was then employed to eliminate covariates from the full model in order to develop the final model. An increase in the objective function of 3.8 or greater $(\mathrm{p}=0.05)$ on removal of a covariate from the full model signified that the variable was important and that covariate was retained in the final model.

\section{Additional Data}

It was to prove difficult to obtain accurate estimates of $\mathrm{Vd} / \mathrm{F}$ and $\mathrm{ka}$ during this analysis. To assess the impact of possible misestimation of $\mathrm{Vd} / \mathrm{F}$ and $\mathrm{ka}$ on the ability to estimate $\mathrm{CL} / \mathrm{F}$, the parameter of most interest, $\mathrm{Vd} / \mathrm{F}$ and $\mathrm{ka}$ were fixed to more reliable values and only $\mathrm{CL} / \mathrm{F}$ was estimated in the modeling process. Additional data from a traditional pharmacokinetic study consisting of more samples per individual in a given dosing interval were analyzed using NONMEM to obtain values for $\mathrm{Vd} / \mathrm{F}$ and $\mathrm{ka}$. These values were subsequently used to fix $\mathrm{Vd} / \mathrm{F}$ and $\mathrm{ka}$ in the analysis of the population data. Thus, analysis of the population data was performed using two models: Model 1 in which all 3 pharmacokinetic parameters were estimated and Model 2 in which fixed estimates of $\mathrm{Vd} / \mathrm{F}$ and ka were used. 
Briefly, the data from the traditional study consisted of 190 observations from 19 HIV infected patients who received nelfinavir monotherapy at doses of $500 \mathrm{mg}$ or $750 \mathrm{mg}$ tid. Data were obtained from a phase II clinical trial, the results of which have previously been reported (18). Each patient provided 10 plasma samples at the following times: predose, $0.5,1,1.5,2,3,4,5,6$ and 8 hours post-dose during a steady-state dosing interval on day 28 of treatment. No patient was taking a drug that is a known inhibitor or inducer of CYP3A4.

\section{RESULTS}

The demographic characteristics of the 174 patients in the population analysis are summarized in Table 1. The mean age (range) was 37 (21-63) years and mean total body weight was $78(42-140) \mathrm{kg}$. The patient population was predominantly male $(89 \%)$ and Caucasian $(78 \%)$.

A one-compartment and a two-compartment model with first-order absorption and firstorder elimination were used to fit the data. It was not possible to obtain model convergence when the two-compartment model was fit to the data, thus a onecompartment model was used. The first-order absorption model provided a significantly better fit to the data as compared to the zero-order absorption model. Thus, the best basic model consisted of the one-compartment model with first-order absorption and first-order elimination. Interindividual variability was best described using an exponential error model and intraindividual variability by a combined proportional and additive error model. 
As previously mentioned, two models were employed in the analysis, Model 1 in which all 3 pharmacokinetic parameters were estimated and Model 2 in which $\mathrm{Vd} / \mathrm{F}$ and ka were fixed to estimates obtained from analysis of the traditional pharmacokinetic data. The parameter estimates from analysis of the traditional data were as follows: CL/F 39.1 (30.1 - 48.1) L/hr, Vd/F $229(161-297) \mathrm{L}$ and ka $0.845(0.60-1.13) \mathrm{h}^{-1}$. Thus Vd/F and ka were fixed to $229 \mathrm{~L}$ and $0.845 \mathrm{~h}^{-1}$, respectively in Model 2.

The basic pharmacokinetic parameter estimates (and 95\% CI) from the fit of Model 1 to the data were as follows: CL/F $40.7(37.7$ - 43.7) L/hr, Vd/F $731(531$ - 931) L and ka $1.22(0.70-1.74) \mathrm{h}^{-1}$. The variability in the estimate of $\mathrm{CL} / \mathrm{F}$, expressed as approximate percent coefficient of variation $(\% \mathrm{CV})$, was $36 \% \mathrm{CV}$. When a term for interindividual variability was included in $\mathrm{Vd} / \mathrm{F}$, the value tended towards zero. Thus it was not possible to model interindividual variability in $\mathrm{Vd} / \mathrm{F}$. A large degree of interindividual variability, $214 \% \mathrm{CV}$ was associated with $\mathrm{ka}$. Model 2 provided estimates of CL/F and its variability of $39.4(36.3-42.5) \mathrm{L} / \mathrm{hr}$ and $39 \% \mathrm{CV}$ respectively. These estimates agreed well with the estimates obtained using Model 1 and both estimates of CL/F agreed favorably with the estimate that was obtained from analysis of the traditional data.

Patient covariates that significantly influenced CL/F using both Models 1 and 2 are shown in Table 2. Neither age, weight, dose level, gender, ethnic origin, baseline viral load, CYP2C19 metabolizing status, history of liver disease nor LFTs grade two or higher appeared to influence $\mathrm{CL} / \mathrm{F}$ in this group of patients. However, a baseline CD4 
count less than 100 cells per $\mu \mathrm{l}$ and concomitant use of either a macrolide antibiotic or fluconazole resulted in a significant decrease in the estimates of $\mathrm{CL} / \mathrm{F}$. The magnitudes of reduction in CL/F were similar using both models and were $17-19 \%, 23-24 \%$ and $26-$ $27 \%$ for CD4 count, macrolide or fluconazole use, respectively. A significant increase in $\mathrm{CL} / \mathrm{F}$ of $55 \%$ was observed in patients taking rifabutin using Model 1 . In contrast, a nonsignificant increase of $37 \%$ in $\mathrm{CL} / \mathrm{F}$ was observed using Model 2. Due to the conflicting evidence of the effect of rifabutin and the small number of patients in the study taking rifabutin, this covariate was excluded from the model building procedure.

The full model contained all of the aforementioned covariates found to be significant. A backward elimination process was then employed to eliminate non-significant covariates from the full model to develop the final model. The final model parameters using both models are shown in Table 3 . The equations for $\mathrm{CL} / \mathrm{F}$ were as follows:

1. Model 1, all parameters are estimated: $\mathrm{CL} / \mathrm{F}=42.7^{*}\left(1-0.256^{*} \mathrm{flu}\right) \mathrm{L} / \mathrm{hr}$ where flu $=1$ if the patient was taking concomitant fluconazole therapy.

2. Model $2, \mathrm{Vd} / \mathrm{F}$ and ka are fixed: $\mathrm{CL} / \mathrm{F}=41.9^{*}\left(1-0.273^{*} \mathrm{flu}\right) \mathrm{L} / \mathrm{hr}$ where flu $=1$ if the patient was taking concomitant fluconazole therapy.

The estimates of $\mathrm{CL} / \mathrm{F}$ in patients not taking fluconazole were comparable between models, $42.7 \mathrm{~L} / \mathrm{hr}$ and 41.9 L/hr for Models 1 and 2, respectively. Additionally, the effect of fluconazole was similar in both models resulting in a reduction in clearance of $26-$ $27 \%$. Interindividual variability in $\mathrm{CL} / \mathrm{F}$ was reduced marginally from $36 \%$ to $34 \%$ and from 39\% to 36\% in Models 1 and 2, respectively. After controlling for use of 
fluconazole, use of a macrolide antibiotic or a low baseline CD4 count did not significantly affect CL/F further. Thus it was not necessary to include either of these covariates in the final model for $\mathrm{CL} / \mathrm{F}$.

This data set was also analyzed using the FOCE method in NONMEM. The only covariate found to be of statistical significance was concomitant use of fluconazole. In contrast to the FO method, a low CD4 count, concomitant use of a macrolide antibiotic and concomitant use of rifabutin were either of borderline significance or were not significant at all when tested alone in CL/F and thus were not included in the full model. Thus, the final model included only the effect of fluconazole. Parameter estimates for the final models are shown in Table 4. The estimates of CL/F were $44.9 \mathrm{~L} / \mathrm{hr}$ and $45.1 \mathrm{~L} / \mathrm{hr}$ for Models 1 and 2, respectively. These results compare favorably with the results obtained from the FO method, $42.7 \mathrm{~L} / \mathrm{hr}$ and $41.9 \mathrm{~L} / \mathrm{hr}$, respectively. Additionally, the reductions in $\mathrm{CL} / \mathrm{F}$ observed in patients taking concomitant fluconazole of $26 \%$ and $30 \%$ for Models 1 and 2, respectively are in good agreement with the reductions of $26 \%$ and $27 \%$ obtained using the FO method.

\section{DISCUSSION}

The pharmacokinetic parameters of nelfinavir were determined in an HIV infected population consisting of 174 individuals. A total of 509 plasma concentrations were used in the analysis. A one-compartment open model with first order absorption and first order elimination best described the data. 
It proved difficult to obtain accurate estimates of $\mathrm{Vd} / \mathrm{F}$ and $\mathrm{ka}$ in the analysis of this data set. In previous Phase I studies, $\mathrm{Vd} / \mathrm{F}$ has been estimated as $2-7 \mathrm{~L} / \mathrm{Kg}$ or $140-490 \mathrm{~L}$ in a $70 \mathrm{Kg}$ man (1). The estimate from this analysis was much larger (734 L) and was associated with large confidence intervals, as was the estimate of $\mathrm{ka}$, which also had a very large degree of interindividual variability. The ability to estimate pharmacokinetic parameters well depends upon the timing and number of plasma samples. In this study, only one early level per dosing interval was taken in each individual. This level was taken at essentially the same time in every individual, two hours after the dose. This is close to the reported $\mathrm{T}_{\max }$ of nelfinavir (2.5-3 hours) (18), a period of the concentration-time profile associated with inherent variability as plasma concentrations change markedly. It is likely that this inherent variability in observed plasma concentrations within an individual, the lack of variability in the timing of the early post dose levels between individuals and the small number of early samples per individual (typically 2 overall) made it impossible to obtain accurate estimates of $\mathrm{Vd} / \mathrm{F}$ and ka. Additionally, the difficulty in estimating these parameters may be compounded by the lack of information in the data set on factors that can influence the absorption and/or bioavailability of nelfinavir. Studies have demonstrated that the $\mathrm{C}_{\max }$ and AUC of nelfinavir are 2-3 times higher in fed versus fasted subjects $(1,22)$. Unfortunately, the timing of the dose relative to meals was not controlled in this study. Also, the bioavailability of protease inhibitors in general has been found to be sensitive to other physiological factors, such as gastric $\mathrm{pH}$ $(2,26)$. Due to the problems encountered in estimating $\mathrm{Vd} / \mathrm{F}$ and $\mathrm{ka}$ in this particular data set, the estimates that were obtained should be interpreted with caution. Estimation of these parameters should be made in the future using more informative data. 
In order to assess any influence of misestimation of $\mathrm{Vd} / \mathrm{F}$ and $\mathrm{ka}$ on the estimation of $\mathrm{CL} / \mathrm{F}$, two models were used in the analysis. In Model 1, all 3 parameters $(\mathrm{CL} / \mathrm{F}, \mathrm{Vd} / \mathrm{F}$ and $\mathrm{ka}$ ) were estimated. In Model 2, the values of $\mathrm{Vd} / \mathrm{F}$ and $\mathrm{ka}$ were fixed to estimates obtained from analysis of traditional pharmacokinetic data obtained from 19 individuals with HIV infection (229 $\mathrm{L}$ and $0.845 \mathrm{~h}^{-1}$ for $\mathrm{Vd} / \mathrm{F}$ and $\mathrm{ka}$, respectively). The estimates obtained for $\mathrm{CL} / \mathrm{F}$ and the influence of fluconazole on $\mathrm{CL} / \mathrm{F}$ were in good agreement between the models. This provides support that estimation of CL/F and the evaluation of the effect of covariates on $\mathrm{CL} / \mathrm{F}$ were not affected by possible misestimation of $\mathrm{Vd} / \mathrm{F}$ and ka. Wade et al. previously investigated the effect of misspecification of ka on the ability to estimate CL using sparsely sampled simulated data (27). They found that misspecification of ka did not markedly affect the ability to estimate CL. The estimates obtained for CL/F were 42.7 L/hr and 42.0 L/hr using Models 1 and 2, respectively. These values compare favorably with previous estimates of the CL/F of nelfinavir of 37.4 $\mathrm{L} / \mathrm{hr}(30)$ and 46.0 L/hr (calculated as Dose/ $\left.\mathrm{AUC}_{0-8 \mathrm{~h}}\right)(18)$.

Azole antifungal agents are commonly prescribed for patients with HIV disease for the treatment and prophylaxis of fungal infections (9). In this study, 25 of 174 patients $(15 \%)$ were receiving concomitant azole therapy. Since 23 of these 25 patients were taking fluconazole, it was only possible to assess the effect of this azole antifungal on the CL/F of nelfinavir. Fluconazole is a known inhibitor of CYP3A4 and CYP2C19, the primary isozymes involved in the metabolism of nelfinavir $(29,31)$. This study found that patients receiving concomitant therapy with fluconazole experienced a statistically significant 
reduction in $\mathrm{CL} / \mathrm{F}$ of $26-27 \%$ compared to patients not taking fluconazole. However, it is unlikely that an effect of this magnitude would be clinically significant and warrant dosage adjustment. A similar decrease in CL/F was observed in a study of 8 healthy volunteers treated with ritonavir who received concomitant fluconazole therapy (4). The authors found that fluconazole produced marginal increases of less than $15 \%$ in the $\mathrm{AUC}_{0-24 h}$ and $\mathrm{C}_{\max }$ of ritonavir (4). In contrast, in a study conducted in $11 \mathrm{HIV}$-infected patients receiving indinavir, investigators found that concomitant fluconazole therapy did not result in a reduction in the $\mathrm{CL} / \mathrm{F}$ of indinavir. Indeed, they found a slight decrease in $\mathrm{AUC}_{0-8 \mathrm{~h}}$ of indinavir that failed to achieve statistical significance (7). The different metabolic pathways of these protease inhibitors may account for the inconsistency of the results.

Concomitant use of a macrolide antibiotic and a baseline CD4 count less than 100 cells per $\mu \mathrm{l}$ were statistically significant covariates for CL/F when tested alone (Table 2). However, the influence of concomitant fluconazole therapy was greater and once this effect had been incorporated into the final model for $\mathrm{CL} / \mathrm{F}$, the effects of concomitant use of a macrolide antibiotic and a low baseline CD4 count were no longer statistically significant. It should be noted that 16 of the 35 patients with a low CD4 count were taking fluconazole and 8 of the 18 patients receiving concomitant macrolide therapy were also taking fluconazole. Thus, the observed influence of a low CD4 count and concomitant macrolide therapy may be explained by the high percentage of patients with these characteristics who were also taking fluconazole. 
In this study, the CYP2C19 metabolizing status of the patient was characterized by the M8 to nelfinavir peak concentration ratio. A patient with a ratio of less than 0.1 was classed as a poor metabolizer. It has previously been reported that patients classed as poor metabolizers have a lower M8/nelfinavir ratio than either intermediate or extensive metabolizers (16). This is probably due to a reduction in CL/F. However, the small number of poor metabolizers identified in this study $(n=6)$ may have prohibited the detection of a significant effect upon CL/F.

The effect of rifabutin on the CL/F of nelfinavir was inconsistent using the models in this analysis. It is probable that this study did not have sufficient power to assess the influence of rifabutin on the CL/F of nelfinavir, since only 5 of the 174 patients in the study were taking rifabutin. In both models, there was a trend for concomitant rifabutin to increase the $\mathrm{CL} / \mathrm{F}$ of nelfinavir (from $37-55 \%$ ). However, only when all three pharmacokinetic parameters were estimated did the increase achieve statistical significance. There is evidence from other clinical studies that rifabutin induces the metabolism of nelfinavir (1). In one study, concomitant administration of rifabutin decreased the AUC and $\mathrm{C}_{\max }$ of nelfinavir by $32 \%$ and $25 \%$, respectively (1).

The FO method in NONMEM involves linear assumptions that the FOCE method does not which increases the risk of obtaining biased parameter estimates. However, the FOCE method is computationally more complicated than the FO method, resulting in a substantially longer time to run an analysis. A limited comparison of some linear approximation methods (e.g. the FO method) with computationally more intensive 
approximation methods (e.g. FOCE method) has shown that the linear approximation methods perform adequately (23). In this study, the population pharmacokinetic parameters were obtained initially by implementing the FO method in NONMEM and the results confirmed using the FOCE method. The final models using both methods did compare favorably showing that, in this instance, the FO method provided adequate estimates. Overall, the estimates of $\mathrm{CL} / \mathrm{F}$ (ranged from $41.9 \mathrm{~L} / \mathrm{hr}$ to $45.1 \mathrm{~L} / \mathrm{hr}$ ) and the effect of fluconazole on $\mathrm{CL} / \mathrm{F}$ (reduction in $\mathrm{CL} / \mathrm{F}$ of $26 \%$ - 30\%) were similar. However, the FOCE method proved to be more discerning in that it did not initially identify the covariates identified by the FO method as statistically significant alone (low CD4 count and concomitant use of a macrolide antibiotic or rifabutin) that were subsequently dropped during the final model building process due to lack of significance.

In conclusion, the population pharmacokinetic parameters of nelfinavir were best described using a one-compartment model with first-order absorption. Estimation of $\mathrm{Vd} / \mathrm{F}$ and ka was difficult using this data and the values obtained should be interpreted with caution. $\mathrm{CL} / \mathrm{F}$ was estimated as $42.7 \mathrm{~L} / \mathrm{h}$ (Model 1 ) and $41.9 \mathrm{~L} / \mathrm{h}$ (Model 2). Patients receiving concomitant therapy with fluconazole had a $26-27 \%$ reduction in $\mathrm{CL} / \mathrm{F}$. A reduction of this magnitude is unlikely to be of clinical significance. The study probably did not have sufficient power to assess the influence of concomitant rifabutin. However, the consistent though statistically insignificant increased $\mathrm{CL} / \mathrm{F}$ observed among patients taking rifabutin in this study is in keeping with evidence of an interaction from previous studies. 


\section{Acknowledgements}

We would like to thank the members of the AG1343-511 Clinical Study Group who were responsible for the conduct of this study. 


\section{REFERENCES}

1. Agouron Prescribing Information. 1998. Agouron Pharmaceuticals, La Jolla, CA.

2. Barry M., S. Gibbons, D. Back and F. Mulcahy. 1997. Protease Inhibitors in Patients with HIV Disease. Clinically Important Pharmacokinetic Considerations. Clin. Pharmacokinet. 32(3): 194-209.

3. Beal S. L. and Sheiner L. B. (eds.). 1994. NONMEM Users Guides, NONMEM Project Group, University of California at San Francisco, San Francisco, CA.

4. Cato III A., G. Cao, A. Hsu, J. Cavanaugh, J. Leonard and R. Granneman. 1997. Evaluation of the Effect of Fluconazole on the Pharmacokinetics of Ritonavir. Drug Metab. Dispos. 25(9): $1104-1106$.

5. Clendennin N., Quart B., Anderson R., Knowles M. and Chang Y. Analysis of Long-term Virologic Data from the Viracept (Nelfinavir, NFV) 511 Protocol Using 3 HIV-RNA Assays. $5^{\text {th }}$ Conference on Retroviruses and Opportunistic Infections, Chicago, 1-5 February 1998, Abstract 372.

6. Deeks S. G., M. Smith, M. Holodniy and J. O. Kahn. 1997. HIV-1 Protease Inhibitors. A Review for Clinicians. JAMA. 277(2): 145-153.

7. De Wit S., M. Debier, M. De Smet, J. McCrea, J. Stone, A. Carides, C. Matthews, P. Deutsch and N. Clumeck. 1998. Effect of Fluconazole on Indinavir Pharmacokinetics in Human Immunodeficiency Virus-Infected Patients. Antimicrob. Agents Chemotherapy. 44(2): 223-227.

8. Flexner C., A. Hsu, B. Kerr, C. Wong, J. Gallant, R. Anderson, M. HealthChiozzi. 1998. Steady-state Pharmacokinetic Interaction Between Ritonavir (RTV), 
Nelfinavir (NFV) and the Nelfinavir Active Metabolite M8 (AG1402). Abstract 42265, $12^{\text {th }}$ World AIDS Conference, Geneva.

9. Goa K. L. and L. B. Barradell. 1995. Fluconazole. An Update of its Pharmacodynamic and Pharmacokinetic Properties and Therapeutic Use in Major Superficial and Systemic Mycoses in Immunocompromised Patients. Drugs. 50(4): $658-690$.

10. Hsu A., R. Granneman and R. J. Bertz. 1998. Ritonavir. Clinical Pharmacokinetics and Interactions with Other Anti-HIV Drugs. Clin. Pharmacokinet. 35(4): 275-291.

11. Kerr B., G Yuen, R Daniels, B Quart and R Anderson. 1997. Strategic Approach to Nelfinavir Mesylate (NFV) Drug Interactions Involving CYP3A Metabolism. Abstract, $4^{\text {th }}$ National Conference on Human Retroviruses and Related Infections.

12. Kohl N. E., E. A. Emini, W. A. Schleif, L. J. Davis, J. C. Heimbach, R. A. F. Dixon, E. M. Scolnick and I. S. Sigal. 1988. Active Human Immunodeficiency Virus Protease is Required for Viral Infectivity. Proceedings of the National Academy of Sciences USA. 85: 4686-4690.

13. Lee C. A., B-H Liang, E. Y. Wu, H. M. Grettenberger, T. M. Sandoval, K. E. Zhang and B. V. Shetty. 1997. Prediction of Nelfinavir Mesylate (Viracept) Clinical Drug Interactions Based on In Vitro Human P450 Metabolism Studies. Abstract, $4^{\text {th }}$ National Conference on Human Retroviruses and Related Infections.

14. Lewis II J. S., C. M. Terriff, D. R. Coulston and M. W. Garrison. 1997. Protease Inhibitors: A Therapeutic Breakthrough for the Treatment of Patients with Human Immunodeficiency Virus. Clinical Therapeutics. 19(2): 187-214. 
15. Lillibridge J. H., B. H. Liang, B. M. Kerr, S Webber, B. Quart, B. V. Shetty and C. A. Lee. 1998. Characterization of the Selectivity and Mechanism of Human Cytochrome P450 Inhibition by the Human Immunodeficiency Virus-Protease Inhibitor Nelfinavir Mesylate. Drug Metabolism and Disposition. 26(7): 609 - 616.

16. Lillibridge J. L., Lee C. A., Pithavala Y. K., Sandoval T. M., Wu E. Y., Zhang K. E., Mazabel E. L., Zhang M. and Kerr B. M. 1998. The Role of CYP2C19 in the Formation of Nelfinavir Hydroxy-t-butylamide (M8): In Vitro/In Vivo Correlation. Abstract $109,5^{\text {th }}$ International ISSX Meeting, Cairns, Australia.

17. Lin J. H. and A. Y. H. Lu. 1998. Inhibition and Induction of Cytochrome P450 and the Clinical Implications. Clinical Pharmacokinetics. 35(5): 361 - 390.

18. Markowitz M., M. Conant, A. Hurley, R. Schluger, M. Duran, J. Peterkin, S. Chapman, A. Patick, A. Hendricks, G. J. Yuen, W. Hoskins, N. Clendininn and D. D. Ho. 1998. A Preliminary Evaluation of Nelfinavir Mesylate, an Inhibitor of Human Immunodeficiency Virus (HIV)-1 Protease, to Treat HIV Infection. The Journal of Infectious Diseases. 177: 1533-40.

19. McDonald C. K. and D. R. Kuritzkes. 1997. Human Immunodeficiency Virus Type 1 Protease Inhibitors. Archives of Internal Medicine. 157: 951-959.

20. Moyle G. J., M. Youle, C. Higgs, J. Monaghan, W. Prince, S. Chapman, N. Clendeninn and M. R. Nelson. 1998. Safety, Pharmacokinetics, and Antiretroviral Activity of the Potent Specific Human Immunodeficiency Virus Protease Inhibitor Nelfinavir: Results of a Phase I/II Trial and Extended Follow-up in Patients Infected with Human Immunodeficiency Virus. J. Clin. Pharmacol. 38: 736 - 743. 
21. Peng C., B. K. Ho, T. W. Chang and N. T. Chang. 1989. Role of Human Immunodeficiency Virus Type 1-Specific Protease in Core Protein Maturation and Viral Infectivity. Journal of Virology. 63(6): 2550-2556.

22. Quart B. D., S. K. Chapman, J. Peterkin et al. 1995. Phase I safety, tolerance, pharmacokinetics and food effect studies of AG1343 - a novel HIV protease

Inhibitor. Abstract $167,2^{\text {nd }}$ National Conference on Human Retroviruses and Related Infections. Jan29-Feb2.

23. Roe D. J. 1997. Comparison of Population Pharmacokinetic Modeling Methods Using Simulated Data: Results from the Population Modeling Workgroup. Statistics in Medicine. 16: 1241-1262.

24. Saag M., Knowles M., Chang Y., Chapman S. and Clendennin N. J. 1997. Durable Effect of Viracept (Nelfinavir Mesylate, NFV) in Triple Combination Therapy. Abtract I-101, 37 $7^{\text {th }}$ Interscience Conference on Antimicrobial Agents and Chemotherapy, Toronto, Canada.

\section{Skowron G., G. Leoung, B. Kerr, A. Dusek, R. Anderson, S. Beebe and R} Grosso. 1998. Lack of Pharmacokinetic Interaction between Nelfinavir and Nevirapine. Editorial Comment. AIDS. 12: 1243 - 1244.

26. Unadkat J. D. and J. M. Agosti. 1990. Problems in Pharmacokinetic Investigations in Patients with HIV Infection. Clinical Pharmacokinetics. 19(3): 172-176.

27. Wade J., A, Kelman, C. Howie and B. Whiting. 1992. Misspecification of ka in NONMEM Analysis. Journal of Pharmacokinetics and Biopharmaceutics. 
28. Wu E. Y., Wilkinson II J. M. and Shetty B. V. 1997. High-performance liquid chromatographic method for the determination of nelfinavir, a novel HIV-1 protease inhibitor, in human plasma. J. Chrom. B., Biomed. Appl. 695: 373-380.

29. Wu E. Y., Sandoval T. M., Zhang K. E., Grettenberger H. M., Hee B. R., Lee C. A., Webber S. and Shetty B. V. 1998. Cytochrome P450 Isoforms involved in the Metabolism of Nelfinavir Mesylate, an HIV-1 Protease Inhibitor. Abstract $110,5^{\text {th }}$ International ISSX Meeting, Cairns, Australia.

30. Yuen G. J., R. Anderson, T. Sandoval, E. Wu, B. V. Shetty and B. M. Kerr. 1997. The Pharmacokinetics (PK) of Nelfinavir (N) Administered Alone and with Rifampin (Rif) in Healthy Volunteers. Clinical Pharmacology and Therapeutics. 61(2): 147, Abstract PI-40.

31. Zhang, M. H., Pithavala Y. K., Lee C. A., Lillibridge J. H., Wu E. Y., Sandoval T. M., Daniels R. G. and Kerr B. M. 1998. Apparent Genetic Polymorphism in Nelfinavir Metabolism: Evaluation of Clinical Relevance. Abstract 264, $12^{\text {th }}$ International Symposium on Microsomes and Drug Oxidations, Montpelier, France. 
Table 1: Characteristics of 174 Patients Evaluated in the Population Pharmacokinetic Analysis of Nelfinavir

\begin{tabular}{|c|c|c|}
\hline Characteristic & $\begin{array}{l}\text { Number } \\
\text { of } \\
\text { Patients } \\
\end{array}$ & $\begin{array}{c}\text { Percent of Total } \\
\text { Study } \\
\text { Population } \\
\end{array}$ \\
\hline Gender (Men/Women) & $155 / 19$ & $89 / 11$ \\
\hline Mean Age, years (range) & $37(21-63)$ & \\
\hline Mean Total Body Weight, kg (range) & $77.7(42-140)$ & \\
\hline \multicolumn{3}{|l|}{ Baseline CD4 Count ( cells per $\mu \mathrm{l}$ ) } \\
\hline$<100$ & 35 & 20 \\
\hline$<300$ and $>100$ & 59 & 34 \\
\hline $\begin{array}{c}>300 \\
\text { Baseline Viral RNA (copies/ml) }\end{array}$ & 80 & 46 \\
\hline$>100,000$ & 68 & 39 \\
\hline$>50,000$ and $<100,000$ & 43 & 25 \\
\hline$<50,000$ & 63 & 36 \\
\hline \multicolumn{3}{|l|}{ Race, } \\
\hline Caucasian & 136 & 78 \\
\hline Black & 21 & 12 \\
\hline Asian & 3 & 2 \\
\hline Hispanic & 7 & 4 \\
\hline Latin American & 4 & 2 \\
\hline Native American & 3 & 2 \\
\hline \multicolumn{3}{|l|}{ Concomitant Medications } \\
\hline Azole (fluconazole) & $25(23)$ & $15(13)$ \\
\hline Macrolide & 18 & 10 \\
\hline Quinolone & 12 & 8 \\
\hline Rifabutin & 5 & 3 \\
\hline History of liver disease & 60 & 34 \\
\hline Liver function tests (LFTs) grade 2 or higher & 51 & 29 \\
\hline \multicolumn{3}{|l|}{ Metabolic Status (Ratio of nelfinavir: M8) } \\
\hline Poor Metabolizer (ratio < 0.1 ) & 6 & 3 \\
\hline Intermediate Metabolizer (ratio $>0.1$ and $<0.3$ ) & 67 & 38 \\
\hline Extensive Metabolizer (ratio $>0.3$ ) & 37 & 21 \\
\hline
\end{tabular}


Table 2: Summary of Analyses of Significant Effects of Patient Covariates tested alone in Clearance

\begin{tabular}{|c|c|c|c|c|c|}
\hline Hypothesis & Parameterization & $\begin{array}{c}\text { Null } \\
\text { Value } \\
\end{array}$ & $\begin{array}{l}\text { Parameter Values } \\
(95 \% \mathrm{CI})\end{array}$ & $\begin{array}{c}\text { Change in } \\
\text { objective function }\end{array}$ & Significanc \\
\hline \multicolumn{6}{|l|}{ Model One } \\
\hline \multicolumn{6}{|c|}{ - Do the following affect $C L F$ ? } \\
\hline CD $t<100$ cells per $\mu \mathrm{l}$ & $\mathrm{CL} / \mathrm{F}=\theta 1 *(1-\theta 4 * \mathrm{~cd} 4)$ & 0 & $04=0.19(0.02,0.36)$ & 10.014 & Significant \\
\hline \multicolumn{6}{|l|}{ Concomitant Medications } \\
\hline Fluconazole & $\mathrm{CL} / \mathrm{F}=\theta 1 *(1-\theta+*$ flu $)$ & 0 & $\theta 4=0.26(0.11,0.40)$ & 17.225 & Significant \\
\hline Macrolide & $\mathrm{CL} / \mathrm{F}=\theta 1 *\left(1-\theta 4^{*} \mathrm{mac}\right)$ & 0 & $\theta t=0.24(0.02 .0 .46)$ & 10.784 & Significant \\
\hline Rifabutin & $\mathrm{CL} / \mathrm{F}=\theta 1 *(1-\theta+*$ rif $)$ & 0 & $\theta 4=0.55(0.32,0.77)$ & 6.035 & Significant \\
\hline
\end{tabular}

\section{Model Two}

- Do the following affect $C L F$ ?

\begin{tabular}{|c|c|c|c|c|c|}
\hline $\begin{array}{l}\text { CD } t<100 \text { cells per } \mu \mathrm{l} \\
\text { Concomitant Medications }\end{array}$ & $\mathrm{CL} / \mathrm{F}=\theta \mathrm{I}^{*}\left(1-\theta 4^{*} \mathrm{~cd}+\right)$ & 0 & $\theta t=0.17(0.01,0.33)$ & 6.978 & Significant \\
\hline Fluconazole & $\mathrm{CL} / \mathrm{F}=\theta 1^{*}(1-\theta 4 * \mathrm{flu})$ & 0 & $\theta 4=0.27(0.15 \cdot 0.40)$ & 18.531 & Significant \\
\hline Macrolide & $\mathrm{CL} / \mathrm{F}=\theta 1^{*}\left(1-\theta 4^{*} \mathrm{mac}\right)$ & 0 & $\theta t=0.23(0.06,0.41)$ & 10.132 & Significant \\
\hline Rifabutin & $\mathrm{CL} / \mathrm{F}=\theta 1 *(1-\theta 4 * \mathrm{rif})$ & 0 & $\theta 4=0.37(0.17 .0 .57)$ & 3.012 & Not Significant \\
\hline
\end{tabular}

${ }^{\mathrm{a}} \mathrm{p}=0.05$

Abbreviations: $C L / F=$ clearance: $L L D=$ log-likelihood difference: $N A=$ not applicable: flu = concomitant fluconazole therapy: mac $=$ concomitant macrolide therapy: rif $=$ concomitant rifabutin therapy . 
Table 3: Final Population Pharmacokinetic Parameters for Model 1 and Model 2 (First Order Method)

\begin{tabular}{|c|c|c|c|c|}
\hline & \multicolumn{2}{|c|}{ Model $1^{a}$} & \multicolumn{2}{|c|}{ Model $2^{a}$} \\
\hline $\begin{array}{l}\text { Parameter } \\
\text { (units) }\end{array}$ & $\begin{array}{c}\text { Parameter } \\
\text { Estimates }(95 \% \mathrm{CI})\end{array}$ & $\begin{array}{c}\text { Interpatient } \\
\text { Variability }^{\mathrm{b}} \\
(95 \% \mathrm{CI})\end{array}$ & $\begin{array}{c}\text { Parameter Estimates } \\
(95 \% \mathrm{CI})\end{array}$ & $\begin{array}{c}\text { Interpatient } \\
\text { Variability }^{\text {b }} \\
(95 \% \mathrm{CI})\end{array}$ \\
\hline$\theta \mathrm{l}^{\mathrm{C}} \mathrm{L} / \mathrm{hr}$ & $42.7(39.3-46.1)$ & $34(27-39)$ & $41.9(38.7-45.1)$ & $36(28-43)$ \\
\hline$\theta 2(\mathrm{Vd} / \mathrm{F}) \mathrm{L}$ & $736(501-971)$ & NI & 229 fixed & $81(65-94)$ \\
\hline $03(\mathrm{ka}) \mathrm{h}^{-1}$ & $1.19(0.200-2.18)$ & 142 & 0.845 fixed & $\mathrm{NI}$ \\
\hline$\theta 4^{\mathrm{c}}$ & $0.256(0.111-0.401)$ & & $0.273(0.150-0.396)$ & \\
\hline$\sigma^{2} l$ & $0.106(0.028-0.184)$ & NA & $0.025(-0.015-0.064)$ & NA \\
\hline$\sigma^{2} 2(\mathrm{mg} / \mathrm{L})$ & $0.265(0.014-0.516)$ & NA & $0.537(0.300-0.778)$ & NA \\
\hline
\end{tabular}

${ }^{a}$ Model 1 - all 3 parameters are estimated; Model 2 - Vd and ka fixed to $229 \mathrm{~L}$ and $0.845 \mathrm{~h}^{-1}$. respectively. approximate coefficient of variation $(\% \mathrm{CV})$

${ }^{c} \mathrm{CL} / \mathrm{F}=\theta 1^{*}\left(1-\theta 4^{*}\right.$ flu $) \mathrm{L} / \mathrm{hr}$ where flu=1 if the patient was taking concomitant fluconazole therapy. else $\mathrm{flu}=($ ).

Abbreviations: $\quad \mathrm{CL} / \mathrm{F}=$ clearance: $\mathrm{Vd} / \mathrm{F}=$ volume of distribution; $\mathrm{ka}=$ absorption rate constant: $\sigma^{2} 1=$ variance of proportional component of residual error: $\sigma^{2} 2=$ variance of additive component of residual error: NI = Not Identifiable; $\mathrm{NA}=$ not applicable 
Table 4: Final Population Pharmacokinetic Parameters for Model 1 and Model 2 (FOCE Method)

\begin{tabular}{|c|c|c|c|c|}
\hline & \multicolumn{2}{|c|}{ Model $1^{\mathrm{a}}$} & \multicolumn{2}{|c|}{ Model $2^{\mathrm{a}}$} \\
\hline $\begin{array}{c}\text { Parameter } \\
\text { (units) }\end{array}$ & $\begin{array}{c}\text { Parameter } \\
\text { Estimates }(95 \% \mathrm{Cl})\end{array}$ & $\begin{array}{c}\text { Interpatient } \\
\text { Variability }^{\mathrm{b}} \\
(95 \% \mathrm{CI})\end{array}$ & $\begin{array}{c}\text { Parameter Estimates } \\
(95 \% \mathrm{CI})\end{array}$ & $\begin{array}{c}\text { Interpatient } \\
\text { Variability }^{\mathrm{b}} \\
(95 \% \mathrm{CI})\end{array}$ \\
\hline$\theta \mathbf{l}^{\mathrm{c}} \mathrm{L} / \mathrm{hr}$ & $44.9(40.9-48.9)$ & $34(28-40)$ & $45.1(41.6-48.6)$ & $34(27-39)$ \\
\hline $02(\mathrm{Vd} / \mathrm{F}) \mathrm{L}$ & $769(363-1175)$ & 53 & 229 fixed & $99(76-117)$ \\
\hline$\theta 3(\mathrm{ka}) \mathrm{h}^{-1}$ & $1.34(-1.76-4.44)$ & 58 & 0.845 fixed & NI \\
\hline$\theta 4^{\mathrm{c}}$ & $0.26(0.13-0.40)$ & & $0.305(0.181-0.429)$ & \\
\hline$\sigma^{2} 1$ & $0.090(-0.001-0.18)$ & NA & $0.035(-0.005-0.075)$ & NA \\
\hline$\sigma^{2} 2(\mathrm{mg} / \mathrm{L})$ & $0.28(0.003-0.55)$ & NA & $0.47(0.28-0.66)$ & NA \\
\hline
\end{tabular}

${ }^{\text {a }}$ Model 1 - all 3 parameters are estimated: Model $2-\mathrm{Vd}$ and ka fixed to $229 \mathrm{~L}$ and $0.845 \mathrm{~h}^{-1}$, respectively. bapproximate coefficient of variation $(\% \mathrm{CV})$

${ }^{\circ} \mathrm{CL} / \mathrm{F}=\theta \mathrm{l} *(1-\theta 4 * \mathrm{flu}) \mathrm{L} / \mathrm{hr}$ where flu=l if the patient was taking concomitant fluconazole therapy, clse flu $=0$.

Abbreviations: $\mathrm{CL} / \mathrm{F}=$ clearance $: \mathrm{Vd} / \mathrm{F}=$ volume of distribution: $\mathrm{ka}=$ absorption rate constant: $\sigma^{2} \mathrm{l}=$ variance of proportional component of residual error: $\sigma^{2} 2=$ variance of additive component of residual error: NI = Not Identifiable: NA = not applicable 


\section{MANUSCRIPT III}

Design of Population Pharmacokinetic Studies Utilizing Sparse Data. ${ }^{*}$ presented at the AAPS $13^{\text {th }}$ Annual Meeting, San Francisco, November 1998. 


\begin{abstract}
Simulation studies are useful tools to investigate issues of study design when planning a prospective pharmacokinetic analysis of sparsely sampled data. In this study simulated data was used to investigate different study designs consisting of 2 samples per individual and to investigate the influence of different sizes of a sub-population on the ability to detect that sub-population. A one-compartment model with intravenous input was used. Two levels of interindividual variability were investigated (30\% and 60\%), intraindividual variability was fixed at $25 \%$ and the sub-population had a $30 \%$ reduced value of clearance $(C L)$.
\end{abstract}

The ability to detect the sub-population and to obtain accurate parameter estimates deteriorated when interindividual variability was increased from $30 \%$ to $60 \%$. When interindividual variability was low (30\%), a sub-population in which the average value of CL was $30 \%$ lower than in the general population, could be identified. However, none of the designs studied here could consistently identify the sub-population when interindividual variability was high $(60 \%)$. In general, estimates of pharmacokinetic parameters were more precise and less biased than estimates of the variability parameters. Accurate pharmacokinetic parameter estimates could be obtained using some of the designs at both levels of interindividual variability. In contrast, variability parameters were unacceptable using all of the designs when interindividual variability was high. The performance of one design, which consisted of three sampling windows covering the whole dosing interval, was superior to the other designs investigated. 
Other design factors such as the total sample size, the level of intraindividual variability and the use of a different algorithm in NONMEM to estimate parameters were evaluated to see if the study design could be further improved upon. This was carried out at the high level of interindividual variability. Although modification of some of these factors did result in improvement in both the ability to detect the sub-population and in the accuracy of parameter estimates, it was still not possible to accurately estimate all of the variability parameters using a 2 sample per individual design. 


\section{INTRODUCTION}

The population approach to pharmacokinetic analysis involves estimating

pharmacokinetic parameters and their variability within a study population and evaluating the effect of demographic and physiological characteristics of the population on the pharmacokinetic parameters (1). This approach can be used to analyze sparsely sampled data from observational studies (2-4). A number of recent articles in the literature have reviewed this topic (5-9) illustrating the considerable interest in the application of this approach. Additionally, in February 1999, the Federal Drug Administration (FDA) issued a guidance document for the pharmaceutical industry concerning population pharmacokinetic studies (10). This document provides recommendations on the design, conduct, analysis and reporting of population pharmacokinetic studies from a regulatory perspective

As previously mentioned, the population approach can be used when only sparsely sampled data are available. When data are sparse the design of the study is important if accurate parameter estimates are to be obtained $(6,11)$. Issues such as the timing of samples, the number of samples per individual, the total number of individuals required for a population analysis and the quality of the data need to be addressed.

An example in which the population approach can be effectively implemented is in the analysis of sparse data collected during large phase III clinical trials (12). It is of paramount importance that population analyses that are designed to be incorporated into these studies should impinge upon the primary objective(s) of the clinical study as little 
as possible (13). As the total number of subjects in the study will most likely be dictated by the primary objective(s) of the clinical trial this is not an aspect of the study design that can be controlled. On the other hand, the number of samples per subject and the timing of samples are issues that should be considered when designing the study. To encourage good compliance with the study protocol it is important to consider factors such as the time spent by clinical investigators, the time spent by the patients in the clinic (these studies are mainly conducted on an out-patient basis) and the additional cost of assaying samples (6). For these reasons, a study design that involves taking as few samples as possible from each individual is preferable.

Several investigations of design issues of population pharmacokinetic studies have been reported in the literature using simulated data $(3,11,14-23)$. Many different designs have been evaluated such as designs including only 1 sample per individual, designs using a one or two-compartment model, and designs using intravenous or oral input. At least 2 samples per individual are necessary if the approach is to identify intraindividual variability and distinguish it from interindividual variability. Thus, if we could assure that the quality of the results obtained are not compromised, a 2 sample per individual design for a one-compartment model with intravenous input would be a good choice.

An important application of the population approach is to evaluate the effect of patient covariates on the pharmacokinetic parameters within the study population. Techniques have been proposed on how best to build a population model to include the effects of covariates that may significantly influence pharmacokinetic parameters and explain 
variability $(24,25)$. However, there is very little information in the literature pertaining to the size of a sub-group (possessing the covariate of interest) necessary to successfully detect the effect of that covariate. In 1985, Sheiner and Benet published one of the earliest papers that specifically addressed the design of population pharmacokinetic analyses in drug development trials (1). They took an empirical approach and suggested that when the full pharmacokinetic screen is implemented (i.e. several samples are taken per individual at different times after a dose) then 10-20 individuals in a sub-group would suffice and a total of 50-100 individuals would be adequate to establish the population pharmacokinetics of a drug. This issue was also addressed at an expert meeting on the design and conduct of population pharmacokinetic studies held in Europe in 1995 (13) Again 20 individuals were proposed for the size of a sub-group based upon the experiences of the individuals present. Vozeh et al. suggested that even as few as 10 individuals in a sub-group would be sufficient in some cases to detect the effect of that sub-group (6). In contrast, Breant and colleagues found that to detect a sub-population with altered pharmacokinetics within their data set, they required approximately 40 patients and $4-5$ blood levels per patient (26). None of these papers specifically addressed the magnitude of the effect to be identified, although it was stated that decisions should be made on a case by case basis (13).

Thus, the objectives of this study were i) to determine if accurate parameter estimates could be obtained using different study designs consisting of only 2 samples per individual, ii) to evaluate the influence of the size of a sub-group with a $30 \%$ reduced clearance on the ability to consistently identify that sub-group, and iii) to evaluate the 
influence of the size of a sub-group on the ability to estimate pharmacokinetic and variability parameters in both populations.

\section{METHODS:}

\section{Pharmacokinetic Model}

Data were simulated based upon the population pharmacokinetic parameters of theophylline. The values used were $2.94 \mathrm{~L} / \mathrm{hr}$ for clearance $(\mathrm{CL})$ and $31.5 \mathrm{~L}$ for volume of distribution $(\mathrm{Vd})(27,28)$. A one-compartment model with intravenous bolus input was used. Plasma concentrations were simulated following a single dose of $300 \mathrm{mg}$.

\section{Statistical Model}

Interindividual variability in both $\mathrm{CL}$ and $\mathrm{Vd}$ were modeled using an exponential error model:

$$
\left.\theta_{\mathrm{j}}=\theta^{\prime *} \exp \left(\eta_{\theta_{\mathrm{j}}}\right)\right)
$$

where $\theta_{\mathbf{j}}$ is the estimate for a pharmacokinetic parameter in the jth individual as predicted by the regression model, $\theta^{\prime}$ is the population mean of the pharmacokinetic parameter, and $\eta_{\theta_{j}}$ represents the random variable that distinguishes the jth individual pharmacokinetic parameter from the population mean value predicted by the regression model. It was assumed that $\eta_{\theta_{j}}$ is a normally distributed random variable with zero mean and variance $\omega^{2}$.

Intraindividual (residual) variability was also described using an exponential error model:

$$
\mathrm{C}_{\mathrm{ij}}=\mathrm{C}_{\mathrm{ij}}^{\prime} \exp \left(\varepsilon_{\mathrm{ij}}\right)
$$


where $C_{i j}$ is the observed serum concentration for the $j$ th individual at time $\mathrm{i}, \mathrm{C}_{\mathrm{ij}}{ }_{\mathrm{j}}$ is the model predicted serum concentration for the jth individual at time $\mathrm{i}$, and $\varepsilon_{\mathrm{ij}}$ is the residual error that represents the difference between the observed concentration and the model predicted concentration. $\varepsilon_{\mathrm{ij}}$ was assumed to be normally distributed with zero mean and variance $\sigma^{2}$

Variability in interindividual variability and intraindividual variability will be represented by their standard deviations which are $\omega_{\mathrm{CL}}, \omega_{\mathrm{Vd}}$ and $\sigma$ for interindividual variability in $\mathrm{CL}$, interindividual variability in $\mathrm{Vd}$ and intraindividual variability, respectively. When the logarithmic model is used to describe either interindividual or intraindividual variability, $\omega$ and $\sigma$ may be regarded as approximate coefficients of variation.

\section{Data}

Data were simulated for 100 individuals each of whom contributed two plasma concentrations. Thus, one data set consisted of 300 observations, 200 plasma concentrations and 100 dosing records. The 100 individuals comprising a data set possessed one of two sets of pharmacokinetic parameters. Individuals in Group A had a "normal" population value of CL of $2.94 \mathrm{~L} / \mathrm{hr}$ and a Vd of $31.5 \mathrm{~L}$ whereas individuals in the sub-group, Group B, had the same population value for Vd but a reduced value for $\mathrm{CL}$ of $2.06 \mathrm{~L} / \mathrm{hr}$. This corresponds to a reduction in CL of $30 \%$. A clinical example where this may occur is in the case of a drug interaction in which a concomitant medication inhibits the metabolism of the study drug causing a reduction in the value for CL. 
Different ratios of individuals in Group A and Group B were used to investigate the influence of the size of the sub-group on the ability to detect that sub-group accurately and to estimate the pharmacokinetic and variability parameters in both groups. The ratios of patients in Group A to Group B were varied as follows: 90:10, 80:20 and 70:30 for Groups A and B, respectively.

\section{Sampling Schedules}

Initially, D-optimal sampling as implemented in ADAPT (29) was used to identify the two optimal times to sample based upon a one-compartment intravenous input model. They were determined as being as early as possible and as late as possible after a dose. To mimic a real life situation in which it is unrealistic to take samples at exactly the same time for each individual, a randomized informative block design was used consisting of sampling windows (18). Three designs that used different sampling windows to obtain the two samples for each individual were evaluated. The sampling windows for each design are shown in Table 1. In Design 1, all patients had the early sample taken between 0.08 and 1 hour, and a late sample taken between 7 and 8 hours after the dose. Similarly, in Design 2 all individuals were sampled between 0.08 and 1 hour, and then between 8 and 24 hours. In Design 3, the complete dosing interval was split into 3 blocks: the first block from 0.08 to 1 hour, the second block from 1 to 8 hours, and the third block from 8 to 24 hours. Each individual was sampled from two different time blocks. The ratio of total samples in the data set was approximately $1: 1: 1$ from each block. 


\section{Data Simulation}

For each of the 100 individuals in a data set, 2 random time points from within the appropriate sampling window were generated in Excel. Data were simulated using the computer program NONMEM (Non-linear Mixed Effects Modeling) (version 4.0, double precision) (30) on an IBM ES-9000 computer. For each scenario, 100 data sets were replicated.

The influence of interindividual variability on the pharmacokinetic parameters was also investigated. The study was carried out in the presence of two levels of interindividual variability in both CL and Vd, a low level of variability of $30 \%$ and a moderately high level of variability of $60 \%$. In all cases intraindividual variability was set at $25 \%$. A total of 1800 data sets were simulated.

\section{Effect of Changing Intraindividual Variability}

To investigate the influence of a lower level of intraindividual variability on the ability to obtain accurate parameter estimates, Design 3, where the ratio of patients in group A to B was $80: 20$, was repeated using an intraindividual variability of 15\% (Design 4). This was done in the presence of interindividual variability of $60 \%$.

\section{Effect of Changing Total Sample Size}

The effect of increasing the total sample size was investigated using Design 3 where the ratio of patients in group $A$ to $B$ was maintained at 80:20. The total sample was increased from 100 individuals to 200 individuals (Design 5). Thus, the data set used in Design 5 
consisted of 160 individuals who were sampled from Group A and 40 who were sampled from group B. This was done in the presence of interindividual variability of $60 \%$ and intraindividual variability of $25 \%$

\section{Data Analysis}

For each simulated data set, estimation of pharmacokinetic and statistical parameters was carried out using NONMEM. Each simulated data set was analyzed using two models i) a basic model in which there was no attempt to distinguish between patients from Groups

$\mathrm{A}$ and $\mathrm{B}$ and ii) a more complex model (full model) in which an additional parameter was included to distinguish between patients in Groups A and B. A drop in the objective function of 3.84 or greater when comparing the full model to the basic model was considered statistically significant $(p=0.05)$. In these instances it was concluded that a sub-group possessing a reduced value of clearance had been identified using NONMEM. Only runs that successfully identified two groups of patients were used to determine the accuracy of parameter estimates. The estimation procedure was run in NONMEM using the first order (FO) method.

\section{FO versus FOCE Method}

A number of different methods of calculating parameter estimates can be used in NONMEM (30). The first order (FO) method uses a first order approximation method that involves linearization of the random effect parameters. This algorithm may produce more biased estimates than the first order conditional estimation (FOCE) method. To 
compare the use of these two mathematical algorithms, Design 3 where the size of Group B was 20 was repeated using the FOCE method (Design 6) and the results compared.

\section{Bias and Precision of Parameter Estimates}

The accuracy of the estimates from each data set were evaluated using the percent prediction error $(\% \mathrm{PE})$ as described by the following equation:

$$
\% \mathrm{PE}=\left(\theta_{\text {sim }}-\theta_{\text {true }}\right) / \theta_{\text {true }} * 100
$$

where $\theta_{\text {true }}$ is the true population value for the parameter and $\theta_{\text {sim }}$ is the estimated population value of the parameter from one simulated data set. The $\% \mathrm{PE}$ was calculated for the 100 simulated datasets in each scenario. The mean $\% \mathrm{PE}$ was used as a measure of bias and the standard deviation (SD) of \% $\mathrm{PE}$ was used as a measure of the precision of parameter estimation. Previous simulation studies have regarded different magnitudes of bias and precision as being acceptable $(11,17,18,22)$. In this study, the following guidelines were employed: a mean $\% \mathrm{PE}$ for a parameter $\leq 15 \%$ was accepted as being unbiased and a SD of $\% \mathrm{PE} \leq 35 \%$ was accepted as being precise (17).

\section{RESULTS}

The percentage of runs in which individuals sampled from Group B were successfully identified using the various designs are listed in Tables 2 and 3 and illustrated in Figures $1 \mathrm{a}$ and $\mathrm{lb}$. Figure $\mathrm{la}$ represents the results when interindividual variability was set at $30 \%$ 
and Figure $1 \mathrm{~b}$ represents the results when interindividual variability was set at $60 \%$. The following results were obtained on analysis of the data:

1. The number of runs where Group B was successfully identified was greater for all designs when interindividual variability was $30 \%$ as compared to $60 \%$.

2. Both Designs 2 and 3 performed better than Design 1 when interindividual variability was $30 \%$ but not when interindividual variability was $60 \%$.

3. In general, using all of the designs, when the size of Group B was increased from 10 to 20 there was marked improvement in the ability to detect Group B. Increasing the size of Group B from 20 or 30 did not offer the same improvement.

For Designs 1 to 3 , bias and precision of pharmacokinetic parameter estimates are shown in Tables 4 and 5 and Figures 2 and 3 when interindividual variability was $30 \%$ and in Tables 6 and 7 and Figures 4 and 5 when interindividual variability was $60 \%$. Bias and precision of variability parameter estimates are shown in Tables 4 to 7 and Figures 6 to 9 .

Looking at the pharmacokinetic parameter estimates first, when interindividual variability was $30 \%$, all 3 pharmacokinetic parameters were acceptable in terms of bias and precision regardless of the design used or the sizes of Group B. When interindividual variability was $60 \%$ only Design 1 failed to give acceptable estimates. Only the estimate of CL of Group B was biased when Group B consisted of 10 individuals. Otherwise, using the other designs, all pharmacokinetic parameters were estimated accurately. 
In general, variability parameters were less well estimated than the pharmacokinetic parameters. When interindividual variability was set at 30\% (Table 4, Figure 6), Design 1 performed adequately in terms of bias at all levels. Using Design 3 , estimates of $\omega_{\mathrm{Cl}}$ and $\omega_{\mathrm{V} d}$ were acceptable but estimates of $\sigma$ were slightly biased. Using Design 2 , biased estimates of nearly all of the parameters were obtained regardless of the size of Group B However, there was a trend for bias to improve as the size of Group B increased using Design 2.

The situation with respect to precision was different. All levels of both Designs 1 and 2 produced imprecise estimates of variability parameters although $\omega_{\mathrm{CI}}$, was measured precisely using Design 2. There did not appear to be an improvement in precision of the parameter estimates as the size of Group B increased. Using Design 3, estimates were in general more precise than estimates obtained with the other designs but in no case did Design 3 produced precise estimates of all 3 variability parameters. However, when parameters were found to be imprecise they were only just above the upper limit of acceptability.

When interindividual variability was set at $60 \%$, all designs performed worse than at $30 \%$. In fact, no design provided estimates of the pharmacokinetic parameters that were acceptable in terms of either bias or precision. Taking Design 1 first, $\omega_{\mathrm{CL}}$ and $\omega_{\mathrm{r}}$ were unbiased when group B consisted of 20 or more individuals but these estimates were imprecise. Estimates of $\sigma$ were biased and imprecise in all cases. Bias and precision of some parameter estimates deteriorated as group B got larger. Using Design 3, estimates 
of $\omega_{\mathrm{CL}}$ were unbiased only when the size of Group B was 30 . Estimates of $\omega_{\mathrm{Vd}}$ were unbiased regardless of the size of Group B. Conversely, $\sigma$ was biased in all cases. In terms of precision, estimates of $\omega_{\mathrm{CL}}$ were only marginally imprecise and when Group B consisted of 20 individuals the estimates of both $\omega_{\mathrm{CL}}$ and $\omega_{\mathrm{Vd}}$ were acceptable although the estimate of $\sigma$ in this scenario was more imprecise as compared to the other cases. There does not appear to be an obvious trend in the level of imprecision using Design 3 Design 2 produced the most biased estimates. In fact, all parameters were biased regardless of the size of Group B and the estimates of $\sigma$ were enormously biased, in the magnitude of $300 \%$ in each case. However, in terms of precision, Design 2 performed comparably to Designs 1 and 3. Estimates of both $\omega_{\mathrm{CL}}$ and $\omega_{\mathrm{vd}}$ were acceptable except $\omega_{\mathrm{rd}}$ when Group B was 30, which was only marginally imprecise. Estimates of $\sigma$ were highly imprecise at all levels and like Design 3 there did not appear to be a definite trend in precision as the size of Group B varied.

\section{Effect of Changing Intraindividual Variability}

The influence of the level of intraindividual variability within the data was investigated. The original simulations were conducted using a level of $25 \%$ (Design 3 ). To investigate the effect of a lower level, the study was repeated where intraindividual variability was reduced to $15 \%$ (Design 4). The results using Designs 3 and 4 are shown in Table 8 and Figures $10 \mathrm{a}$ and $10 \mathrm{~b}$. In terms of bias and precision, reducing intraindividual variability from $25 \%$ to $15 \%$ did not affect the estimation of the pharmacokinetic parameters or the interindividual variability parameters. The only noticeable effect was upon the estimates 
of intraindividual variability. When intraindividual variability was lower, estimates of $\sigma$ were both more biased and less precise.

\section{Effect of Changing Total Sample Size}

The results of increasing the total sample size from 100 individuals (Design 3) to 200 individuals (Design 5) are shown in Table 9 and Figures $11 \mathrm{a}$ and $11 \mathrm{~b}$. Using Design 5, the estimate of $\omega_{C L}$ was unbiased and estimation of CL of Group B, $\omega_{\mathrm{Vd}}$ and $\sigma$ were improved. In terms of precision, the biggest change was in the precision of $\sigma$ which was much improved using Design 5 but still not acceptable. The estimate of $\omega_{\mathrm{rd}}$ was marginally worse with Design 5 but still within the acceptable limits.

\section{FO versus FOCE Method}

The results comparing the FO method (Design 3) to the FOCE method (Design 6) are shown in Table 10 and Figures $12 \mathrm{a}$ and $12 \mathrm{~b}$. Unbiased and precise estimates of all 3 pharmacokinetic parameters were obtained using both methods. Variability parameters

were less biased and more precise using the FOCE method. Only $\sigma$ was biased using the FOCE method. The FO method produced an imprecise estimate of $\sigma$ whereas all 3 variability parameters were precise using the FOCE method.

\section{DISCUSSION}

The population approach to pharmacokinetics is used to obtain estimates of the pharmacokinetic parameters and their variability within a population. The approach is versatile in that it can be applied in a variety of different situations e.g. when data is rich, 
when data is sparse or when a combination of the two kinds of data is available. In the case of phase III clinical trials, when data is sparse and there is a large, heterogeneous population in comparison to the populations of traditional studies, more realistic estimates of the variability of the parameters can be obtained. Patient specific parameters such as demographic characteristics or physiological variables can be evaluated as potential sources to explain some of the variability. In this way, the behavior of the drug in different populations can be characterized and the need for dosage adjustment addressed. When data are sparse, particular attention must be given to the design of the study as good quality results can only be achieved if good quality data are available. There are many factors that are influential and should be taken into consideration when the study is being planned. These include the pharmacokinetic characteristics of the drug under study, the primary objectives of the study, the timing and number of samples, the heterogeneity of the study population and the cost of collecting and analyzing the samples. Another consideration to take into account is the size of a sub-population possessing a characteristic that is to be evaluated for an effect upon a pharmacokinetic parameter. If an effect is to be detected then the sub-population must be of sufficient size to provide the study with the power to detect this effect. Simulation studies are ideal tools to investigate these types of issues prior to execution of the study. Different designs can be investigated to determine the optimal design for a given situation.

In this study, data were simulated using a one-compartment model with intravenous input according to various study designs. Initially 3 designs were evaluated. Each design comprised 2 samples per individual and 100 individuals. In Design 1 the samples were 
taken between 0.08 and 1 hour and between 7 and 8 hours, in Design 2 they were taken between 0.08 and 1 hour and 8 and 24 hours and in Design 3 each individual contributed 2 samples from 2 of the following 3 sampling windows: 0.08 to 1 hour, 1 to 8 hours and 8 to 24 hours. Additionally, different combinations of individuals were used to make up the study population. Individuals could be sampled from one of two groups, Group A where the population average value of $\mathrm{CL}$ was $2.94 \mathrm{~L} / \mathrm{hr}$ and Group B where the population average value of $\mathrm{CL}$ was $2.06 \mathrm{~L} / \mathrm{hr}$. The Group B average value represents a $30 \%$ reduction in $\mathrm{CL}$. The efficiency of the different study designs in obtaining accurate parameter estimates was evaluated.

First, the ability to identify the sub-population was investigated. When interindividual variability was low, the performance of Design 1 was substantially worse than Designs 2 and 3 in identifying Group B. In order to detect group B, where the population average value of $\mathrm{CL}$ is reduced, the study design must provide informative data about $\mathrm{CL}$. The half-life of the drug in this study was 7.4 hours. Using Design 1, the late sample was taken between 7 and 8 hours after administration of the drug i.e. approximately one halflife after dosing. Ette et al used a single sample per individual design and found that when the late sampling point was approximately one half-life after dosing, performance of the study design was worse than when the sample was taken at a later time (19). They found that the optimal time period to gain information about CL was 1.4 - 3 half-lives after administration of the drug. The results observed in this study are consistent with this observation which suggests that Design 1 performed badly because it did not contain enough relevant information to obtain accurate estimates for CL of either group A or 
group B. On the other hand, Designs 2 and 3 did contain information within the optimal period to estimate CL and thus these designs performed better.

At a level of $30 \%$ interindividual variability, increasing the size of Group B from 20 to 30 individuals did not improve upon the ability to detect Group B. Thus, the previously suggested size of a sub-population of $20(1,13)$ appears to be acceptable to detect a $30 \%$ or greater change in CL when interindividual variability is low.

In the case of high interindividual variability $(60 \%)$, it became substantially more difficult to detect group B using all designs. In fact, none of the designs were consistently able to detect the sub-population. Even when the size of the sub-population was 30 , the number of runs in which the sub-population was successfully identified was only 60 to $70 \%$ for the various designs. In contrast to the performance observed when interindividual variability was low, increasing the size of Group B from 20 to 30 individuals resulted in marked improvement in detecting group B for Designs 1 and 3 Design 1 performed better than Designs 2 and 3 in detecting the sub-group when the size of the sub-group was 30,69\% detected versus $59 \%$ and $62 \%$ for Designs 2 and 3 , respectively. There is no obvious reason why this would be the case and it may just be a spurious finding considering the overall low performance of all designs.

None of the study designs investigated here were adequate when variability was high. A study by Breant et al used real data on cyclosporine where $\omega_{\mathrm{CL}}$, was approximately 30 $40 \%$ and $\omega_{V d}$ was $60-100 \%$. They investigated the effect of sample size on the ability to 
accurately determine the pharmacokinetic parameters of a one-compartment model (26). By stepwise addition of 1 sample at a time starting from just 1 sample in 1 patient they found that parameter estimates tended to converge when $10-20$ patients contributed $2-$ 4 blood samples each. However to detect a sub-population with altered pharmacokinetics they required more patients and more samples per patient (approximately 40 patients and $4-5$ blood levels per patient). A drawback to their study was that an optimal sampling strategy was not employed in selecting the blood levels. The lack of planned sampling times and the small number of subjects in total may have contributed to the large number of samples required per individual to detect the sub-population. The situation in this study was similar in that none of the 2 sample designs investigated performed adequately. Consequently, more samples per individual may be required to detect a $30 \%$ reduction in CL when interindividual variability is $60 \%$ or higher. Under these circumstances, the previously reported size of 20 for a sub-population would not be sufficient.

An alternative approach to increasing the number of samples per individual may be to increase the total size of the study population. This was investigated using Design 3 (100 individuals) and Design 5 (200 individuals). The percentage of individuals in group B was maintained at $20 \%$ and interindividual variability was set at $60 \%$. Increasing the total sample size resulted in marked improvement in the ability to detect the subpopulation. The percentage of runs in which group B was successfully identified increased from $49 \%$ to $80 \%$. Thus, increasing the total number of individuals in the study population yet maintaining the number of samples per individual at 2 , aided in identifying the sub-group. 
When interindividual variability was $60 \%$ and either intraindividual variability was reduced to $15 \%$ or the FOCE method was used to analyze the data, the effect on the ability to detect the sub-group was only minimal. When the size of group B was $20 \%$ of the total population, changing either of these design factors resulted in an increase from $49 \%$ to $53 \%$ and $54 \%$, respectively, of runs in which the sub-population was successfully identified.

This study shows that, especially when the drug exhibits a high degree of interindividual variability, in the range of $60 \%$, a non-significant effect of a covariate may be a consequence of inadequate power to detect an effect rather than a lack of effect altogether. Only a maximum of approximately $60-70 \%$ of runs for a given design successfully identified the sub-population in this study under these conditions. Thus, caution needs to be taken when interpreting non-significant effects of covariates in population pharmacokinetic studies.

The accuracy of estimates of the pharmacokinetic parameters of the model were used to evaluate the different designs. When interindividual variability was low, accurate estimates of CL in Group A, CL of group B and Vd were obtained regardless of the size of Group B and irrespective of the design used (Tables 4 and 5). Estimates of Vd were stable across designs and different sizes of Group B. In all designs tested at least twothirds of the population were sampled during the period 0.08 to 1 hour after the dose. It is the very early times after administration of a single dose that provides information about 
the parameter, Vd. Thus, it would appear that all of the designs included sufficient information to accurately estimate Vd. However, the designs differed in the amount of information that was available to obtain estimates of CL. As previously mentioned, the optimal time to obtain information about CL has been shown to be $1.4-3$ half-lives after a dose. Both Designs 2 and 3 consisted of sampling windows that encompassed this period and so they would be expected to perform better than Design 1. When the size of the sub-population was 10 this was clearly evident, both bias and precision were substantially worse with Design 1 as compared with Designs 2 and 3. In general, the estimates of both CL of Group A and CL of Group B were worse for Design 1 as compared to Designs 2 and 3. However, estimates were still within acceptable limits of precision using Design 1 .

When interindividual variability was high $(60 \%)$, all 3 pharmacokinetic parameters were estimated with less precision and greater bias than at the lower level of interindividual variability (30\%). Intuitively this makes sense that as the variability inherent in a parameter increases it becomes harder to accurately estimate that parameter with the same fixed population. Overall, the performance of Design 1 was poorest in terms of estimating both CL of Group A and CL of Group B. This is likely to be due to the reason given previously, the lack of informative data on these parameters. For Designs 1 and 3 there was marked improvement in the bias of the estimates of CL of Group B when the size of that group was increased from 10 to 20 . Very little change was observed when the size of Group B was increased from 20 to 30 . In contrast, Design 2 performed similarly in terms of estimating the CL of Group B irrespective of the size of Group B. All 
individuals in Design 2 had a sample taken in the time range necessary to estimate CL accurately, compared to only two-thirds of individuals in Design 3 and none in Design 1. This may explain why Design 2 performed better than the other designs when the size of Group B was 10. In general, using all designs, precision of CL estimates improved as the size of Group B increased but estimates were acceptable at all levels. As seen with the low level of interindividual variability, when interindividual variability was high, estimates of $\mathrm{Vd}$ were stable and accurate in terms of both bias and precision across designs and irrespective of the size of the sub-group.

It is accepted that for a fixed sample size, pharmacokinetic parameters are estimated more accurately than the associated variability parameters $(11,22,31)$. This observation was confirmed at both levels of interindividual variability studied here. When interindividual variability was low, Design 1 produced acceptable estimates of all variability parameters in terms of bias yet all of the estimates were imprecise. In a previous simulation study, Sheiner and Beal found that an imprecise estimate of $\omega_{\mathrm{Vd}}$ prohibited the detection of bias in that parameter (3). Thus, the high level of imprecision observed in estimating all of the variability parameters using Design 1 may have masked the ability for bias to be detected. With Design 2 almost all of the parameters were biased regardless of the size of the sub-group. However, precision of $\omega_{\mathrm{CL}}$. was better with Design 2 than it was with Design 1 although this was the only parameter using Design 2 to be acceptable in terms of precision. This is probably a direct consequence of the more informative study design with respect to $\mathrm{CL}$. Design 3 performed the best overall in estimating the variability parameters. The majority of parameters were acceptable in terms of bias, the exception 
being $\sigma$. Precision of estimates was relatively unaffected by the size of Group B and estimates were precise or only marginally imprecise in most instances. Design 3 differed from the two previous designs in that three sampling windows were used to obtain samples even though the number of samples per individual remained at two. In so doing, the whole of the concentration-time profile was covered from 0.08 hours to 24 hours after the dose. Ensuring that samples were taken at random has been shown in the past to be a robust design $(1,12,32)$. The use of random sampling can protect against misspecification of the underlying structural model and situations where a single model is not adequate for all individuals. Optimal sampling has been shown to be of benefit when samples are sparse $(33,34)$. However, a drawback to its use is that optimal sampling does not take into consideration interindividual variability so an optimal time for one individual may be sub-optimal for another especially if interindividual variability is high (18). The use of sampling windows employed in Design 3 ensured that there was a randomness of the data throughout the dosing interval including times that provide optimal information on the parameters of the model. This may account for the superior performance of this design compared to the other two designs. Using Design 3, when the size of Group B was 10 or 20 , the variability estimates were virtually identical in terms of precision. When the size of Group B was increased to 30 , estimates of $\omega_{\mathrm{CL}}$ and $\omega_{\mathrm{Vd}}$ improved but the estimate of $\sigma$ deteriorated. In a previous simulation study in which a 2 sample per individual design was implemented, there was difficulty differentiating between interindividual and intraindividual variability (15). Inclusion of a third sample per individual was required to effectively partition the two types of variability. At a low level of interindividual variability, this phenomenon was apparent using Design 2 and Design 3. It was most 
obvious with Design 2 perhaps because of the large difference in time between the two samples from each individual in this design (the first sample was taken between 0.08 and 1 hour and the second sample between 8 and 24 hours). Some of the individuals in Design 3 had samples taken closer together which may have aided in partitioning the variability correctly with this design.

As seen with the pharmacokinetic parameters, estimation of the variability parameters deteriorated when interindividual variability was increased to the higher level of $60 \%$. Design 2 performed worst overall at estimating the variability parameters at this level of interindividual variability. All estimates were highly biased, especially estimates of $\sigma$ which exceeded $300 \%$. Estimates of $\omega_{C L}$ and $\omega_{v d}$ were for the most part precise but the estimates of $\sigma$ were very imprecise. There was no trend for estimates to improve when the size of Group B was increased. Both $\omega_{\mathrm{CL}}$ and $\omega_{\mathrm{Vd}}$ were associated with negative biases and $\sigma$ with positive biases. This is possibly a result of the difficulty in differentiating between interindividual and intraindividual variability associated with the 2 sample design. None of the levels of Design 1 provided unbiased estimates of all of the parameters. There was a trend for bias in $\omega_{\mathrm{CL}}$ and $\sigma$ to increase and bias in $\omega_{\mathrm{Vd}}$ to decrease as the size of Group B increased. This may be a consequence of the difficulty associated with estimating these parameters from only two samples as already mentioned Design 3 provided unbiased estimates of $\omega_{\mathrm{Vd}}$ irrespective of the size of group B and unbiased estimates of $\omega_{\mathrm{CL}}$ only when the size of Group B was 30 . In all cases, the estimates of $\sigma$ were highly biased. There was no apparent trend in the precision of parameter estimates using Design 3. When the size of the sub-group was 20 , precision in 
$\omega_{\mathrm{CL}}$ and $\omega_{\mathrm{Vd}}$ improved but at the expense of precision in $\sigma$. This problem in partitioning variability was seen with all of the study designs although with Design 2 it was more pronounced. With Designs 1 and 3, at least some of the individuals had samples that were closer together in time which may have helped to partition the variability.

Design 3 in which the sub-population consisted of 20 individuals was chosen as a base model to evaluate 3 additional modifications to the study design. First, the effect of reducing the level of intraindividual variability was investigated (Design 4), second the effect of increasing the size of the total study population was considered (Design 5) and finally, the effect of using the FOCE algorithm in NONMEM instead of the FO method was investigated (Design 6). Each additional factor was considered separately at the high level of interindividual variability of $60 \%$.

The level of intraindividual variability selected for this study $(25 \%)$ represents a moderately variable drug (16). Previous simulation studies $(3,11)$ have often used a more modest level of $15 \%$, a value these researchers feel is more commonly observed clinically. When the effect of decreasing the intraindividual variability from $25 \%$ to $15 \%$ was studied, the only parameter estimate that was markedly affected was $\sigma$. Both bias and precision were worse when intraindividual variability was $15 \%$. As previously mentioned, when only two samples are taken per individual there are problems distinguishing the two types of variability. The erroneous partitioning of interindividual variability into intraindividual variability leads to a proportionally larger error in the intraindividual variability when the starting value is low. 
Initially in this study, designs were investigated using a fixed number of samples per individual in a fixed total population. Precision of parameter estimates is influenced by the total size of the study population. Thus, increasing the size of the total population from 100 individuals (Design 3) to 200 individuals (Design 5) should result in more accurate parameter estimates. This is in fact what was observed (Table 9). The biggest change occurred in the precision of $\sigma$ which was much improved using Design 5 although it was still not acceptable. The estimate of $\omega_{\mathrm{Vd}}$ was slightly worse with Design 5 but still within the acceptable limits. Thus, doubling the sample size did not lead to acceptable estimates of all parameters although some improvement was observed. Using Design 5 the estimate of $\omega_{\mathrm{CL}}$ was unbiased and estimation of $\mathrm{CL}$ of Group $\mathrm{B}, \omega_{\mathrm{Vd}}$ and $\sigma$ improved in terms of bias when compared to Design 3. Increasing the total sample size further may lead to further improvements in the parameter estimates.

The final factor to be evaluated was the effect of using the FOCE algorithm as implemented in NONMEM. In early versions of the NONMEM program, only the FO method was available. This method involves a linear approximation of the random effect parameters in the model that may lead to bias in parameter estimates. In contrast, the FOCE method does not use this linear approximation and so may be expected to produce less biased parameter estimates. A problem in the past with the FOCE method was that it is more complex than the FO method and so requires much more computer time to perform an analysis especially with large data sets and/or complex structural models. However, the improvement in the speed of computers means that this is not as great of an issue today. In this study, there was a substantial difference between the two methods 
with respect to estimation of the variability parameters (Table 10). Using the FOCE method, all parameters were precise and only $\sigma$ was biased. However, with the FO method, $\sigma$ was more biased and imprecise and $\omega_{\mathrm{Cl}}$ was biased. In general terms, all of the variability parameters were better estimated when the FOCE method was used in NONMEM as opposed to the FO method. This is in keeping with the observations of Jonsson and colleagues who found that the FOCE method produced more accurate estimates of some parameters (14).

\section{CONCLUSIONS:}

This study evaluated 3 sampling designs in various study populations. The designs were evaluated in terms of their ability to provide accurate estimates of the parameters of the model and to identify a sub-population with reduced clearance. These results show that modification of various details of the design influenced the results obtained. In addition, other factors such as the primary objectives of the study and the cost of analyzing samples need to be taken into consideration when designing a population pharmacokinetic study. Thus each population study should be considered on an individual basis and the factors relevant to that situation can be assessed.

Under the conditions of this study, the following general conclusions on study design can be drawn:

1. When interindividual variability was low (30\%), a sub-group of 20 individuals was adequate to detect a sub-group in which CL was reduced by $30 \%$. No benefit was 
observed when the size of the sub-population was increased to 30 but there was deterioration when the sub-population was reduced to 10 .

2. When interindividual variability was high $(60 \%)$, a sub-group of 30 was not enough to consistently identify the sub-group. No design identified the sub-group more than $70 \%$ of the time. Thus, when interindividual variability was high, none of the 2 sample designs evaluated in this study could consistently identify a sub-group with a $30 \%$ reduced $\mathrm{CL}$.

3. When interindividual variability was high, increasing the size of the sub-group beyond $30 \%$ of the total population or increasing the number of samples per individual may help to identify the sub-group. These effects were not investigated in this study.

4. When interindividual variability was high, increasing the total size of the study population from 100 individuals to 200 individuals resulted in marked improvement in the ability to identify the sub-group.

5. Both pharmacokinetic parameters and variability parameters were more difficult to estimate when interindividual variability was high

6. All designs accurately estimated the pharmacokinetic parameters when interindividual variability was $30 \%$. At the $60 \%$ level, Vd estimates were stable and estimates of $\mathrm{CL}$ were acceptable when study designs contained samples taken at later times i.e. 1 to 3 half-lives after administration of the drug.

7. Of the 3 sampling designs investigated, one design consisted of 3 sampling windows that covered a period of approximately 3 half-lives. This design performed the best overall of the designs and when interindividual variability was low, most of the 
variability parameters could be estimated accurately using this design whereas the other 2 designs performed badly at this level. When interindividual variability was high, none of the designs tested were able to produce acceptable estimates of variability parameters. Additionally, all designs suffered from the inability to differentiate interindividual variability from intraindividual variability.

8. The difficulty in partitioning variability was more pronounced using a lower level of intraindividual variability. When the true value for $\sigma$ is lower, interindividual variability that is wrongly partitioned as intraindividual variability will have a greater effect upon the estimate of $\sigma$. This explains why the estimate of $\sigma$ deteriorated at the lower level of intraindividual variability.

9. Increasing the total size of the study population resulted in better detection of the subgroup and an increase in the accuracy of some parameter estimates.

10. At the high level of interindividual variability studied, the FOCE method resulted in marked improvement of the variability estimates as compared to the FO method. Use of the FOCE method did not affect the ability to detect the sub-population.

In summary, Design 3 performed best overall. This design consisted of 3 sampling windows that ensured a random spread of the data throughout the dosing interval including the optimal time periods to gain information on individual parameters. However, at the high level of interindividual variability studied here $(60 \%)$, this design still did not perform consistently. 


\section{REFERENCES}

1. Sheiner L. B. and Benet L. Z. Premarketing Observational Studies of Population Pharmacokinetics of New Drugs. Clinical Pharmacology and Therapeutics, November $1985 ; 38(5): 481-487$.

2. Aarons L. Sparse Data Analysis. European Journal of Drug Metabolism and Pharmacokinetics, 1993; 18 (1):97-100.

3. Sheiner L. B. and Beal S. L. Evaluation of methods for estimating population pharmacokinetic parameters III. Monoexponential model: Routine clinical pharmacokinetic data. Journal of Pharmacokinetics and Biopharmaceutics, 1983; 11 (3): 303-319.

4. Sheiner L. B. and Ludden T. M. Population Pharmacokinetics/Dynamics. Annual Review of Pharmacology and Toxicology, 1992; 32: 185-209.

5. Samara E. and Granneman R. Role of population pharmacokinetics in drug development. A pharmaceutical industry perspective. Clinical Pharmacokinetics, 1997; 32 (4): 294-312.

6. Vozeh S., Steimer J. L., Rowland M., Morselli P., Mentre F., Balant L. P. and Aarons L. The use of population pharmacokinetics in drug development. Clinical Pharmacokinetics, 1996; 30 (2): 81-93.

7. McLachlan A. J. Sparse Concentration Data Analysis using a Population approach: a valuable tool in clinical pharmacology. Clinical and Experimental Pharmacology and Physiology, 1996; 23: 995-999 
8. Tett S. E., Holford N. H. G. and McLachlan A. J. Population Pharmacokinetics and Pharmacodynamics: An Underutilized resource. Drug Information Journal, 1998; 32: $693-710$

9. Jackson K. A. and Rosenbaum S. E. The Application of Population Pharmacokinetics to the Drug Development Process. Drug Development and Industrial Pharmacy, 1998; $24(12): 1155-1162$.

10. Guidance for Industry: Population Pharmacokinetics. U.S. Department of Health and Human Services, Food and Drug Administration, Center for Drug Evaluation (CDER) (February 1999).

11. Ette E. I., Sun H. and Ludden T. M. Balanced Designs in longitudinal population pharmacokinetic studies. Journal of Clinical Pharmacology, 1998; 38(5): 417-423

12. Antal E. J., Grasela T. H. and Smith R. B. An Evaluation of Population Pharmacokinetics in Therapeutic Trials. Part III. Prospective Data Collection versus Retrospective Data Assembly. Clinical Pharmacology and Therapeutics, 1989; 46: $552-559$.

13. Aarons L., Balant L. P., Mentre F.,Morselli P. L., Rowland M., Steimer J-L. and Vozeh S. Practical Experience and issues in designing and performing population pharmacokinetic / pharmacodynamic studies. European Journal of Clinical Pharmacology, 1996; 49: $251-254$

14. Jonsson E. N., Wade J. R. and Karlsson M. O. Comparison of Some Practical Sampling Strategies for Population Pharmacokinetic Studies. Journal of Pharmacokinetics and Biopharmaceutics, 1996; 24 (2): 245-263. 
15. Al-Banna M. K., Kelman A. W. and Whiting B. Experimental design and efficient parameter estimation in population pharmacokinetics. Journal of Pharmacokinetics and Biopharmaceutics, 1990; 18 (4): 347-360.

16. White D. B., Walawander C. A., Tung Y. and Grasela T. H. An Evaluation of Point and Interval Estimates in Population Pharmacokinetics using NONMEM analysis. Journal of Pharmacokinetics and Biopharmaceutics, 1991; 19 (1): 87-112

17. Sun H., Ette E. I. and Ludden T. M. On the recording of sampling times and parameter estimation from repeated measures pharmacokinetic data. Journal of Pharmacokinetics and Biopharmaceutics, 1996; 24 (6): 637-650.

18. Ette E. I., Sun H. and Ludden T. M. Design of population pharmacokinetic studies. Proceedings of the American Statistical Association (Biopharmaceutics Section), $1994 ; 487-492$.

19. Ette E. I., Kelman A. W, Howie C. A. and Whiting B. Interpretation of Simulation Studies for efficient estimation of population pharmacokinetic parameters. The Annals of Pharmacotherapy, 1993; 27(9): 1034-1039.

20. Ette E. I., Sun H. and Ludden T. M. Ignorability and Parameter estimation in longitudinal population pharmacokinetic studies. Journal of Clinical Pharmacology, $1998 ; 38(3): 221-226$.

21. Ette E. I., Howie C. A., Kelman A. W. and Whiting B. Experimental design and efficient parameter estimation in preclinical pharmacokinetic studies. Pharmaceutical Research, 1995; 12(5): 729-737. 
22. Ette E. I., Kelman A. W., Howie C. A. and Whiting B. Analysis of animal pharmacokinetic data: Performance of the one point per animal design. Journal of Pharmacokinetics and Biopharmaceutics, 1995; 23 (6): $551-566$

23. Jones C. D., Sun H. and Ette E. I. Designing cross-sectional population pharmacokinetic studies: implications for pediatric and animal studies. Clinical Research and Regulatory Affairs, 1996; 13 (3 \& 4): $133-165$

24. Maitre P. O., Buhrer M., Thomson D. and Stanski D. R. A Three-Step Approach Combining Bayesian Regression And NONMEM Population Analysis. Journal of Pharmacokinetics and Biopharmaceutics, 1991; 19 (4): 377-384.

25. Mandema J. W., Verotta D. and Sheiner L. B. Building Population PharmacokineticPharmacodynamic Models. I. Models for Covariate Effects. Journal of Pharmacokinetics and Biopharmaceutics, 1992; 20 (5): 511-528.

26. Breant V., Charpiat B., Sab J. M., Maire P. and Jelliffe R. W. How many patients and blood levels are necessary for population pharmacokinetic analysis? A study of a one compartment model applied to cyclosporine. European Journal of Clinical Pharmacology, 1996; $51: 283-288$.

27. Hendeles L., Weinberger M. and Bighley L. Disposition of Theophylline after a single intravenous infusion of aminophylline. The American Review of Respiratory Disease, 1978; 118(1): 97-103.

28. Mitenko P.A. and Ogilvie R. A. Pharmacokinetics of intravenous theophylline. Clinical Pharmacology and Therapeutics, 1973; 14(4): 509-513.

29. D'Argenio D. Z. and Schumitzky A. ADAPT II User's Guide, Biomedical Simulation Resource, University of Southern California, Los Angeles, 1992. 
30. Beal S. L. and Sheiner L. B. NONMEM User's Guide Parts I-VIII, University of California, San Francisco, 1992-98

31. Sheiner L. B. and Beal S. L. Evaluation of methods for estimating population pharmacokinetic parameters II. Biexponential model with experimental pharmacokinetic data. Journal of Pharmacokinetics and Biopharmaceutics, 1981; 9 (5): $635-651$.

32. Hashimoto Y. and Sheiner L. B. Designs for population pharmacodynamics: Value of pharmacokinetic data and population analysis. Journal of Pharmacokinetics and Biopharmaceutics, 1991; 19 (3): $333-353$.

33. DiStephano III, J. J. Optimized blood sampling protocols and sequential design of kinetic experiments. American Journal of Physiology, 1981; 240: R259-R265.

34. D'Argenio D. Z. Optimal sampling times for pharmacokinetic experiments. Journal of Pharmacokinetics and Biopharmaceutics, 1981; $9(6)$ : $739-756$. 
Table 1: Sampling Windows for Designs 1 to 3.

\begin{tabular}{|cc|}
\hline Design & Time of samples 1 and 2 (hrs) \\
\hline 1 & $0.08-1$ and $7-8$ \\
\hline 2 & $0.08-1$ and $8-24$ \\
& $0.08-1$ and $1-8$ \\
& or \\
3 & $0.08-1$ and $8-24$ \\
& or \\
& $1-8$ and $8-24$ \\
\hline
\end{tabular}


Table 2: Percent of NONMEM Runs in Which Group B was

Successfully identified when Interindividual Variability was $30 \%$.

\begin{tabular}{|ccc|}
\hline Design $^{\text {a }}$ & $\begin{array}{c}\text { Number of Individuals } \\
\text { in Group B }\end{array}$ & $\begin{array}{c}\text { Percent Runs where Group B } \\
\text { was Successfully Identified }\end{array}$ \\
\hline 1 & 10 & 59 \\
1 & 20 & 73 \\
1 & 30 & 84 \\
& & \\
2 & 10 & 67 \\
2 & 20 & 94 \\
2 & 30 & 97 \\
& & 74 \\
3 & 10 & 93 \\
3 & 30 & 93 \\
\hline
\end{tabular}

a Details of Designs 1 to 3 are given in Table 1 . 
Table 3: Number of NONMEM Runs in Which Group B was

Successfully identified when Interindividual Variability was $60 \%$

\begin{tabular}{|ccc|}
\hline Design $^{\text {a }}$ & $\begin{array}{c}\text { Number of Individuals } \\
\text { in Group B }\end{array}$ & $\begin{array}{c}\text { Percent Runs where Group B } \\
\text { was Successfully Identified }\end{array}$ \\
\hline 1 & 10 & 27 \\
1 & 20 & 54 \\
1 & 30 & 69 \\
& & \\
2 & 10 & 41 \\
2 & 20 & 59 \\
2 & 30 & 59 \\
& & \\
3 & 10 & 37 \\
3 & 20 & 49 \\
3 & 30 & 62 \\
5 & 20 & 53 \\
5 & 20 & 80 \\
\hline & & 54 \\
\hline
\end{tabular}

a Details of Designs 1 to 3 are given in Table 1. Designs 4 to 6 are the same as Design 3 except for the following modifications: Design 4 uses a level of intraindividual variability of $15 \%$ (Design 3 uses 25\%), the total population for Design 5 is 200 individuals (Design 3 is 100 individuals), and Design 6 was analyzed using the FOCE method in NONMEM (Design 3 used the FO method). 
Table 4: Percent Bias of Parameter Estimates using all Three Designs when Interindividual Variability in Clearance and Volume of Distribution were $30 \%$.

\begin{tabular}{|c|c|c|c|c|c|c|c|}
\hline Design & $\begin{array}{l}\text { Ratio of } \\
\text { Group A: } \\
\text { Group B }\end{array}$ & $\begin{array}{c}\text { CL of } \\
\text { Group A }\end{array}$ & $\begin{array}{c}\text { CL of } \\
\text { Group B }\end{array}$ & Vd & $\omega_{\mathrm{CL}}$ & $\omega_{\mathrm{Vd}}$ & $\sigma$ \\
\hline $1^{d}$ & $90: 10$ & 3 & -9 & -7 & 5 & 2 & 10 \\
\hline 1 & $80: 20$ & 5 & -1 & -7 & -5 & 10 & 3 \\
\hline 1 & $70: 30$ & 4 & 2 & -7 & 10 & 7 & -3 \\
\hline $2^{b}$ & $90: 10$ & -4 & -6 & -6 & -27 & -16 & 30 \\
\hline 2 & $80: 20$ & -4 & -1 & -5 & -27 & -16 & 31 \\
\hline 2 & $70: 30$ & -4 & 0 & -6 & -22 & -11 & 31 \\
\hline $3^{c}$ & $90: 10$ & -1 & -3 & -5 & -12 & -3 & 11 \\
\hline 3 & $80: 20$ & -2 & -3 & -5 & -12 & -3 & 18 \\
\hline 3 & $70: 30$ & -2 & 0 & -6 & -13 & -2 & 18 \\
\hline
\end{tabular}

Abbreviations: $\mathrm{CL}=$ Clearance. $\mathrm{Vd}=$ Volume of Distribution, $\omega_{(\mathrm{C}}$, represents interindividual variability of $\mathrm{CL}$, (1) $\mathrm{Vd}$ represents interindividual variability of $\mathrm{Vd}, \sigma$ represents intraindividual variability.

${ }^{\text {" }}$ first sample taken between 0.08 and 1 hour and second sample taken between 7 and 8 hours.

${ }^{b}$ first sample taken between 0.08 and 1 hour and second sample taken between 8 and 24 hours.

${ }^{\circ} 2$ samples taken from 2 of the 3 following sampling windows: 0.08 to 1 hour, 1 to 8 hours and 8 to 24 hours. 
Table 5: Percent Precision of Parameter Estimates using all Three Designs when Interindividual Variability in Clearance and Volume of Distribution were 30\%.

\begin{tabular}{|cccccccc|}
\hline Design & $\begin{array}{c}\text { Ratio of } \\
\text { Group A: } \\
\text { Group B }\end{array}$ & $\begin{array}{c}\text { CL of } \\
\text { Group A }\end{array}$ & $\begin{array}{c}\text { CL of } \\
\text { Group B }\end{array}$ & Vd & $\omega_{\mathrm{CL}}$ & $\omega_{\mathbf{V d}}$ & $\sigma$ \\
\hline $1^{\mathrm{a}}$ & $90: 10$ & 5 & 16 & + & 77 & 42 & 63 \\
$1^{1}$ & $80: 20$ & 5 & 13 & + & 73 & 48 & 50 \\
$1^{1}$ & $70: 30$ & 5 & 11 & + & 74 & 39 & 51 \\
$2^{\mathrm{b}}$ & $90: 10$ & 3 & 11 & 3 & 28 & 39 & 57 \\
$2^{2}$ & $80: 20$ & 4 & 8 & 4 & 27 & 48 & 61 \\
2 & $70: 30$ & 4 & 7 & + & 32 & 44 & 60 \\
$3^{\mathrm{c}}$ & $90: 10$ & 4 & 11 & + & 36 & 37 & 33 \\
3 & $80: 20$ & 4 & 11 & + & 36 & 38 & 34 \\
3 & $70: 30$ & 5 & 9 & + & 34 & 35 & 43 \\
\hline
\end{tabular}

Abbreviations: $\mathrm{CL}=$ Clearance. $\mathrm{Vd}=$ Volume of Distribution. $\omega_{(1,1}$, represents interindividual variability of CL. (i) $V_{d}$ represents interindividual variability of $V d . \sigma$ represents intraindividual variability. ${ }^{a}$ first sample taken between 0.08 and 1 hour and second sample taken between 7 and 8 hours.

${ }^{\mathrm{b}}$ first sample taken between 0.08 and 1 hour and second sample taken between 8 and 24 hours.

c 2 samples taken from 2 of the 3 following sampling windows: 0.08 to 1 hour. 1 to 8 hours and 8 to 24 hours. 
Table 6: Percent Bias of Parameter Estimates using all Three Designs when Interindividual Variability in Clearance and Volume of Distribution were $60 \%$.

\begin{tabular}{|c|c|c|c|c|c|c|c|}
\hline Design & $\begin{array}{l}\text { Ratio of } \\
\text { Group A: } \\
\text { Group B }\end{array}$ & $\begin{array}{c}\text { CL of } \\
\text { Group A }\end{array}$ & $\begin{array}{c}\text { CL of } \\
\text { Group B }\end{array}$ & Vd & $\omega_{\mathrm{CL}}$ & $\omega_{\mathrm{vd}}$ & $\sigma$ \\
\hline $1^{a}$ & $90: 10$ & 13 & -16 & -12 & -6 & 30 & -23 \\
\hline 1 & $80: 20$ & 13 & 2 & -13 & -9 & 10 & 31 \\
\hline 1 & $70: 30$ & 15 & 5 & -13 & -13 & 7 & 66 \\
\hline $2^{b}$ & $90: 10$ & -7 & -9 & -13 & -58 & -48 & 330 \\
\hline 2 & $80: 20$ & -7 & -9 & -15 & -63 & -49 & 321 \\
\hline 2 & $70: 30$ & -8 & -7 & -12 & -59 & -43 & 326 \\
\hline $3^{\mathrm{c}}$ & $90: 10$ & 6 & -13 & -12 & -21 & -1 & 79 \\
\hline 3 & $80: 20$ & 3 & -5 & -11 & -25 & -7 & 97 \\
\hline 3 & $70: 30$ & 4 & -4 & -12 & -15 & 3 & 83 \\
\hline
\end{tabular}

Abbreviations: $\mathrm{CL}=$ Clearance. $\mathrm{Vd}=$ Volume of Distribution, $\omega_{\mathrm{CL}}$, represents interindividual variability of CL. (1) $\mathrm{Vd}_{\mathrm{d}}$ represents interindividual variability of $\mathrm{Vd}$. $\sigma$ represents intraindividual variability.

${ }^{a}$ first sample taken between 0.08 and 1 hour and second sample taken between 7 and 8 hours.

${ }^{\mathrm{b}}$ first sample taken between 0.08 and 1 hour and second sample taken between 8 and 24 hours.

" 2 samples taken from 2 of the 3 following sampling windows: 0.08 to 1 hour. 1 to 8 hours and 8 to 24 hours. 
Table 7: Percent Precision of Parameter Estimates using all Three Designs when Interindividual Variability in Clearance and Volume of Distribution were 60\%.

\begin{tabular}{|cccccccc|}
\hline Design & $\begin{array}{c}\text { Ratio of } \\
\text { Group A: } \\
\text { Group B }\end{array}$ & $\begin{array}{c}\text { CL of } \\
\text { Group A }\end{array}$ & $\begin{array}{c}\text { CL of } \\
\text { Group B }\end{array}$ & Vd & $\omega_{\mathbf{C L}}$ & $\omega_{\text {Vd }}$ & $\sigma$ \\
\hline $1^{\text {a }}$ & $90: 10$ & 9 & 25 & 7 & 27 & 43 & 109 \\
\hline 1 & $80: 20$ & 9 & 17 & 6 & 47 & 48 & 165 \\
$1^{1}$ & $70: 30$ & 8 & 18 & 5 & 55 & 39 & 162 \\
$2^{\mathrm{b}}$ & $90: 10$ & 6 & 28 & 7 & 22 & 30 & 158 \\
$2^{2}$ & $80: 20$ & 6 & 15 & 6 & 15 & 25 & 155 \\
2 & $70: 30$ & 6 & 10 & 7 & 26 & 38 & 183 \\
$3^{\mathrm{c}}$ & $90: 10$ & 9 & 21 & 9 & 38 & 45 & 99 \\
3 & $80: 20$ & 7 & 14 & 7 & 28 & 26 & 102 \\
3 & $70: 30$ & 9 & 14 & 7 & 38 & 58 & 93 \\
\hline
\end{tabular}

Abbreviations: $\mathrm{CL}=$ Clearance. $\mathrm{Vd}=$ Volume of Distribution, $\omega_{C \mathrm{CL}}$ represents interindividual variability of $\mathrm{CL}$, (1) $_{\mathrm{Vd}}$ represents interindividual variability of $\mathrm{Vd}, \sigma$ represents intraindividual variability.

${ }^{a}$ first sample taken between 0.08 and 1 hour and second sample taken between 7 and 8 hours.

${ }^{b}$ first sample taken between 0.08 and 1 hour and second sample taken between 8 and 24 hours.

" 2 samples taken from 2 of the 3 following sampling windows: 0.08 to 1 hour. 1 to 8 hours and 8 to 24 hours. 
Table 8: Percent Bias and Precision of Parameter Estimates using Different Levels of Intraindividual Variability.

\begin{tabular}{|c|cc|cc|}
\hline Parameter & \multicolumn{2}{|c|}{ \% Bias } & \multicolumn{2}{c|}{ \% Precision } \\
& Design 3 & Design 4 & Design 3 & Design 4 \\
\hline Group A CL & 3 & 6 & 7 & 8 \\
Vd & -11 & -10 & 7 & 7 \\
Group B CL & -5 & -2 & 14 & 14 \\
$\omega_{\mathrm{CL}}$ & -25 & -21 & 28 & 25 \\
$\omega_{\mathrm{Vd}}$ & -7 & -6 & 26 & 26 \\
$\sigma$ & 97 & 163 & 102 & 208 \\
& & & & \\
\hline
\end{tabular}

Abbreviations: $\mathrm{CL}=$ Clearance, $\mathrm{Vd}=$ Volume of Distribution, ()$_{(1]}$. represents interindividual variability of $\mathrm{CL} . \omega_{\mathrm{Vd}}$ represents interindividual variability of $\mathrm{Vd} . \sigma$ represents intraindividual variability

Both Design 3 and Design 4 consist of 2 samples per individual taken from three sampling windows - sce Table 1

Design 3: Intraindividual variability $=25 \%$, interindividual variability $=60 \%$.

Design 4: Intraindividual variability $=15 \%$. interindividual variability $=60 \%$ 
Table 9: Percent Bias and Precision of Parameter Estimates using Different Total

Numbers of Individuals.

\begin{tabular}{|c|cc|cc|}
\hline Parameter & \multicolumn{2}{|c|}{ \% Bias } & \multicolumn{2}{c|}{ \% Precision } \\
& Design 3 & Design 5 & Design 3 & Design 5 \\
\hline \multirow{2}{*}{ Group A CL } & 3 & 3 & 74 & 6 \\
Vd & -11 & -12 & 74 & 56 \\
Group B CL & -5 & -1 & 14 & 136 \\
$\omega_{\mathrm{CL}}$ & -25 & -12 & 28 & 266 \\
$\omega_{\mathrm{Vd}}$ & -7 & -5 & 26 & 34 \\
$\sigma$ & 97 & 86 & 102 & 72 \\
\hline
\end{tabular}

Abbreviations: $\mathrm{CL}=$ Clearance. $\mathrm{Vd}=$ Volume of Distribution. $\left.{ }_{(1)}\right)_{1}$. represents interindividual variability of CL. (1) $\mathrm{vd}_{\mathrm{d}}$ represents interindividual variability of $\mathrm{Vd} . \sigma$ represents intraindividual variability

Both Design 3 and Design 5 consist of 2 samples per individual taken froın three sampling windows - sec Table 1 .

Design 3: Total number of individuals $=100$. interindividual variability $=60 \%$. intraindividual variability $=$ $25 \%$.

Design 5 : Total number of individuals $=200$. interindividual variability $=60 \%$. intraindividual variability $=$ $25 \%$. 
Table 10: Percent Bias and Precision of Parameter Estimates obtained when the FO Method was compared to the FOCE Method.

\begin{tabular}{|c|cc|cc|}
\hline Parameter & \multicolumn{2}{|c|}{ \% Bias } & \multicolumn{2}{c|}{ \% Precision } \\
& Design 3 & Design 6 & Design 3 & Design 6 \\
\hline \multirow{2}{*}{ Group A CL } & 3 & 9 & 7 & 11 \\
Vd & -11 & -6 & 7 & 7 \\
Group B CL & -5 & -8 & 14 & 13 \\
$\omega_{\mathrm{CL}}$ & -25 & 10 & 28 & 24 \\
$\omega_{\mathrm{Vd}}$ & -7 & -2 & 26 & 21 \\
$\sigma$ & 97 & -45 & 102 & \\
\hline
\end{tabular}

Abbreviations: $\mathrm{CL}=$ Clearance. $\mathrm{Vd}=$ Volume of Distribution. ${ }_{(1)}{ }_{\mathrm{C} L}$, represents interindividual variability of $\mathrm{CL} . \leftrightarrow_{\mathrm{Vd}}$ represents interindividual variability of $\mathrm{Vd} . \sigma$ represents intraindividual variability.

Both Design 3 and Design 6 consist of 2 samples per individual taken from three sampling windows - see Table 1.

Design 3: FO method used. interindividual variability $=60 \%$, intraindividual variability $=25 \%$.

Design 6: FOCE method used. interindividual variability $=60 \%$. intraindividual variability $=25 \%$. 
Figures 1a - b: Percent Runs in which Group B was Successfully Identified

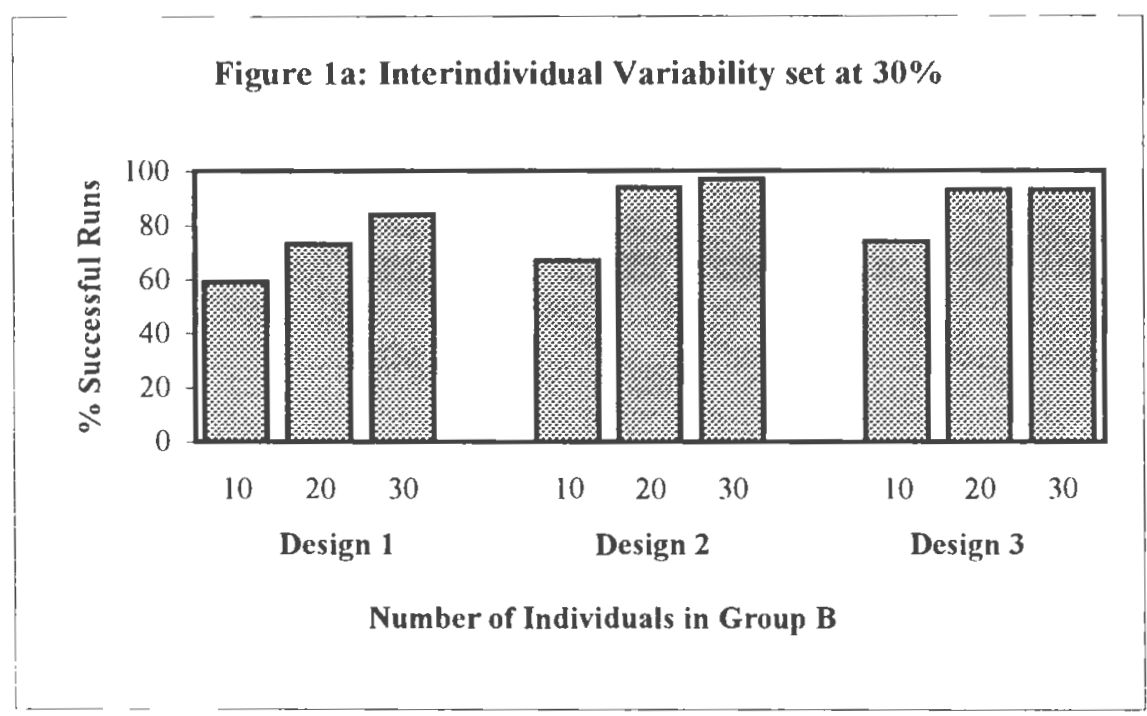

Figure 1b: Interindividual Variability set at $60 \%$

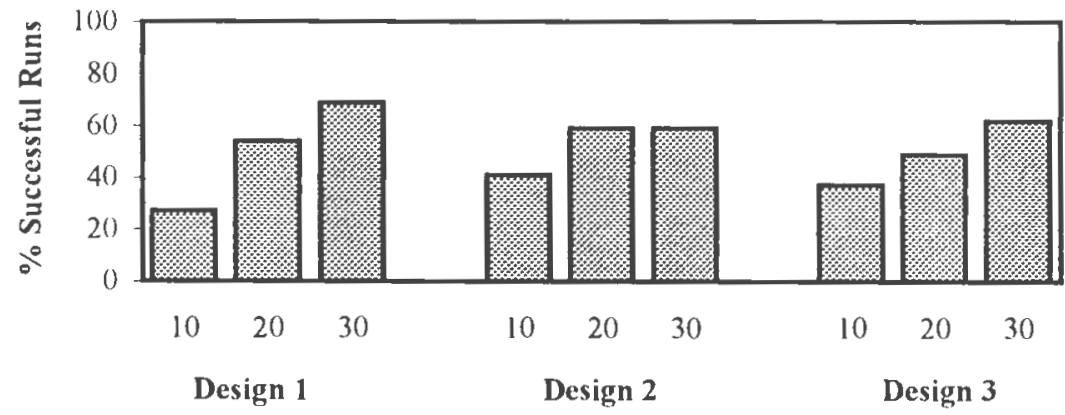

Number of Individuals in Group B

Note:

Design 1: 1 sample taken between 0.08 and 1 hour, and 1 taken between 7 and 8 hours Design 2: 1 sample taken between 0.08 and 1 hour, and I taken between 8 and 24 hours Design 3: 2 samples taken from 2 of 3 sampling windows: 0.08 to 1 hour, 1 to 8 hours and 8 to 24 hours 
Figures 2a - c: Percent Bias in Pharmacokinetic Parameter Estimates when Interindividual Variability is Set at $30 \%$.
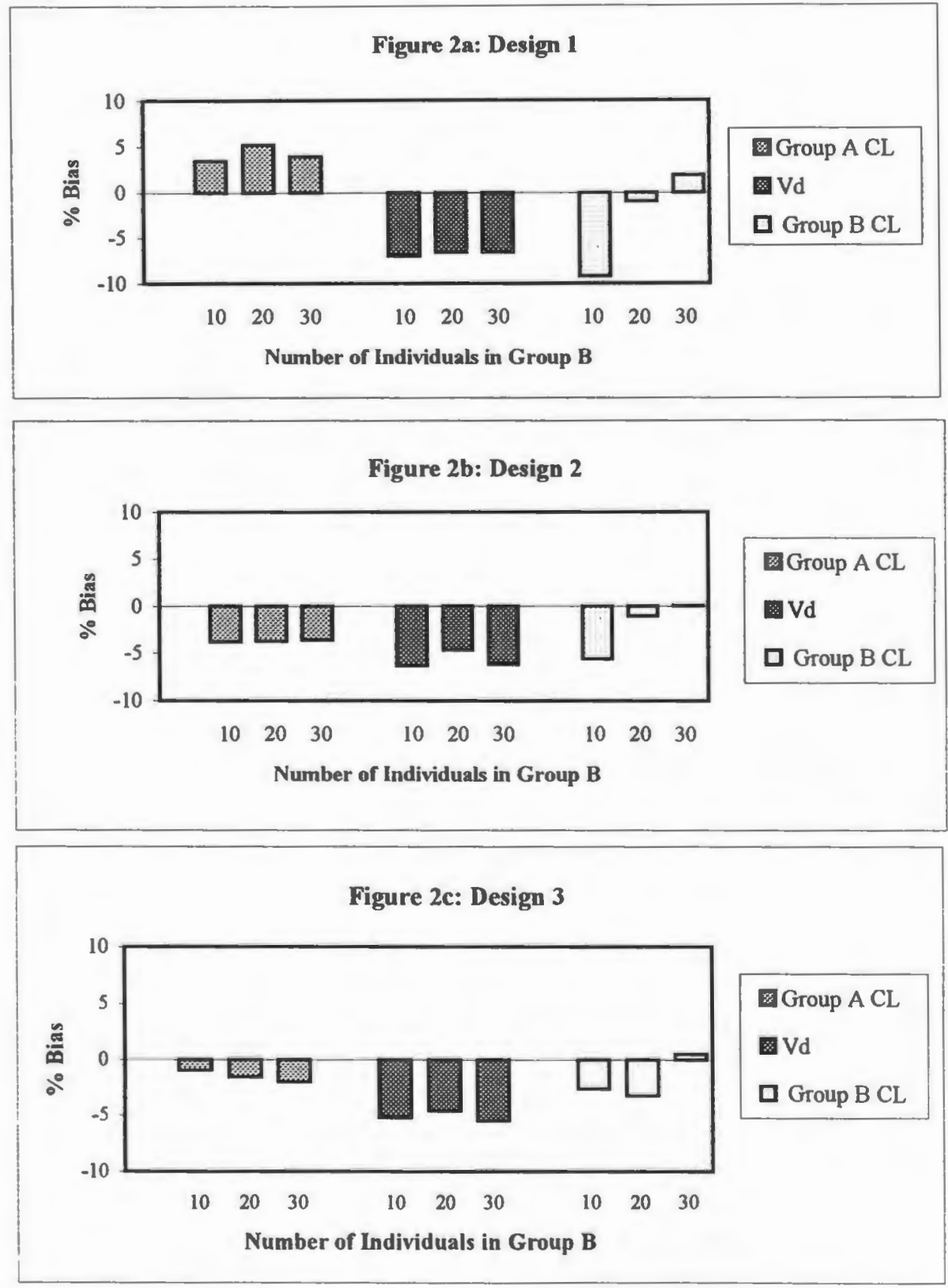

Note:

Design 1: 1 sample taken between 0.08 and 1 hour, and 1 taken between 7 and 8 hours Design 2: 1 sample taken between 0.08 and 1 hour, and 1 taken between 8 and 24 hours Design 3: 2 samples taken from 2 of 3 sampling windows: 0.08 to 1 hour, 1 to 8 hours and 8 to 24 hours 
Figures 3a - c: Percent Precision in Pharmacokinetic Parameter Estimates when Interindividual Variability is Set at $30 \%$.
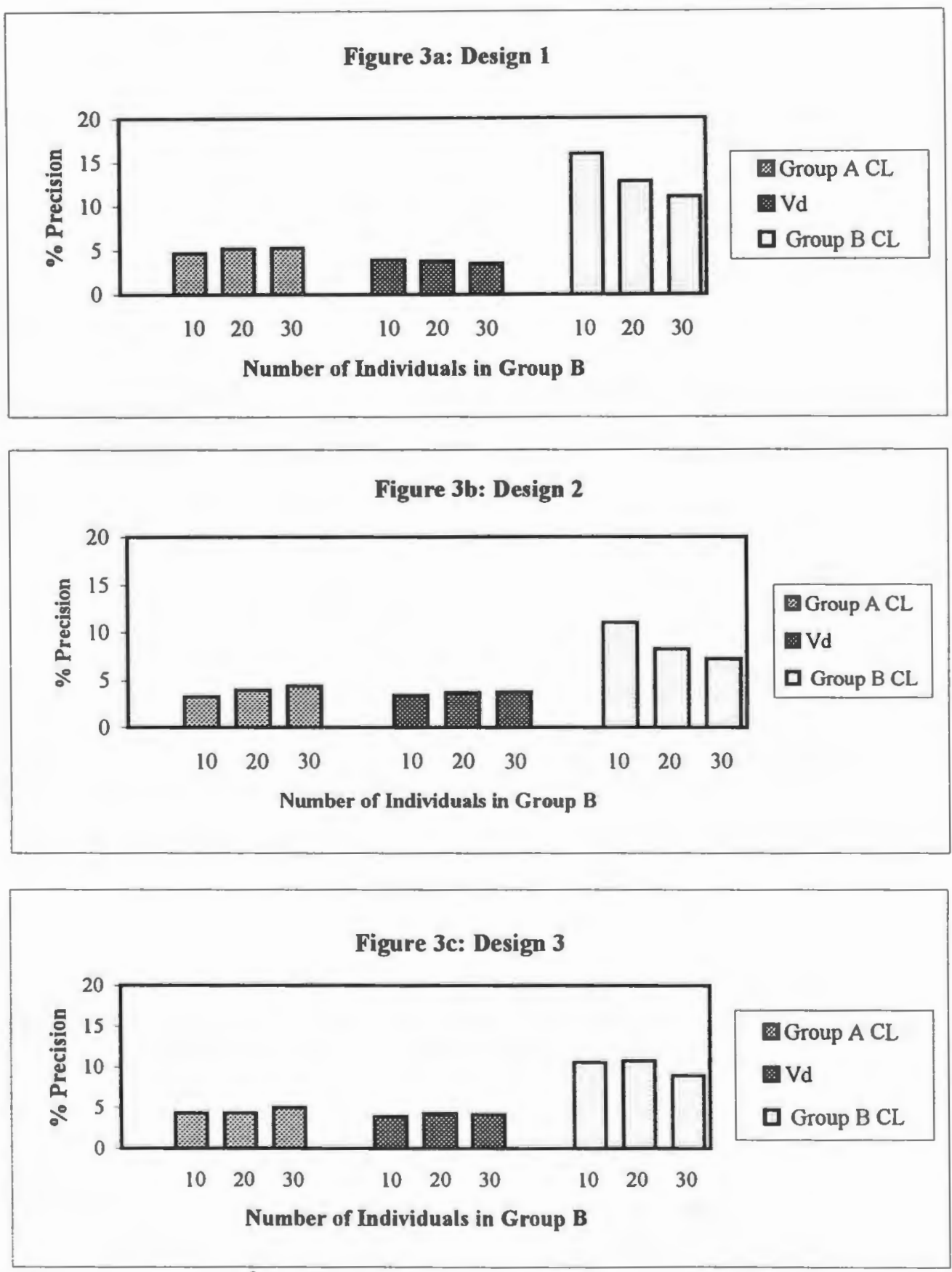

Note:

Design 1: 1 sample taken between 0.08 and 1 hour, and 1 taken between 7 and 8 hours Design 2: 1 sample taken between 0.08 and 1 hour, and 1 taken between 8 and 24 hours Design 3: 2 samples taken from 2 of 3 sampling windows: 0.08 to 1 hour, 1 to 8 hours and 8 to 24 hours 
Figures 4a - c: Percent Bias in Pharmacokinetic Parameter Estimates when Interindividual Variability is Set at $60 \%$.
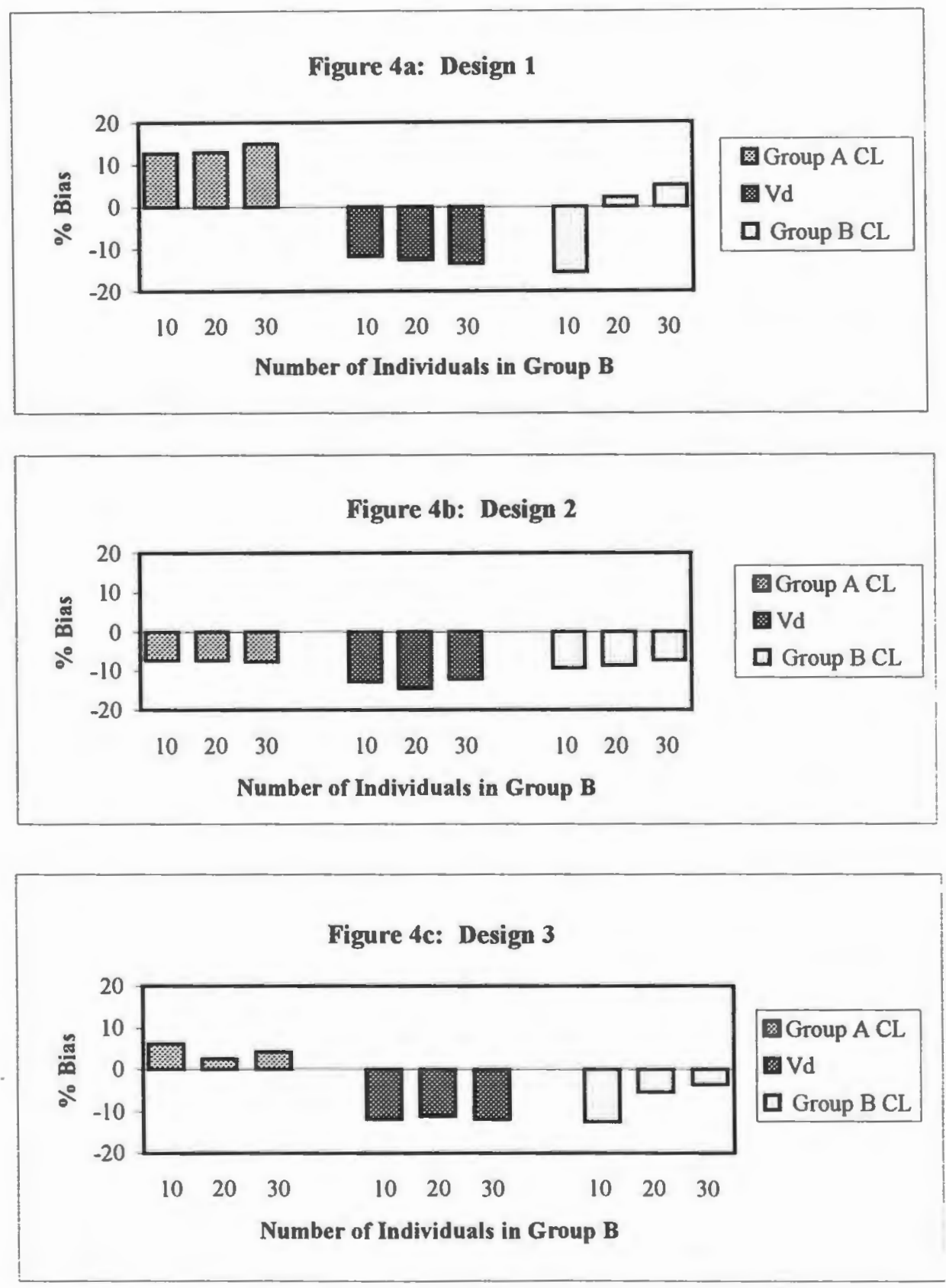

Note:

Design 1: 1 sample taken between 0.08 and 1 hour, and 1 taken between 7 and 8 hours Design 2: I sample taken between 0.08 and I hour, and 1 taken between 8 and 24 hours Design 3: 2 samples taken from 2 of 3 sampling windows: 0.08 to 1 hour, 1 to 8 hours and 8 to 24 hours 
Figures 5a - c: Percent Precision in Pharmacokinetic Parameter Estimates when Interindividual Variability is Set at $60 \%$.
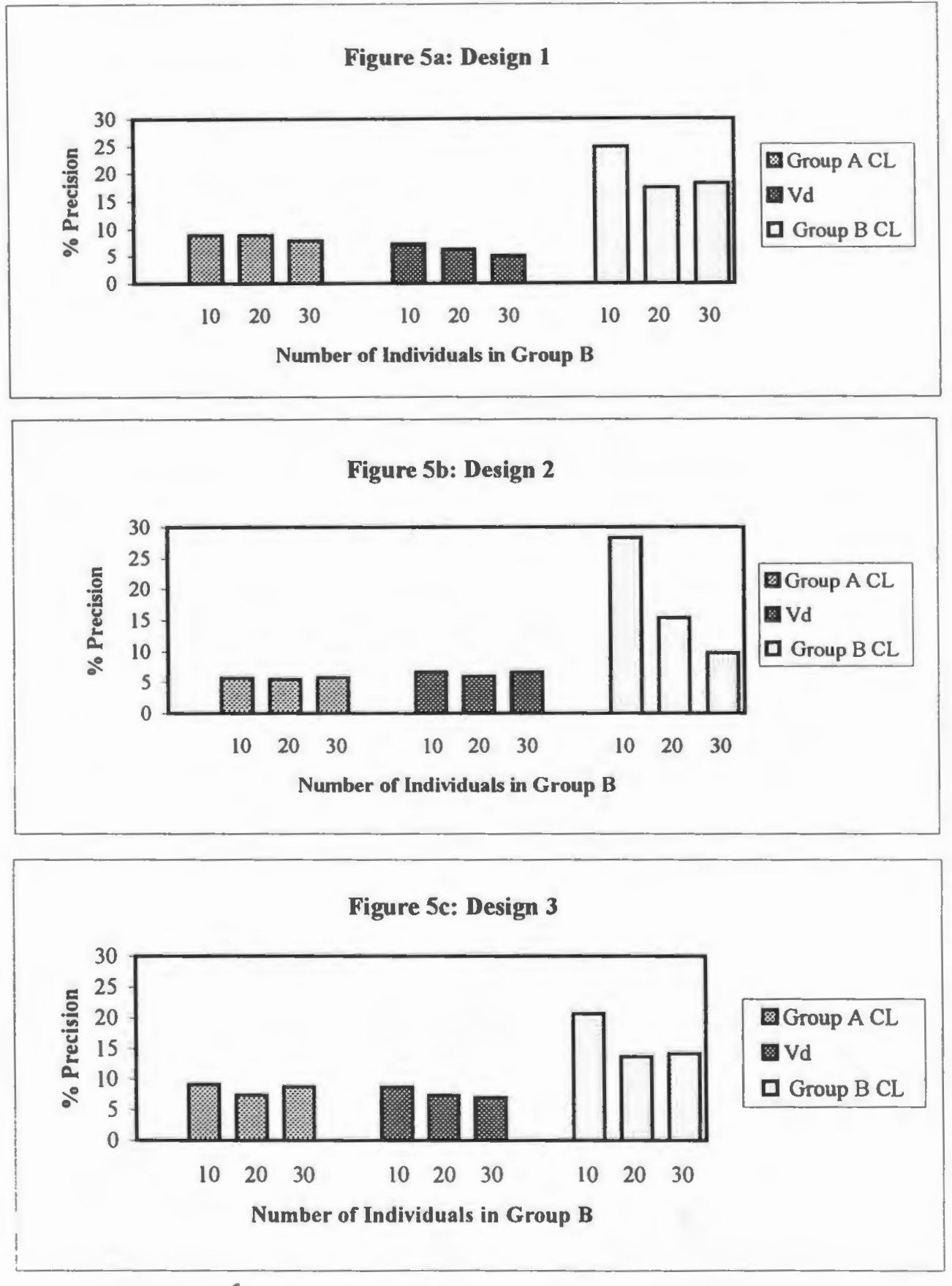

Note:

Design 1: 1 sample taken between 0.08 and 1 hour, and 1 taken between 7 and 8 hours Design 2: 1 sample taken between 0.08 and 1 hour, and 1 taken between 8 and 24 hours Design 3: 2 samples taken from 2 of 3 sampling windows: 0.08 to 1 hour, 1 to 8 hours and 8 to 24 hours 
Figures 6a - c: Percent Bias in Variability Parameter Estimates when Interindividual Variability is Set at $30 \%$.
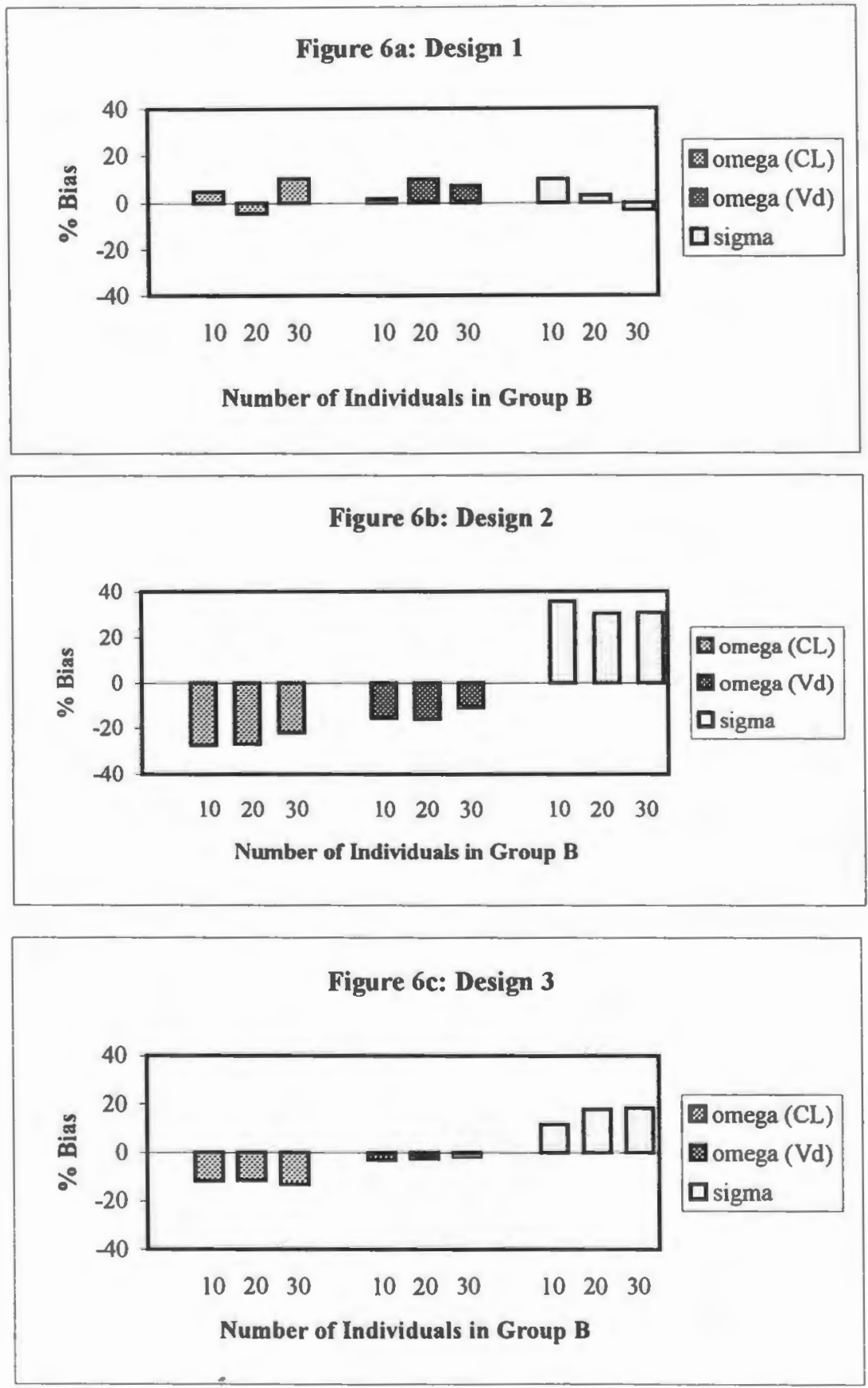

Note:

Design 1: 1 sample taken between 0.08 and 1 hour, and 1 taken between 7 and 8 hours Design 2: 1 sample taken between 0.08 and 1 hour, and 1 taken between 8 and 24 hours Design 3: 2 samples taken from 2 of 3 sampling windows: 0.08 to 1 hour, 1 to 8 hours and 8 to 24 hours 
Figures 7a - c: Percent Precision in Variability Parameter Estimates when Interindividual Variability is Set at $30 \%$.

Figure 7a: Design 1

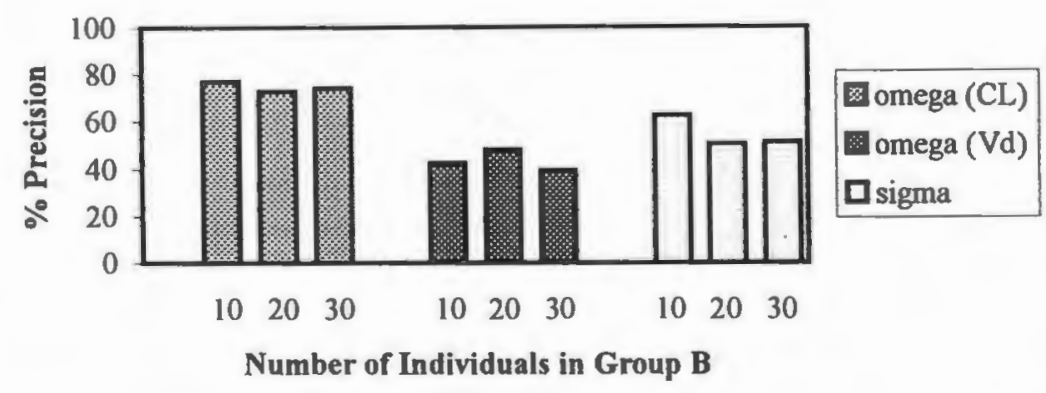

Figure7b: Design 2

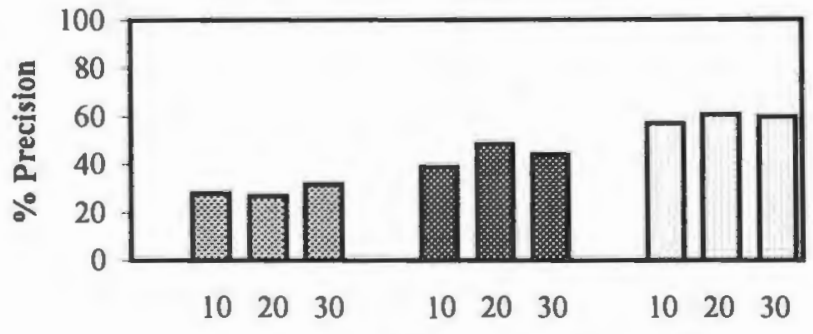

Number of Individuals in Group B

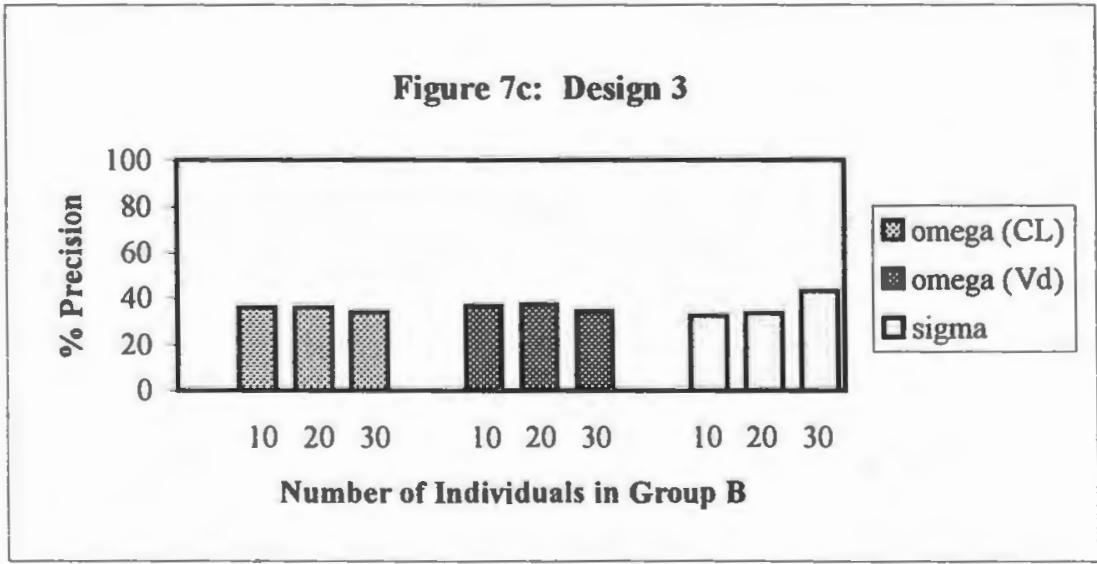

Note:

Design 1: 1 sample taken between 0.08 and 1 hour, and 1 taken between 7 and 8 hours Design 2: 1 sample taken between 0.08 and 1 hour, and 1 taken between 8 and 24 hours Design 3: 2 samples taken from 2 of 3 sampling windows: 0.08 to 1 hour, 1 to 8 hours and 8 to 24 hours 
Figures 8a - c: Percent Bias in Variability Parameter Estimates when Interindividual Variability is Set at $60 \%$.
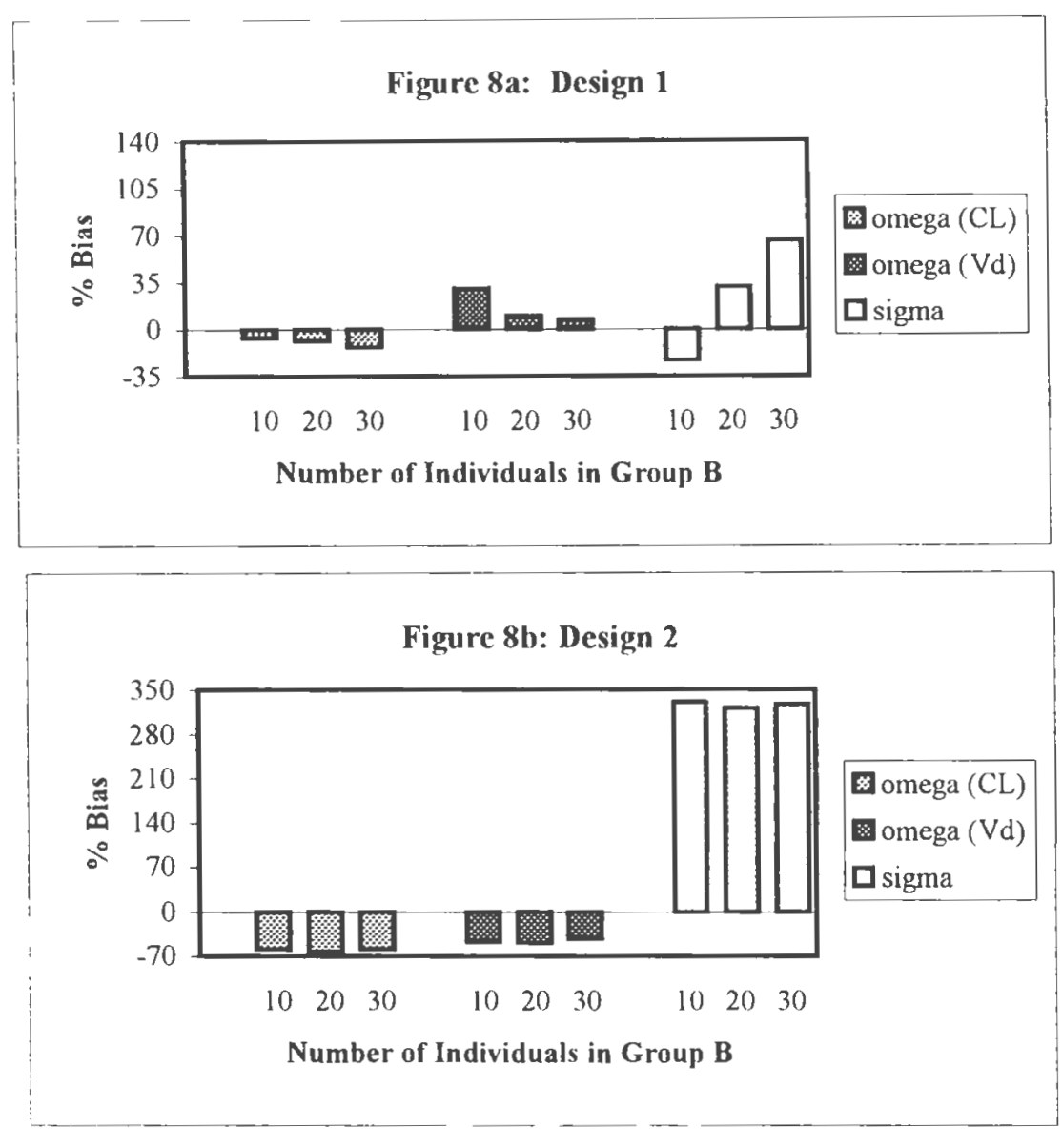

Figure 8c: Design 3

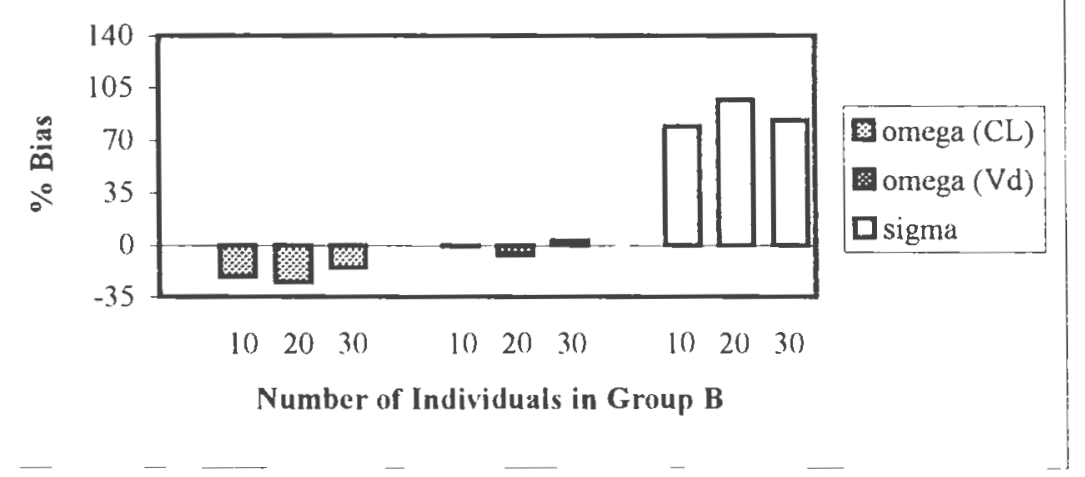

Note:

1)esign 1: 1 sample taken between 0.18 and 1 hour, and 1 taken between 7 and 8 hours Design 2: I sample taken between 0.08 and 1 hour, and 1 taken between 8 and 24 hours Design 3: 2 samples taken from 2 of 3 sampling windows 0.08 to I hour. 1 to 8 hours and 8 to 24 hours 
Figures 9a - c: Percent Precision in Variability Parameter Estimates when Interindividual Variability is Set at $60 \%$.
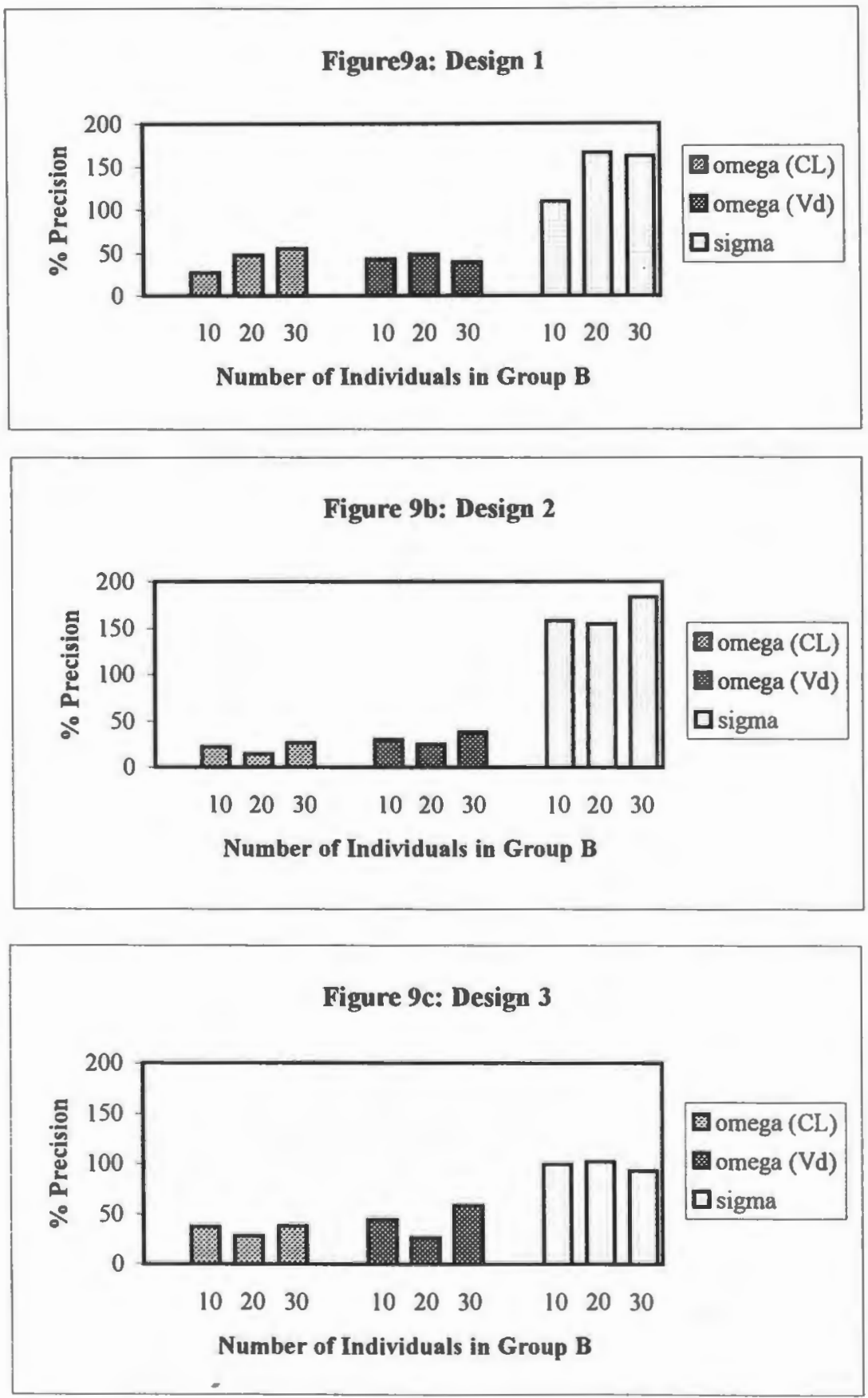

Note:

Design 1: 1 sample taken between 0.08 and 1 hour, and 1 taken between 7 and 8 hours Design 2: 1 sample taken between 0.08 and 1 hour, and 1 taken between 8 and 24 hours Design 3: 2 samples taken from 2 of 3 sampling windows: 0.08 to 1 hour, 1 to 8 hours and 8 to 24 hours 
Figures10a - b: Percent Bias and Precision in Parameter Estimates comparing Design 3 to Design 4.
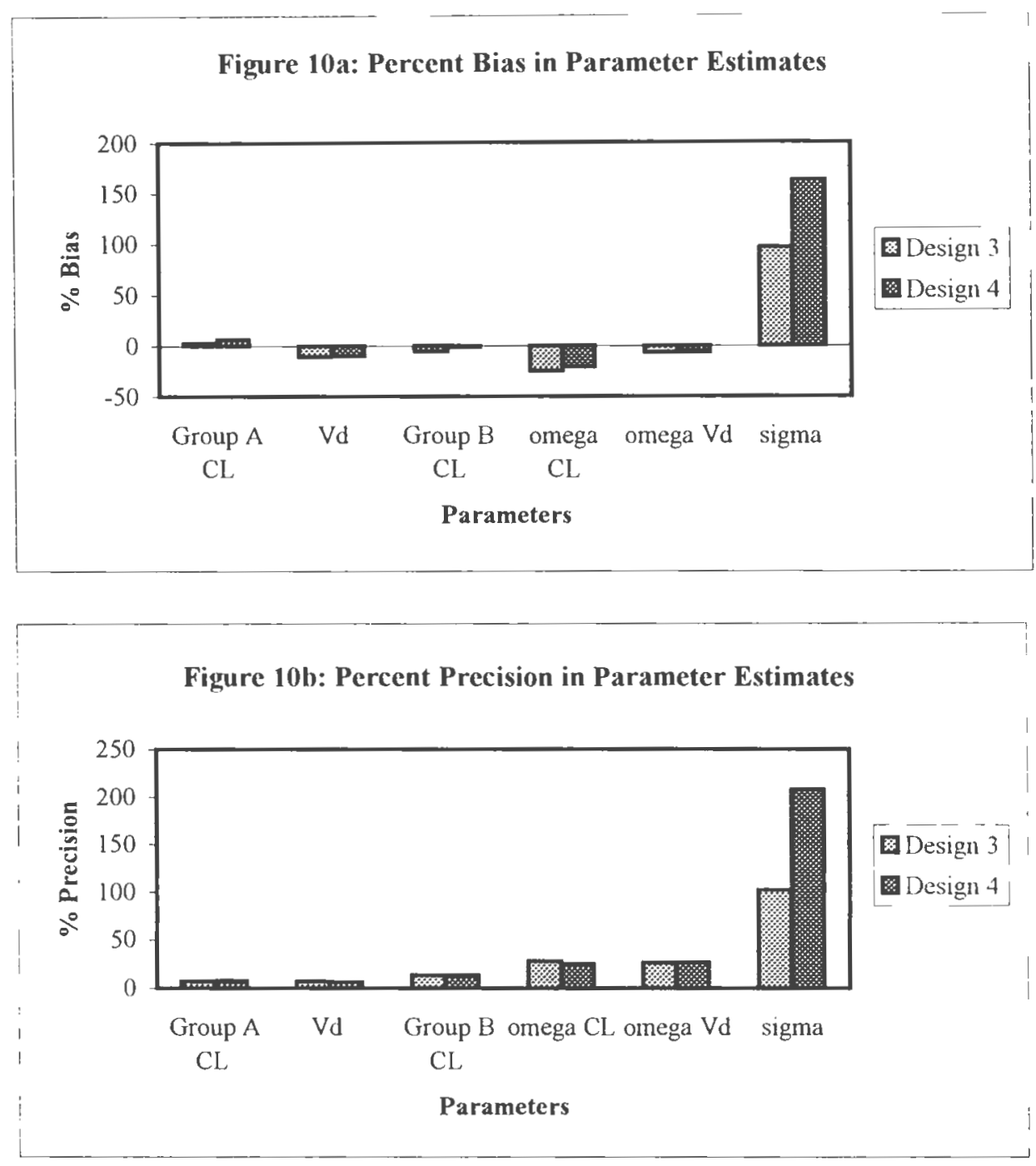

Note:

Design 3: Intraindividual variability is set at $25 \%$

Design 4: Intraindividual variability is set at $15 \%$ Interindividual variability set at $60 \%$ in both designs.

Design 3 and 4 each consist of 2 samples per individual taken from 2 of 3 sampling windows: 0.08 to 1 hour, 1 to 8 hours and 8 to 24 hours 
Figures11a - b: Percent Bias and Precision in Parameter Estimates comparing Design 3 to Design 5.
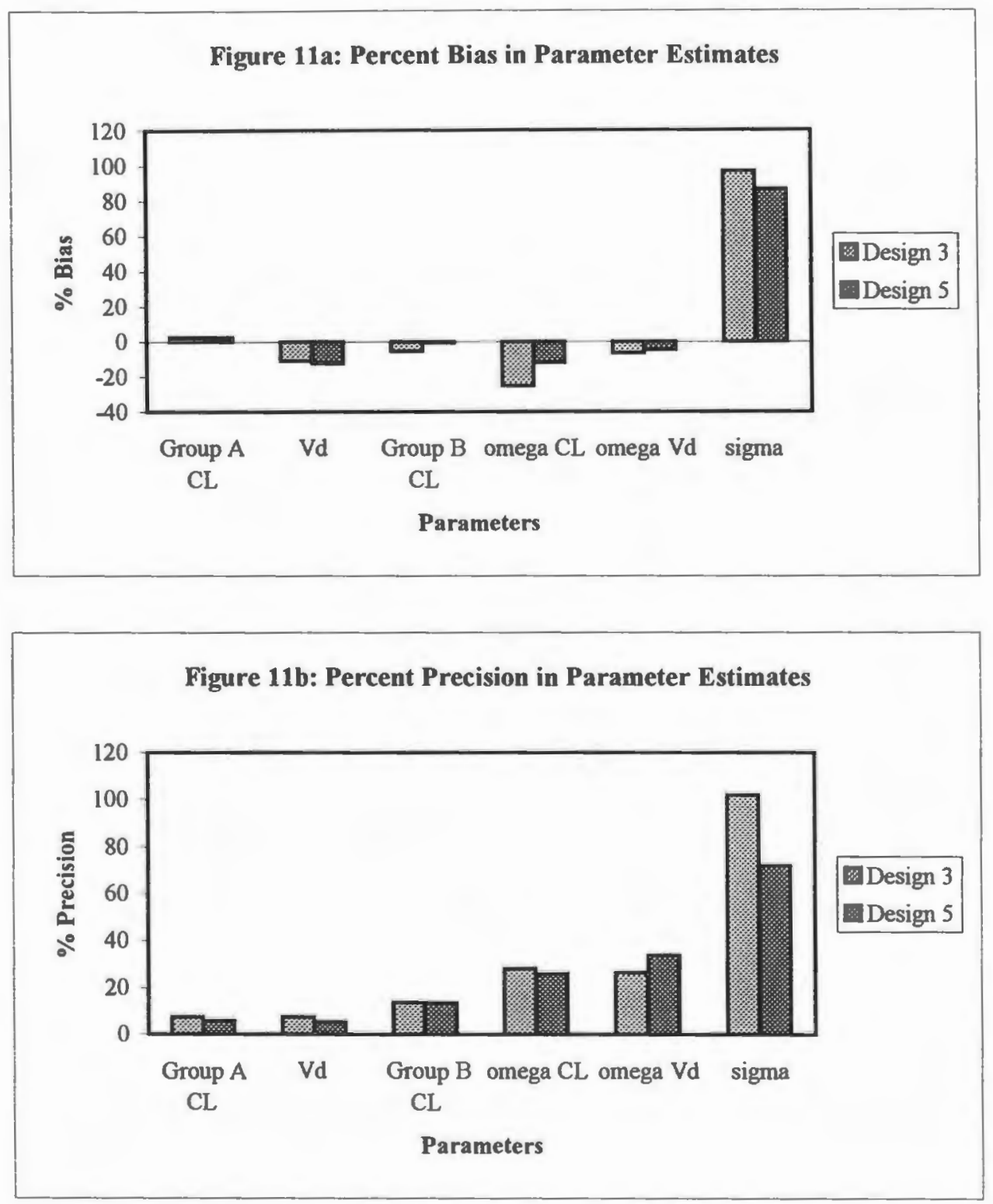

Note:

Interindividual variability set at $60 \%$ and intraindividual variability set at $25 \%$.

Design 3: Total number of Individuals $=100$.

Design 5: Total Number of Individuals $=200$.

Design 3 and 4 each consist of 2 samples per individual taken from 2 of 3 sampling windows:

0.08 to 1 hour, 1 to 8 hours and 8 to 24 hours 
Figures12a - b: Percent Bias and Precision in Parameter Estimates comparing Design 3 to Design 5.
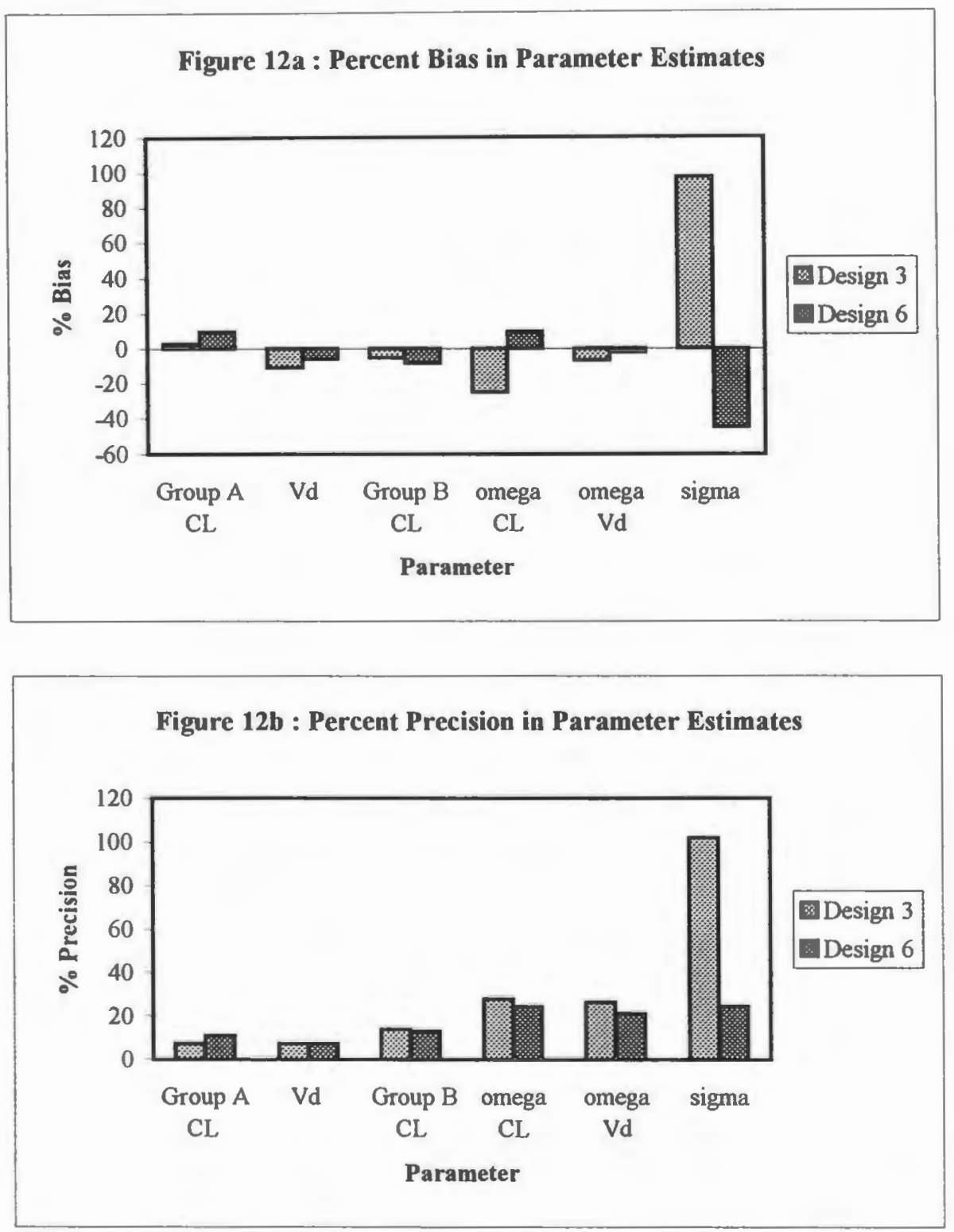

Note:

Interindividual variability set at $60 \%$ and intraindividual variability set at $25 \%$. Design 3: FO method in NONMEM used to analyze the data.

Design 6: FOCE method in NONMEM used to analyze the data.

Design 3 and 4 each cunsist of 2 samples per individual taken from 2 of 3 sampling windows: 0.08 to 1 hour, 1 to 8 hours and 8 to 24 hours 


\section{SUMMARY OF CONCLUSIONS}

The population approach to pharmacokinetic analysis is a relatively new approach that has gained acceptance as a tool to aid in the drug development process. This is illustrated by the number of articles on the subject that have been published recently, both reviewing and applying the methodology, and the publication by the Federal Drug Administration (FDA) of a document in February 1999 providing guidance to the pharmaceutical industry on the conduct, design and analysis of these studies.

A major advantage of the population approach is the ability to apply the methodology in situations when only sparse data per individual is available. By doing so, large, heterogeneous populations can be studied to obtain estimates of the variability of the pharmacokinetics of the drug in a population more representative of the true population to be treated. Additionally, the effects of patient covariates, such as body weight and gender, can be evaluated for an influence on the pharmacokinetic parameters and the variability of the drug. If applicable, decisions to modify the dose in specific subpopulations can then be taken based on this knowledge.

The pharmacokinetic parameters of the protease inhibitor, nelfinavir were determined using sparse data obtained from patients enrolled in a phase III clinical study and the effects of patient covariates on the pharmacokinetic parameters were investigated. The data was such that the majority of patients in the study had blood samples taken on two study visits for analysis of nelfinavir concentrations. Two samples were taken on each 
occasion in accordance with a study protocol at two hours post-dose and immediately pre-dose.

The results showed first, that clearance was estimated accurately and the estimate obtained was in agreement with the estimates from previously conducted traditional studies. However, problems were encountered in estimating the other structural model parameters, volume of distribution and the absorption rate constant in addition to their variability. This was likely to be a consequence of the study design. Information early in the dosing interval, the period that contains information on volume of distribution and the absorption rate constant, was insufficient. There was only one early sample per dosing interval for each patient and there was very little variability in the timing of these samples, most were around 2 hours post dose. In contrast, there was good spread of the data at later time points allowing accurate estimation of clearance. Optimal sampling times were used in this study to obtain information on the pharmacokinetics of nelfinavir. It has previously been shown that there are pitfalls to the use of optimal sampling times e.g. if there is model misspecification or high interindividual variability which resulted in sub-optimal times for some patients. Random sampling has been advocated by many investigators to protect against this happening. The randomness of the later time points allowed clearance to be accurately estimated.

In an attempt to assess the impact of poor estimation of volume of distribution and the absorption rate constant on the estimation of clearance, these parameters were fixed to values obtained from analysis of more extensive data. When the data was re-analyzed 
using this model, the estimates obtained for clearance and its variability were similar to the previous estimates obtained when volume of distribution and the absorption rate constant were not fixed. Thus the inability to determine volume of distribution and the absorption rate constant did not affect the ability to estimate clearance.

Due to the difficulties in estimating volume of distribution, the effects of various patient covariates were only evaluated on clearance. Concomitant use of the azole antifungal, fluconazole was the only covariate found to significantly effect clearance. It resulted in a reduction in clearance of nelfinavir of approximately $30 \%$. Concomitant use of rifabutin had previously been shown to affect clearance but it was not significant in this analysis. This was probably due to lack of power to detect the effect rather than a lack of effect altogether as only 5 of 174 patients were taking this concomitant drug.

Analysis of this real data set highlighted the fact that a well designed study is essential if accurate pharmacokinetic parameters are to be obtained and the effects of covariates are to be identified when the population approach is applied to sparse data. Simulation studies can be effectively used to investigate various design issues prior to conducting the study. Thus, a study using simulated data was conducted to evaluate different study designs on the ability to accurately determine parameter estimates. Additionally, the effect of different sizes of a sub-population, in which clearance is reduced by $30 \%$, was evaluated on the ability to detect that sub-population. 
The study evaluated 3 different study designs each comprising 2 samples per individual in 100 individuals. Individuals were sampled from 2 groups, Group A in which individuals had a 'normal' value of clearance and Group B in which individuals had a $30 \%$ reduced value of clearance. The one-compartment model with intravenous input was used and two levels of interindividual variability were investigated, a low level of $30 \%$ and a high level of $60 \%$. Intraindividual variability was fixed at $25 \%$

The ability to detect the sub-population with reduced clearance was better when interindividual variability was low. When Group B consisted of 20 individuals this subpopulation could be consistently identified with the designs that included sampling times 1 to 3 half-lives after the dose was administered. At the high level of interindividual variability, none of the designs investigated were consistently able to identify the subpopulation even when that population consisted of 30 individuals. Increasing the total number of subjects aided in identifying the sub-population when interindividual variability was high.

Both pharmacokinetic parameters and variability parameters were more difficult to estimate when interindividual variability was high. Pharmacokinetic parameters were accurately estimated when interindividual variability was $30 \%$. The designs with the later sampling times were also able to estimate the pharmacokinetic parameters accurately when interindividual variability was $60 \%$. 
One of the designs investigated performed better than the other designs. It consisted of 3 sampling windows that covered a period of approximately 3 half-lives. When interindividual variability was low, most of the variability parameters could be estimated accurately using this design whereas the other 2 designs performed badly even at this level. None of the designs tested were able to produce acceptable estimates of variability parameters at the high level of variability. Problems were encountered in estimating the variability parameters using all of the designs due to the inability to differentiate interindividual variability from intraindividual variability.

Various other design factors were altered to see if accurate variability parameter estimates could be obtained. Although increasing the size of the total study population or using the FOCE algorithm in NONMEM resulted in improvements in parameter estimates, none of the designs provided unbiased and precise estimates of all of the variability parameters.

A well designed 2 sample per individual study produced accurate parameter estimates and identified a sub-population with a $30 \%$ reduction in clearance when interindividual variability was low $(30 \%)$. However, when interindividual variability was high $(60 \%)$, this design had problems identifying the sub-population and estimating some of the variability parameters of the model. 
SECTION III 


\begin{abstract}
APPENDIX A
The following tables and figures provide additional data on the modeling process that was employed in Manuscript II.
\end{abstract}

Two data sets were used in the population analysis of nelfinavir detailed in Manuscript II of this dissertation. To di ferentiate between the two data sets, the original data will be referred to as the populat on data and the data used to obtain estimates of $\mathrm{Vd} / \mathrm{F}$ and $\mathrm{ka}$ will be referred to as the raditional data. During analysis of the population data set, difficulty was encountered in estimating volume of distribution $(\mathrm{Vd} / \mathrm{F})$ and the absorption rate constant $(\mathrm{ka})$. To assess the impact of fixing these two parameters to known values on the ability to estimate $\mathrm{CL} / \mathrm{F}$ and to assess the effect of covariates on this parameter, the analysis was repeated using fixed values for these two parameters obtained from analysis of data from a traditional study. Prior estimates of ka had not been reported in the literature hence the reaso 1 this data was obtained. Initially a decision had to be made on whether to combine the two data sets. The results of analyses using both data sets alone and the combination of the two are shown in table 1 . Addition of a lag time to the one compartment model did not provide a better fit to either the population or the traditional data alone whereas a mociel incorporating a lag time did provide a better fit to the data when the two data sets were combined. There was no apparent reason as to why this was the case. The estimates $\mathrm{O}^{\circ} \mathrm{CL} / \mathrm{F}$ were similar irrespective of the model used to fit to the data or the data set used. The similarity of the estimates of CL/F, the lack of need for a lag time parameter when the data sets were analyzed separately and the lack of covariate 
information contained in the traditional data resulted in the population data set alone being used for further analyses. The traditional data set was used solely to provide estimates of $\mathrm{Vd} / \mathrm{F}$ and $\mathrm{ka}$ to be used as fixed values for further analyses of the population data only. These values were $229 \mathrm{~L}$ and $0.845 \mathrm{~h}^{-1}$ for $\mathrm{Vd} / \mathrm{F}$ and $\mathrm{ka}$, respectively.

Table 1: Parameter Estimates of the Basic Models of the Different Data Sets.

\begin{tabular}{|c|c|c|c|c|c|}
\hline Model & $\begin{array}{c}\text { Description of Model and } \\
\text { Data }\end{array}$ & MOF & $\begin{array}{c}\text { Theta } 1 \\
\text { (CL) }\end{array}$ & $\begin{array}{c}\text { Theta } 2 \\
\text { (Vd) }\end{array}$ & $\begin{array}{c}\text { Theta } 3 \\
\text { (ka) }\end{array}$ \\
\hline 1 & $\begin{array}{l}\text { population data o'ly - no lag } \\
\text { time in model }\end{array}$ & 467.7 & 40.7 & 733 & 1.21 \\
\hline 2 & $\begin{array}{l}\text { population data only - lag time } \\
\text { in model }\end{array}$ & 466.96 & 41.1 & 743 & 1.53 \\
\hline 3 & $\begin{array}{l}\text { traditional data orty - no lag } \\
\text { time in model }\end{array}$ & -106.6 & 39.1 & 229 & 0.845 \\
\hline$t$ & $\begin{array}{l}\text { traditional data ouly - lag time } \\
\text { in model }\end{array}$ & -105.6 & 37.8 & 286 & 1.02 \\
\hline 5 & $\begin{array}{l}\text { traditional and population data } \\
\text { - no lag time in model }\end{array}$ & 504 & 39.9 & 627 & 0.953 \\
\hline 6 & $\begin{array}{l}\text { traditional and population data } \\
\text { - no lag time in model, where } \\
\text { V/F constrained to be low }\end{array}$ & $\begin{array}{l}\text { Would not } \\
\text { converge }\end{array}$ & & & \\
\hline 7 & $\begin{array}{l}\text { traditional and population data } \\
\text { - lag time in nodil }\end{array}$ & 494.4 & 40.2 & 631 & 1.51 \\
\hline
\end{tabular}

Abbreviations: $\mathrm{MOF}=$ minim $\mathrm{m}$ value of the objective function, $\mathrm{CL} / \mathrm{F}-$ clearance. $\mathrm{Vd} / \mathrm{F}-$ volume of distribution. ka - absorption ri te constant 
Table 2: Basic Model Parameter Estimates using Four Different Models

\begin{tabular}{|c|c|c|c|c|}
\hline Model Criteria & $(\mathrm{L} / \mathrm{F}(\mathrm{L} / \mathrm{hr})$ & $\overline{V d} / \mathbf{F}(L)$ & $\mathbf{k a}\left(h^{-1}\right)$ & $\begin{array}{l}\text { Eta } 1 \text { (Estimate of } \\
\text { variability in CL) }\end{array}$ \\
\hline All parameters estimated & 40.7 & 733 & 1.21 & 0.13 \\
\hline $\mathrm{Vd} / \mathrm{F}$ fixed to $229 \mathrm{~L}$ & 38.5 & 229 & 0.155 & 0.129 \\
\hline ka fixed to $0.845 \mathrm{~h}^{-1}$ & 40.2 & 660 & 0.845 & 0.127 \\
\hline $\mathrm{Vd} / \mathrm{F}$ fixed to $229 \mathrm{~L}$ and & 39.4 & 229 & 0.845 & 0.152 \\
\hline ka fixed to $0.845 \mathrm{~h}^{-1}$ & & & & \\
\hline
\end{tabular}

Abbreviations: $\mathrm{CL} / \mathrm{F}=$ clearar ce. $\mathrm{Vd} / \mathrm{F}=$ volume of distribution. $\mathrm{ka}=$ absorption rate constant .

Initially, four different m sdels were fitted to the population data set and the basic models were evaluated (Table 2). Three of the models used a fixed estimate for $\mathrm{Vd} / \mathrm{F}$, ka or both parameters. The parameter(s) were fixed to the estimates obtained from analysis of the traditional data as mentioned previously. These results showed that estimates of CL/F were similar irrespective of the model used. Only two of these models were used in the full analysis of the population data in Manuscript II. These were Model 1 (all parameters are estimated) and Model $2\left(\mathrm{Vd} / \mathrm{F}\right.$ fixed to $229 \mathrm{~L}$ and ka fixed to $\left.0.845 \mathrm{~h}^{-1}\right)$. 
Table 3: Results of Covariates that were found to be Statistically Significant in Clearance using Four Different Models ${ }^{\mathrm{a}}$.

\begin{tabular}{|ccccc|}
\hline Model Criteria & Cd4 & Mac & Rif & Flu \\
\cline { 4 - 5 } All parameters estimated & 0.81 & 0.76 & 1.55 & 0.74 \\
Vd/F fixed to 229 L & 0.81 & 0.75 & 1.53 & 0.74 \\
ka fixed to 0.845 $\mathrm{h}^{-1}$ & 0.81 & 0.76 & 1.53 & 0.74 \\
Vd/F fixed to 229 $\mathrm{L}_{\text {and }}$ & 0.83 & 0.77 & $1.37^{\mathrm{b}}$ & 0.73 \\
ka fixed to 0.845 $\mathrm{h}^{-1}$ & & & & \\
\end{tabular}

Abbreviations: cd4 - CD4 count less than 100 cells per $\mu \mathrm{l}$, mac $=$ concomitant therapy with a macrolide antibiotic, rif $=$ concomitant tlierapy with rifabutin. flu $=$ concomitant therapy with fluconazole. $\mathrm{Vd} / \mathrm{F}=$ volume of distribution, $\mathrm{ka}=$ alsorption rate constant. $\mathrm{NS}=$ not statistically significant.

${ }^{a}$ This table lists the proportionality constants that clearance $(\mathrm{CL} / \mathrm{F})$ is multiplied by when patients in the study possessed the characteri itic of interest e.g. $\mathrm{CL} / \mathrm{F}=\mathrm{CL} / \mathrm{F} * 0.812$ for patients with a $\mathrm{CD} 4$ count less than 100 cells per $\mu$ l using the model in which all parameters were estimated i.e. patients with a low CD4 count have a typical value of clearance that is $81 \%$ of the typical value of CL/F for patients who do not have a low CD4 count.

${ }^{\mathrm{b}}$ When the model in which both ka and Vd were fixed was used, the effect of rifabutin on CL/F was not significant although the direction and inagnitude of the effect were similar to the estimates obtained using the other models. 
Table 4: Results of Covariates tested for an Effect on Clearance using Model 1 and Model 2 (FO Method).

\begin{tabular}{|c|c|c|c|c|c|c|}
\hline \multirow[b]{2}{*}{ Covariate tested } & \multicolumn{3}{|c|}{ Model One } & \multicolumn{3}{|c|}{ Model Two } \\
\hline & $\triangle$ in $\mathrm{MOF}$ & $\begin{array}{l}\text { Effect on } \\
\text { CL/F }\end{array}$ & Significance & $\triangle$ in MOF & $\begin{array}{c}\text { Effect on } \\
\text { CL/F }\end{array}$ & Significance \\
\hline Wt & 0.24 & 0.11 & NS & 1.57 & 0.11 & NS \\
\hline Age & 0.003 & -0.01 & NS & 0.11 & -0.05 & NS \\
\hline Gender & 0.17 & 0.97 & NS & 0.14 & 1.03 & NS \\
\hline Race $=$ Caucasian & 2.02 & 0.89 & NS & 2.67 & 0.88 & NS \\
\hline Race = Black & 0.03 & 0.98 & NS & 0.50 & 1.08 & NS \\
\hline Race $=$ Asian & 0.55 & 1.15 & NS & 0.03 & 1.03 & NS \\
\hline Race $=$ Hispanic & 2.19 & 1.2 .3 & NS & 1.11 & 1.19 & NS \\
\hline Race $=$ Latin American & 1.43 & 1.28 & NS & 0.81 & 1.21 & NS \\
\hline Race $=$ Native American & 0.05 & 0.95 & NS & 0.52 & 1.21 & NS \\
\hline Dose $(500 \mathrm{mg}$ or $750 \mathrm{mg}$ tid) & 0.39 & 0.96 & NS & 5.77 & 1.29 & Borderline \\
\hline CD4 $<100$ cells per $\mu \mathrm{l}$ & 10.01 & 0.81 & Significant & 7.00 & 0.83 & Significant \\
\hline $\begin{array}{c}\text { CD4 }>100 \text { and }<300 \text { cells } \\
\text { per } \mu 1\end{array}$ & 1.76 & 1.08 & NS & 0.66 & 1.05 & $\begin{array}{l}\text { Not } \\
\text { Significant }\end{array}$ \\
\hline CD4 $>300$ cells per $\mu \mathrm{l}$ & 2.05 & 1.08 & NS & 2.37 & 1.1 & NS \\
\hline $\mathrm{RNA}>100,000 \mathrm{copies} / \mathrm{ml}$ & 5.28 & 0.88 & Borderline & 5.15 & 0.87 & Borderline \\
\hline $\begin{array}{l}\text { RNA }>50,000 \text { and }< \\
100,000 \text { copies } / \mathrm{ml}\end{array}$ & 0.25 & 1.0 .3 & NS & 0.06 & 1.02 & NS \\
\hline RNA $<50,000$ copies $/ \mathrm{ml}$ & 4.1 & 1.13 & Borderline & 4.84 & 1.15 & Borderline \\
\hline $\begin{array}{l}\text { Concoinitant therapy with } \\
\text { quinolone antibiotic. }\end{array}$ & () & 1 & NS & 0.04 & 0.98 & NS \\
\hline $\begin{array}{l}\text { Concomitant therapy with } \\
\text { macrolide antibiotic. }\end{array}$ & 10.78 & 0.76 & Significant & 10.13 & 0.77 & Significant \\
\hline $\begin{array}{c}\text { Concominitant therapy with } \\
\text { rifabutin. }\end{array}$ & 6.04 & 1.55 & Significant & 3.01 & 1.37 & NS \\
\hline $\begin{array}{l}\text { Concomitant therapy with } \\
\text { fluconazole. }\end{array}$ & 17.23 & $0.7 t$ & Significant & 18.53 & 0.73 & Significant \\
\hline History of liver disease & 0.002 & 1 & NS & 0.29 & 1.03 & NS \\
\hline Raised LFTs & 2.65 & 0.90 & NS & 2.29 & 0.91 & NS \\
\hline Metabolizing status & 1.66 & 8.79 & NS & 1.11 & 7.54 & NS \\
\hline Poor metabolizer & 0.08 & 0.98 & NS & 0.21 & 0.97 & NS \\
\hline Intermediate metabolizer & 0.77 & 0.95 & NS & 0.20 & 0.97 & NS \\
\hline Extensive metabolizer & 1.71 & 1.09 & NS & 1.18 & 1.08 & NS \\
\hline
\end{tabular}

a Effect on Clearance (CL/F): if the patient possesses the characteristic of column I then the typical value of CL/F should be multiplied by the constint in this column e.g. using model 1, a patient taking concomitant fluconazole has a significantly reduced clearance of $74 \%$ (typical value* 0.74 ).

A covariate was considered statisically significant if the $\triangle$ in the MOF when comparing the basic model to the full model was 3.8 or greater and the $15 \%$ confidence interval for the effect did not contain the null value (the null value was either 0 or 1 depending on th: covariate to be tested). A covariate was considered of borderline significance if the $\Delta$ in the MOF was 3.8 or greater : nd the $95 \%$ confidence interval for the effect contained the null value. If the $\triangle$ in the MOF was less than 3.8 then the covariate was considered to be not significant. 
Table 5: Results of Covariates tested for an Effect on Clearance using Model 1 and

Model 2 (FOCE Method).

\begin{tabular}{|c|c|c|c|c|c|c|}
\hline \multirow[b]{2}{*}{ Covariate tested } & \multicolumn{3}{|c|}{ Model One } & \multicolumn{3}{|c|}{ Model Two } \\
\hline & $\begin{array}{l}\triangle \text { in } \\
\text { MOF }\end{array}$ & $\begin{array}{c}\text { Effect on } \\
\text { CL/F }\end{array}$ & Significance & $\begin{array}{l}\triangle \text { in } \\
\text { MOF }\end{array}$ & $\begin{array}{c}\text { Effect on } \\
\text { CL/F }\end{array}$ & Significance \\
\hline Wt & $\overline{0} \overline{92}$ & 0.09 & NS & 1.14 & 0.11 & NS \\
\hline Age & 0.101 & -0.01 & NS & 0.32 & -0.09 & NS \\
\hline Gender & 008 & 0.97 & NS & 0.08 & 1.03 & NS \\
\hline Race $=$ Caucasian & 064 & 0.93 & NS & 1.66 & 0.89 & NS \\
\hline Race $=$ Black & 014 & 0.95 & NS & 0.60 & 1.1 & NS \\
\hline Race $=$ Asian & 017 & 1.09 & NS & -2.29 & 1 & NS \\
\hline Race $=$ Hispanic & 129 & 1.2 & NS & 0.31 & 1.1 & NS \\
\hline Race = Latin American & 112 & 1.3 & NS & -1.41 & 1.27 & NS \\
\hline Race $=$ Native American & 023 & 0.88 & NS & -2.12 & 1.17 & NS \\
\hline $\begin{array}{c}\text { Dose }(500 \mathrm{mg} \text { or } 750 \mathrm{mg} \\
\text { tid })\end{array}$ & 139 & 0.9 & NS & -3.20 & 1.1 & NS \\
\hline CD4 $<100$ cells per $\mu 1$ & 5.16 & 0.84 & Borderline & 0.57 & 0.86 & NS \\
\hline $\begin{array}{c}\text { CD4 }>100 \text { and }<300 \\
\text { cells per } \mu \mathrm{l}\end{array}$ & 020 & 1.03 & NS & -2.28 & 1.01 & NS \\
\hline CD4 $>300$ cells per $\mu \mathrm{l}$ & 197 & 1.09 & NS & -0.56 & 1.1 & NS \\
\hline RNA $>100,000$ copies/m! & 294 & 0.89 & NS & 0.54 & 0.88 & NS \\
\hline $\begin{array}{l}\text { RNA > 50,000 and < } \\
100,000 \text { copies } / \mathrm{ml}\end{array}$ & 047 & 0.95 & NS & 0.04 & 0.99 & NS \\
\hline RNA $<50,000$ copies $/ \mathrm{ml}$ & 5.99 & 1.18 & Borderline & 1.06 & 1.15 & NS \\
\hline $\begin{array}{l}\text { Concomitant therapy } \\
\text { with a quinolone } \\
\text { antibiotic. }\end{array}$ & 007 & 1.03 & NS & -2.17 & 1.05 & NS \\
\hline $\begin{array}{c}\text { Concomitant therapy } \\
\text { with a macrolide } \\
\text { antibiotic. }\end{array}$ & 4.66 & 0.80 & Borderline & 1.48 & 0.81 & NS \\
\hline $\begin{array}{l}\text { Concomitant therapy } \\
\text { with rifabutin. }\end{array}$ & 356 & 1.44 & NS & 1.54 & 1.31 & NS \\
\hline $\begin{array}{l}\text { Conconitant therapy } \\
\text { with fluconazole. }\end{array}$ & 13.112 & 0.74 & Significant & 12.0 & 0.70 & Significant \\
\hline History of liver disease & 011 & 1.02 & NS & 0.03 & 1.01 & NS \\
\hline Raised LFTs & 115 & 0.93 & NS & -1.20 & 0.92 & NS \\
\hline Metabolizing status & 021 & 3.74 & NS & -2.23 & -2.31 & NS \\
\hline Poor metabolizer & 005 & 1.01 & NS & 0.48 & 1.05 & NS \\
\hline Internediate metabolizer & 081 & 0.94 & NS & -1.48 & 0.94 & NS \\
\hline Extensive metabolizer & 061 & 1.06 & NS & -2.26 & 1.01 & NS \\
\hline
\end{tabular}

${ }^{a}$ Effect on clearance (CL/F): if th 2 patient possesses the characteristic of columun 1 then the tvpical value of CL/F should be multiplied by the constint in this column e.g. using model 1, a patient taking concomitant fluconazole has a significantly reduced clearance of $74 \%$ (typical value 0.74 ).

A covariate was considered signilicant if the $\lrcorner$ in the MOF when the full model was compared to the reduced model was 3.84 or greater and the $95 \%$ contidence interval for the effect did not contain the null value (the null value was either 0 or 1 depending on the col ariate to be tested). A covariate was considered of borderline significance if the $\triangle$ in the MOF was 3.8 or greater and the $15 \%$ confidence interval for the effect contained the null value. If the $\triangle$ in the MOF was less than 3.8 then the covaria e was considered to be not significant. 
Figure 1: Concentration versus Time for Patient who received a dose of 500mg three times a day.

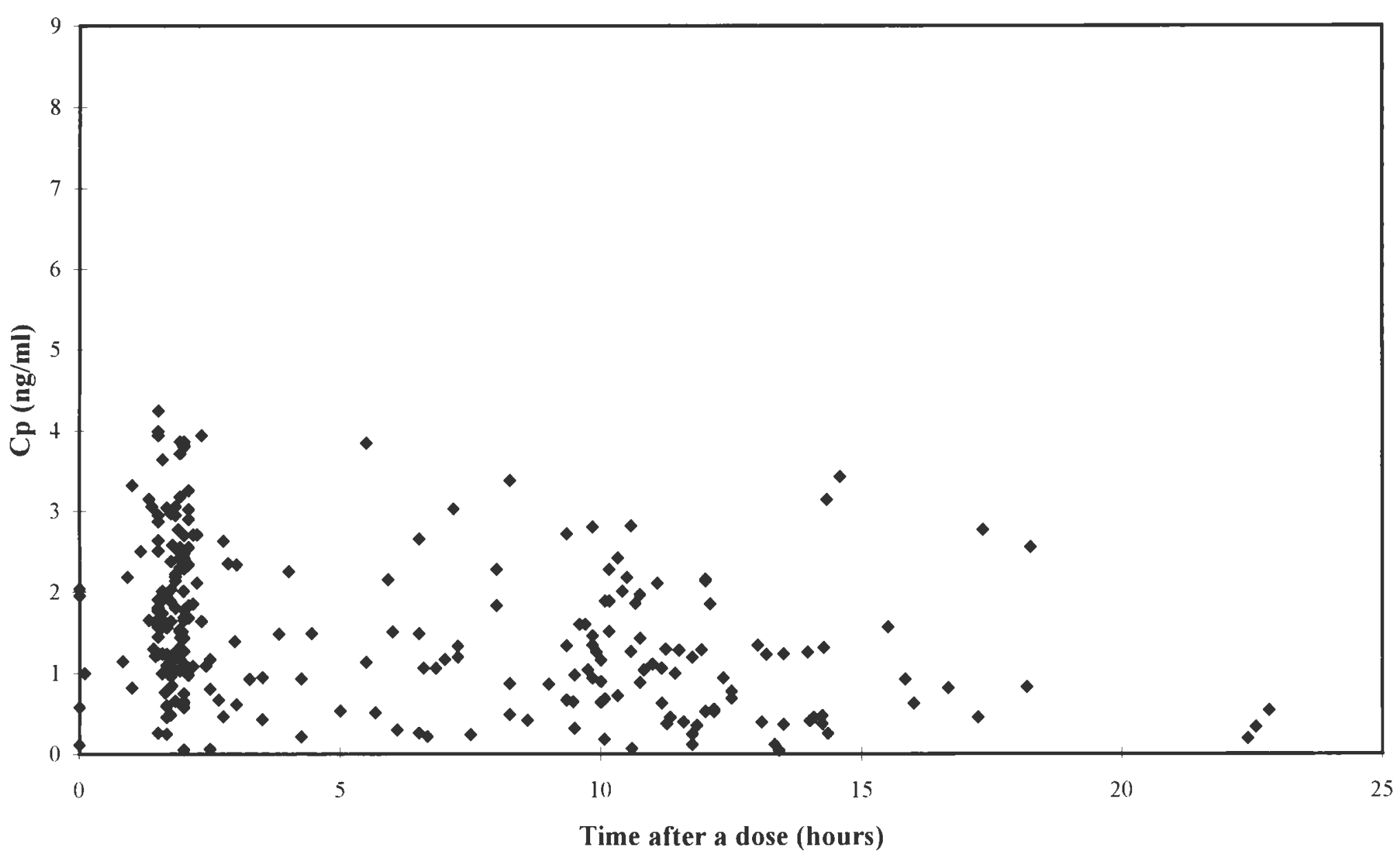


Figure 2: Concentration versus Time for Patient who received a dose of $750 \mathrm{mg}$ three times a day.

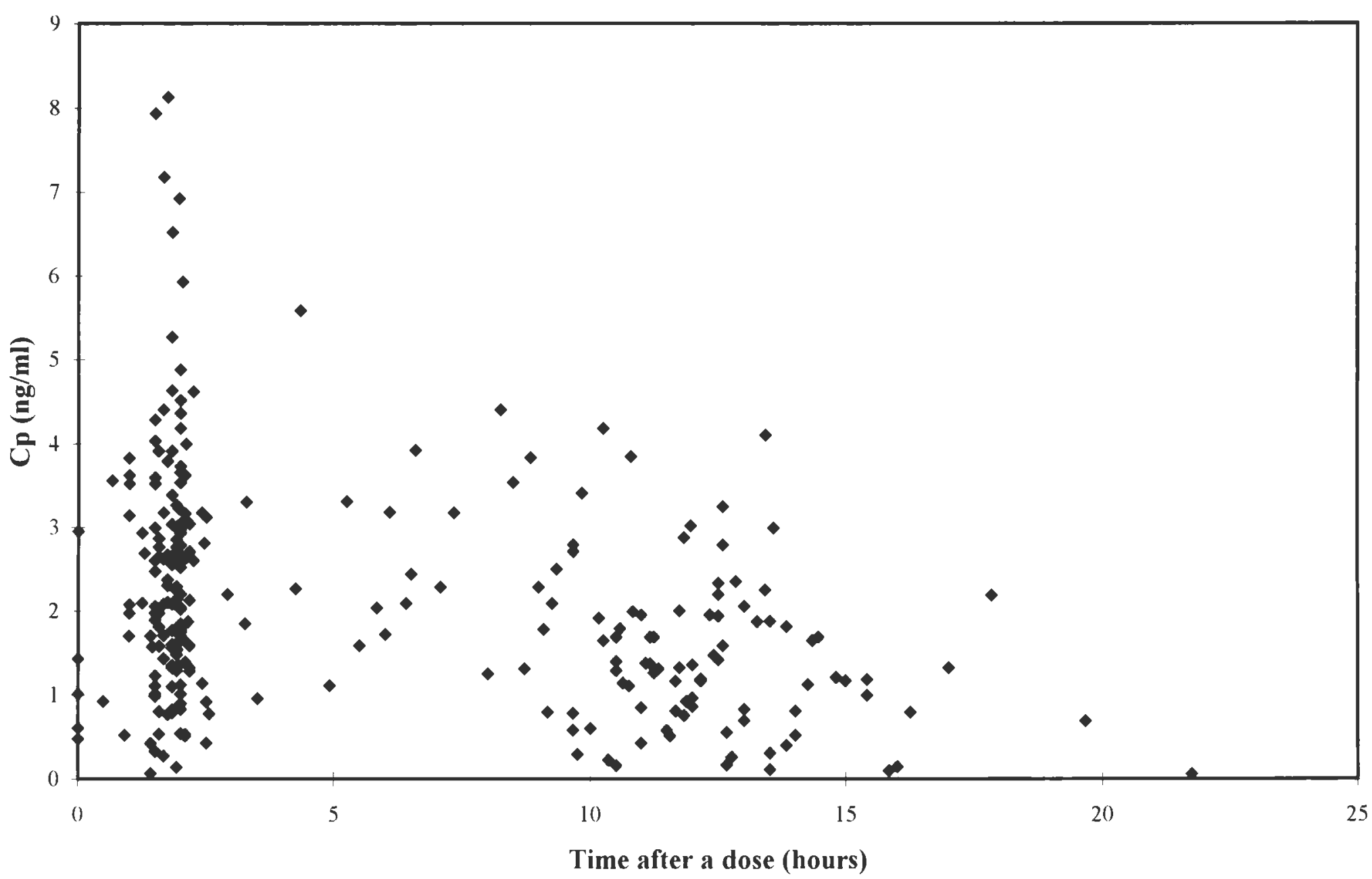


Figure 3: NONMEM Control File for the Final Model (Model 1 and FO Method)

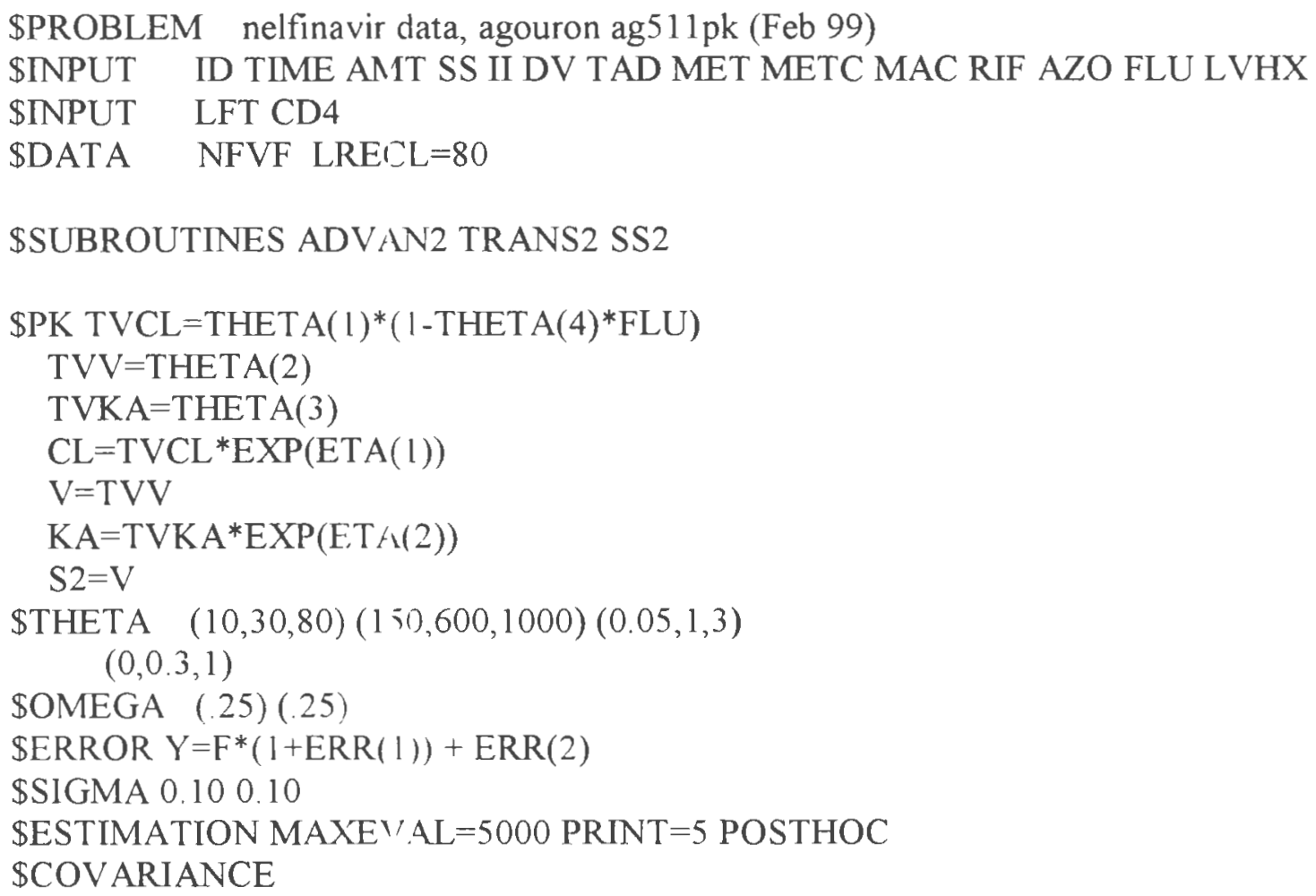


Figure 4: NONMEM Control File for the Final Model (Model 1 and FOCE Method)

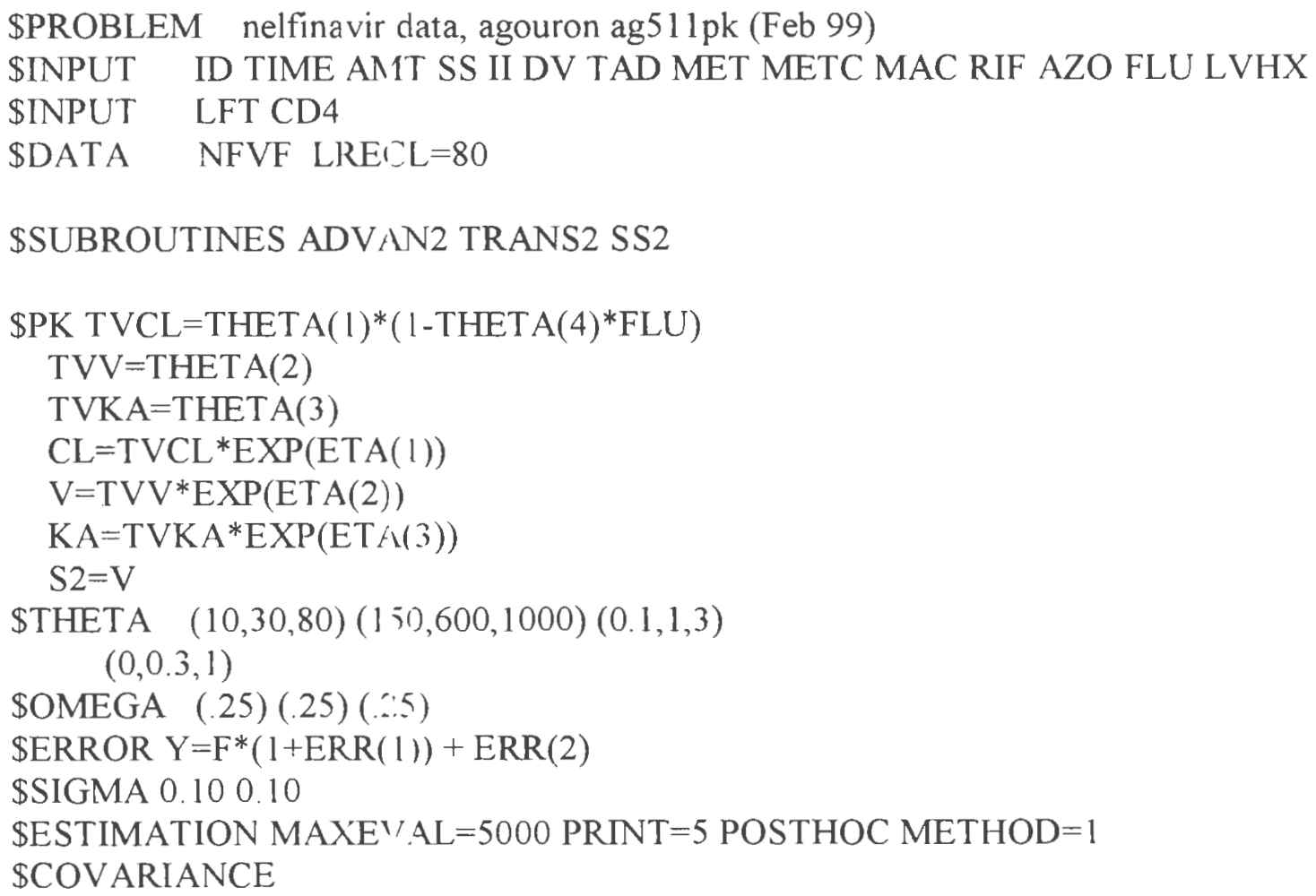


Figure 5: NONMEM Control File for the Final Model (Model 2 and FO Method)

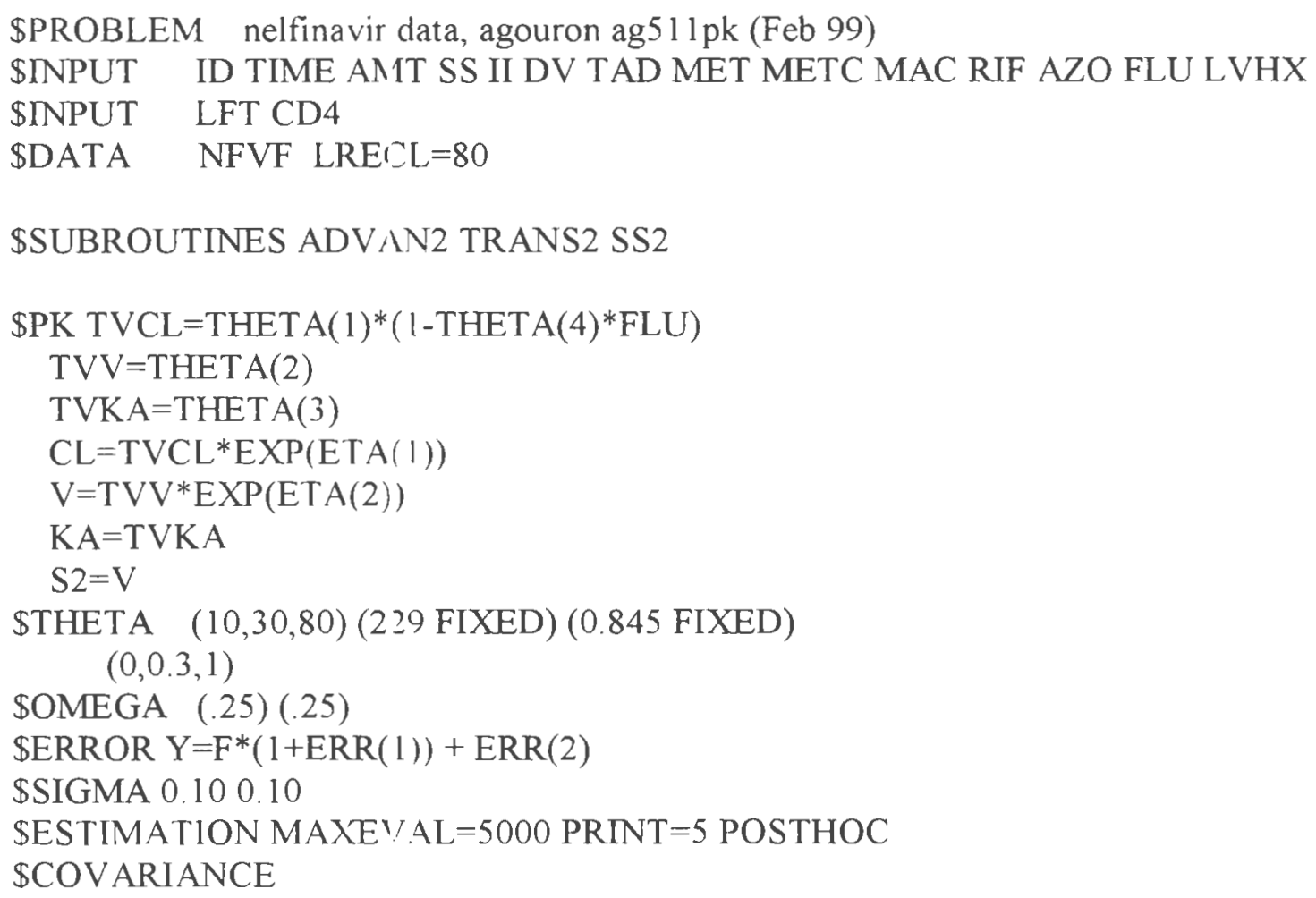


Figure 6: NONMEM Control File for the Final Model (Model 2 and FOCE Method)

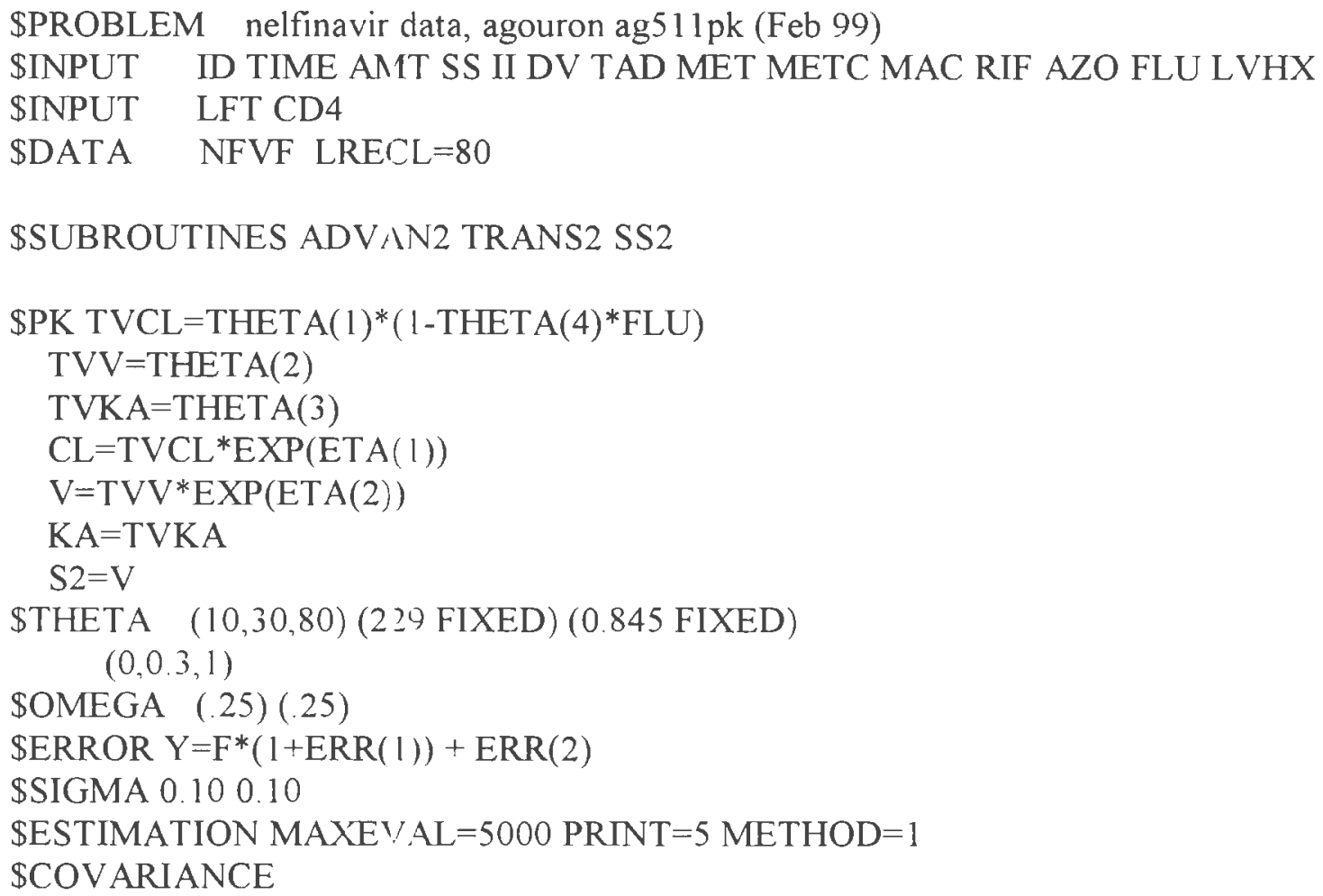




\section{BIBLIOGRAPHY}

Aarons L. Sparse Data Analysis. European Journal of Drug Metabolism and

Pharmacokinetics, 1993; 18 (1): 97-100.

Aarons L. Population pharmacokinetics: Theory and practice. British Journal of Clinical Pharmacology, 1991; 32: 669-670.

Aarons L., Balant L. P., Mentre F., Morselli P. L., Rowland M., Steimer J-L. and Vozeh S. Population approaches in drug development: Report on an expert meeting to discuss population pharmacokinetic/pharmacodynamic software. European Journal of ('linical Pharmacology, 1994; 46: 389-391.

Aarons L., Balant L. P., Mentre F., Morselli P. L., Rowland M., Steimer J-L. and Vozeh S. Practical Experience and issues in designing and performing population pharmacokinetic / pharmacodynamic studies. European Journal of ( linical Pharmacology, 1996; 49: $251-254$.

Aarons L., Mandema J. W. and Danhof M. A population analysis of the pharmacokinetics and pharmacodynamics of midazolam in the rat. Journal of Pharmacokinetics and Biopharmaceutics, 1991; 19 (5): 485-496.

Agouron Prescribing Information. Agouron Pharmaceuticals, La Jolla, CA. 
Al-Banna M. K., Kelman A. W. and Whiting B. Experimental design and efficient parameter estimation in population pharmacokinetics. Journal of Pharmacokinetics and Biopharmaceutics, 1990; 18 (4): 347-360.

Antal E. J., Grasela T. H. and Smith R. B. The application of population pharmacokinetic analyses to large scale clinical efficacy trials. Journal of Pharmacokinetics and Biopharmaceutics, 1991; 19 (3): 37S - 46S.

Antal E. J., Grasela T. H. and Smith R. B. An Evaluation of Population Pharmacokinetics in Therapeutic Trials. Part III. Prospective Data Collection versus Retrospective Data Assembly. Clinical Pharmacology and Therapeutics, 1989; 46: 552-559.

Barry M., Gibbons S., Back D. and Mulcahy F. Protease Inhibitors in Patients with HIV Disease. Clinically Important Pharmacokinetic Considerations. Clinical Pharmacokinetics, 1997; 32 (3): 194-209.

Beal S. L. and Sheiner L. B. Estimating population kinetics. CRC C'ritical Reviews in Biomedical Engineering, 1982; 8 (3): 195-222

Beal S. L. and Sheiner L. B. (eds.), NONMFM Users (imides, NONMEM Project Group, University of California at San Francisco, San Francisco, CA. 1992. 
Breant V., Charpiat B., Sab J. M., Maire P. and Jelliffe R. W. How many patients and blood levels are necessary for population pharmacokinetic analysis? A study of a one compartment model applied to cyclosporine. European Journal of Clinical Pharmacology, 1996; 51: 283 - 288 .

Burstein A. H., Gal P. and Forrest A. Evaluation of a sparse sampling strategy for determining vancomycin pharmacokinetics in preterm neonates: application of optimal sampling theory. Annals of Pharmacotherapy, 1997; 31: 980-3.

Cato III A., Cao G., Hsu A., Cavanaugh J., Leonard J. and Granneman R. Evaluation of the Effect of Fluconazole on the Pharmacokinetics of Ritonavir. Drug Metabolism and Disposition, 1997; 25(9): $1104-1106$

Clendennin N., Quart B., Anderson R., Knowles M. and Chang Y. Analysis of Long-term Virologic Data from the Viracept (Nelfinavir, NFV) 511 Protocol Using 3 HIV-RNA Assays. $5^{\text {th }}$ ('onference on Retroviruses and Opportunistic Infections, Chicago, 1-5 February, 1998, Abstract 372.

Colburn W. A. Controversy IV: Population Pharmacokinetics, NONMEM and the Pharmacokinetic Screen; Academic, Industrial and Regulatory Perspectives. Journal of C.linical Pharmacology, 1989; 29: 1-6. 
D'Argenio D. Z. and Schumitzky A. ADAPT II Iser's Guide, Biomedical Simulation Resource, University of Southern California, Los Angeles, 1992.

D'Argenio D. Z. Optimal sampling times for pharmacokinetic experiments. Journal of Pharmacokinetics and Biopharmaceutics, 1981; 9 (6): 739-756.

Davidian M. and Gallant A. R. The nonlinear mixed effects model with a smooth random effects density. Biometrika, 1993; 80: 475-488.

Deeks S. G., Smith M., Holodniy M. and Kahn J. O. HIV-1 Protease Inhibitors. A Review for Clinicians. JAMA, Jan 8 1997; 277 (2): 145-153.

DeVane C. L., Grasela T. H., Antal E. J., and Miller R. L. An evaluation of population pharmacokinetics in therapeutic trials. Part IV. Application to postmarketing surveillance Clinical Pharmacology and Therapeutics, 1993; 53: 521-528.

De Wit S., Debier M., De Smet M., McCrea J., Stone J., Carides A., Matthews C., Deutsch P. and Clumeck N. Effect of Fluconazole on Indinavir Pharmacokinetics in Human Immunodeficiency Virus-Infected Patients. Antimicrobial Agents and (hemotherapy, Feb 1998; 44 (2): 223-227.

DiStephano III J. J. Optimized blood sampling protocols and sequential design of kinetic experiments. American Journal of Physiology, 1981; 240: R259-R265. 
Drusano G. L., Forrest A., Snyder M. J., Reed M. D. and Blumer J. L. An evaluation of optimal sampling strategy and adaptive study design. Clinical Pharmacology and Therapeutics, 1988; 44: 232-238;

Drusano G. L., Forrest A., Plaisance K. I. and Wade J. C. A prospective evaluation of optimal sampling theory in the determination of the steady-state pharmacokinetics of piperacillin in febrile neutropenic patients. Clinical Pharmacology and Therapeutics, $1989 ; 45: 635-641$.

Drusano G. L., Forrest A., Yuen G., Plaisance K. and Leslie J. Optimal Sampling Theory: Effect of error in a nominal parameter value in bias and precision of parameter estimation. Journal of Clinical Pharmacology, 1994; 34(10): 967-974.

Ette E. I. Stability and performance of a population pharmacokinetic model. Journal of Clinical Pharmacology, 1997; 37: 486-495.

Ette E. I., Howie C. A., Kelman A. W. and Whiting B. Experimental design and efficient parameter estimation in preclinical pharmacokinetic studies. Pharmaceutical Research, 1995: $12(5): 729-737$ 
Ette E. I., Kelman A. W, Howie C. A. and Whiting B. Interpretation of Simulation Studies for efficient estimation of population pharmacokinetic parameters. The Annals of Pharmacotherapy, 1993; 27(9): 1034-1039.

Ette E. I., Kelman A. W., Howie C. A. and Whiting B. Influence of inter-animal variability on the estimation of population pharmacokinetic parameters in pre-clinical studies. Clinical Research and Regulatory Affairs, 1994; 11(2): 121-139.

Ette E. I., Kelman A. W., Howie C. A. and Whiting B. An application of the population approach to animal pharmacokinetics during drug development. ('linical Research and Regulatory Affairs, 1994; 11 (3 and 4): 243-255.

Ette E. I., Kelman A. W., Howie C. A. and Whiting B. Analysis of animal pharmacokinetic data: Performance of the one point per animal design. Journal of Pharmacokinetics and Biopharmaceutics, 1995; 23 (6): 551 - 566.

Ette E. I., Sun H. and Ludden T. M. Design of population pharmacokinetic studies. Proceedings of the American Statistical Association (Biopharmaceutics Section), 1994; 487-492.

Ette E. I., Sun H. and Ludden T. M. Ignorability and Parameter estimation in longitudinal population pharmacokinetic studies. Journal of (linical Pharmacology, 1998; 38(3): $221-226$ 
Ette E. I., Sun H. and Ludden T. M. Balanced Designs in longitudinal population pharmacokinetic studies. Journal of ('linical Pharmacology, 1998; 38(5): 417-423.

Flexner C., Hsu A., Kerr B., Wong C., Gallant J., Anderson R., Health-Chiozzi M. Steady-state Pharmacokinetic Interaction Between Ritonavir (RTV), Nelfinavir (NFV) and the Nelfinavir Active Metabolite M8 (AG1402). $12^{\text {th }}$ World AIDS (.onference, Geneva, 1998; Abstract 42265 .

Forrest A., Ballow C. H., Nix D. E., Birmingham M. C. and Schentag J. J. Development of a population pharmacokinetic model and optimal sampling strategies for intravenous ciprofloxacin. Antimicrobial Agents and ('hemotherapy, 1993; 37(5): 1065-1072.

Goa K. L. and Barradell L. B. Fluconazole. An Update of its Pharmacodynamic and Pharmacokinetic Properties and Therapeutic Use in Major Superficial and Systemic Mycoses in Immunocompromised Patients. Drugs, 1995; 50 (4): 658-690.

Grasela T. H., Antal E. J., Townsend R. J., and Smith R. B. An evaluation of population pharmacokinetics in therapeutic trials. Part 1. Comparison of methodologies. (linical Pharmacology and Therapeutics, 1986; 39 (6): 605-612. 
Grasela T. H., Antal E. J., and Smith R. B. An evaluation of population pharmacokinetics in therapeutic trials. Part II. Detection of a drug-drug interaction. Clinical Pharmacology and Therapeutics, 1987; 42: 433-441.

Guidance for Industry: Population Pharmacokinetics. U.S. Department of Health and Human Services, Food and Drug Administration, Center for Drug Evaluation (CDER), February 1999.

Guidance for Industry: Population Pharmacokinetics (Draft Guidance). U.S. Department of Health and Human Services, Food and Drug Administration, Center for Drug Evaluation (CDER), September 1997.

Hashimoto Y. and Sheiner L. B. Designs for population pharmacodynamics: Value of pharmacokinetic data and population analysis. Journal of Pharmacokinetics and Biopharmaceutics, 1981; 19 (3): $333-353$

Hendeles L., Weinberger M. and Bighley L. Disposition of Theophylline after a single intravenous infusion of aminophylline. The American Review of Respiratory Disease, $1978 ; 118(1): 97-103$

Hsu A., Granneman R. and Bertz R. J. Ritonavir. Clinical Pharmacokinetics and Interactions with Other Anti-HIV Drugs. (linical Pharmacokinetics, 1998; 35 (4): 275 291. 
Jackson K. A. and Rosenbaum S. E. The Application of Population Pharmacokinetics to the Drug Development Process. Drug Development and Industrial Pharmacy, 1998; 24 (12): 1155-1162.

Jelliffe R. W., Schumitsky A., Bayard D., Milman M., Van Guilder M., Wang X., Jiang F., Barbaut X. and Maire P. Model-based, goal-oriented, individualized drug therapy. Clinical Pharmacokinetics, 1998; 34 (1), 57-77.

Jones C. D., Sun H. and Ette E. I. Designing cross-sectional population pharmacokinetic studies: implications for pediatric and animal studies. ('inical Research and Regulatory Affairs, 1996; 13 (3\& 4): $133-165$

Jonsson E. N., Wade J. R. and Karlsson M. O. Comparison of Some Practical Sampling Strategies for Population Pharmacokinetic Studies. Journal of Pharmacokinetics and Biopharmacentics, 1996; 24 (2): 245-263.

Kerr B., Yuen G., Daniels R., Quart B. and Anderson R. Strategic Approach to Nelfinavir Mesylate (NFV) Drug Interactions Involving CYP3A Metabolism. $f^{\text {th }}$ National Conference on Human Retroviruses and Related Infections, 1997; Abstract.

Kohl N. E., Emini E. A., Schleif W. A., Davis L. J., Heimbach J. C., Dixon R. A. F., Scolnick E. M. and Sigal I. S. Active Human Immunodeficiency Virus Protease is 
Required for Viral Infectivity. Proceedings of the National Academy of Sciences USA, July $1988 ; 85: 4686-4690$.

Lee C. A., Liang B-H., Wu E. Y., Grettenberger H. M., Sandoval T. M., Zhang K. E. and Shetty B. V. Prediction of Nelfinavir Mesylate (Viracept) Clinical Drug Interactions Based on In Vitro Human P450 Metabolism Studies. $f^{\text {th }}$ National ( onference on Human Retroviruses and Related Infections, 1997; Abstract.

Lewis II J. S., Terriff C. M., Coulston D. R. and Garrison M.W. Protease Inhibitors: A Therapeutic Breakthrough for the Treatment of Patients with Human Immunodeficiency Virus. (Yinical Therapeutics, 1997; 19 (2): 187-214.

Lillibridge J. H., Liang B. H., Kerr B. M., Webber S., Quart B., Shetty B. V. and Lee C. A. Characterization of the Selectivity and Mechanism of Human Cytochrome P450 Inhibition by the Human Immunodeficiency Virus-Protease Inhibitor Nelfinavir Mesylate. Drug Metabolism and Disposition, 1998; 26 (7): 609 - 616.

Lillibridge J. L., Lee C. A., Pithavala Y. K., Sandoval T. M., Wu E. Y., Zhang K. E., Mazabel E. L., Zhang M. and Kerr B. M. The Role of CYP2C19 in the Formation of Nelfinavir Hydroxy-t-butylamide (M8): In Vitro/In Vivo Correlation. $5^{\text {th }}$ International ISSX Meeting, Cairns, Australia, October 25-29, 1998; Abstract 109. 
Lin J. H. and Lu A. Y. H. Inhibition and Induction of Cytochrome P450 and the Clinical Implications. Clinical Pharmacokinetics, Nov1998; 35 (5): $361-390$

Lindstrom M. J. and Bates D. M. Nonlinear mixed effects models for repeated measures data. Biometrics, $1990 ; 46: 673-687$

Ludden T. M. Population pharmacokinetics. Journal of ('linical Pharmacology, 1988; 28: 1059-1063.

Maitre P. O., Buhrer M., Thomson D. and Stanski D. R. A Three-Step Approach Combining Bayesian Regression and NONMEM Population Analysis. Journal of Pharmacokinetics and Biopharmacentics, $1991 ; 19$ (4): 377-384.

Mallet A. A maximum likelihood estimation method for random coefficient regression models, Biometrika, 1986; 73: 645-656.

Mandema J. W., Verotta D. and Sheiner L. B. Building Population PharmacokineticPharmacodynamic Models. I. Models for Covariate Effects. Journal of Pharmacokinetics and Biopharmaceutics, 1992; 20 (5): $511-528$.

Markowitz M., Conant M., Hurley A., Schluger R., Duran M., Peterkin J., Chapman S., Patick A., Hendricks A., Yuen G. J., Hoskins W., Clendininn N. and Ho D. D. A Preliminary Evaluation of Nelfinavir Mesylate, an Inhibitor of Human Immunodeficiency 
Virus (HIV)-1 Protease, to Treat HIV Infection. The Journal of Infectious Diseases, 1998; 177: 1533-40.

McDonald C. K. and Kuritzkes D. R. Human Immunodeficiency Virus Type 1 Protease Inhibitors. Archives of Internal Medicine, May 12 1997; 157: 951-959.

McLachlan A. J. Sparse Concentration Data Analysis using a Population approach: a valuable tool in clinical pharmacology. (Cinical and Experimental Pharmacology and Physiology, 1996; 23: 995-999.

Mitenko P.A. and Ogilvie R. A. Pharmacokinetics of intravenous theophylline ('linical Pharmacology and Therapeutics, 1973; 14(4): 509-513

Moyle G. J., Youle M., Higgs C., Monaghan J., Prince W., Chapman S., Clendeninn N. and Nelson M. R. Safety, Pharmacokinetics, and Antiretroviral Activity of the Potent Specific Human Immunodeficiency Virus Protease Inhibitor Nelfinavir: Results of a Phase I/II Trial and Extended Follow-up in Patients Infected with Human Immunodeficiency Virus. Journal of ('linical Pharmacology, 1998; 38: 736 - 743.

Peck C. C., Barr W. H., Benet L. Z., Collins J., Desjardins R. E., Furst D. E., Harter J. G., Levy G., Ludden T., Rodman J. H. et al. Conference Report: Opportunities for integration of pharmacokinetics, pharmacodynamics and toxicokinetics in rational drug development. Clinical Pharmacology and Therapeutics, 1992; 51: 465-473. 
Peng C, Ho B. K., Chang T. W. and Chang N. T. Role of Human Immunodeficiency Virus Type 1-Specific Protease in Core Protein Maturation and Viral Infectivity. Journal of Virology, June 1989; 63(6): 2550-2556

Proceedings from the Public Meeting on FDA's Proposed Regulation to Increase Pediatric Use Information for Drugs and Biologics, U.S. Department of Health and Human Services, Food and Drug Administration, Center for Drug Evaluation (CDER), October 271997.

Quart BD, Chapman SK, Peterkin J et al. Phase I safety, tolerance, pharmacokinetics and food effect studies of AG1343 - a novel HIV protease Inhibitor. $2^{\text {nd }}$ National Conference on Human Retroviruses and Related Infections, Jan29-Feb2, 1995; Abstract 167.

Roe D. J. Comparison of Population Pharmacokinetic Modeling Methods Using Simulated Data: Results from the Population Modeling Workgroup. Statistics in Medicine, 1997; 16: 1241-1262.

Rosenbaum S. E., Carter A. A., and Dudley M. N. Population pharmacokinetics: Fundamentals, methods and applications. Drug Development and Industrial Pharmacy, $1995 ; 21(9): 1115-1141$ 
Saag M., Knowles M., Chang Y., Chapman S. and Clendennin N. J. Durable Effect of Viracept (Nelfinavir Mesylate, NFV) in Triple Combination Therapy. $37^{\text {th }}$ Interscience ('onference on Antimicrobial Agents and ('hemotherapy, Toronto, 28 September - 1 October, 1997; Abstract I-101.

Samara E. and Granneman R. Role of population pharmacokinetics in drug development. A pharmaceutical industry perspective. ('linical Pharmacokinetics, 1997; 32 (4): 294312.

Schumitzky A. Nonparametric EM algorithms for estimating prior distributions. Applied Mathematics and Computation, 1991; 45; 141-157.

Sheiner L. B. and Benet L. Z. Premarketing Observational Studies of Population Pharmacokinetics of New Drugs. ('linical Pharmacology and Therapeutics, November $1985 ; 38(5): 481-487$.

Sheiner L. B. and Beal S. L. Evaluation of methods for estimating population pharmacokinetic parameters II. Biexponential model and experimental pharmacokinetic data. Journal of Pharmacokinetics and Biopharmaceutics, 1981; 9 (5): 635-651.

Sheiner L. B. and Beal S. L. Evaluation of methods for estimating population pharmacokinetic parameters III. Monoexponential model: Routine clinical 
pharmacokinetic data. Journal of Pharmacokinetics and Biopharmaceutics, 1983; 11 (3): 303-319.

Sheiner L. B. and Grasela T. H. An introduction to mixed effect modeling: Concepts, definitions and justification. Journal of Pharmacokinetics and Biopharmaceutics, 1991; $19(3): 11 S-24 S$

Sheiner L. B. and Ludden T. M. Population Pharmacokinetics/Dynamics. Annual Review of Pharmacology and Toxicology, 1992; 32: 185-209.

Skowron G., Leoung G., Kerr B., Dusek A., Anderson R., Beebe S. and Grosso R. Lack of Pharmacokinetic Interaction Between Nelfinavir and Nevirapine. Editorial Comment. AII)S, 1998; 12: $1243-1244$

Sun H., Ette E. I. and Ludden T. M. On the recording of sampling times and parameter estimation from repeated measures pharmacokinetic data. Journal of Pharmacokinetics and Biopharmaceutics, 1996; 24 (6): 637-650.

Temple R. Discussion paper on the testing of drugs in the elderly. Memorandum of the Food and Drug Administration of DHHS, Washington, DC, 1983. 
Tett S. E., Holford N. H. G. and McLachlan A. J. Population Pharmacokinetics and Pharmacodynamics: An Underutilized resource. Drug Information Journal, 1998; 32 693-710.

Thomson A. H. and Whiting B. Bayesian parameter estimation and population pharmacokinetics, Clinical Pharmacokinetics, 1992; 22 (6): 447-467.

Troconiz I. F., Lopez-Bustamante L. G. and Fos D. Tenoxicam Pharmacokinetics in rats: A population model. Journal of Pharmaceutical Sciences, 1995; 84 (12), 1482- 1487.

Unadkat J. D. and Agosti J. M. Problems in Pharmacokinetic Investigations in Patients with HIV Infection. (linical Pharmacokinetics, 1990; 19(3): 172-176.

Vonesh E. F. and Carter R. L., Mixed-effects nonlinear regression for unbalanced repeated measures. Biometrics, 1992; 48: 1-17.

Vonesh E. F. Non-linear models for the analysis of longitudinal data. Statistics in Medicine, 1992; 11, 1929-1954.

Vozeh S., Steimer J. L., Rowland M., Morselli P., Mentre F., Balant L. P. and Aarons L. The use of population pharmacokinetics in drug development. ('linical Pharmacokinetics, 1996; 30 (2): 81-93. 
Wade J., Kelman A., Howie C. and Whiting B. Misspecification of ka in NONMEM Analysis. Journal of Pharmacokinetics and Biopharmaceutics, 1993; 21(2): 209-222.

Wakefield J., Smith A. F. M., Racine-Poon A., and Gelfand A. Bayesian analysis of linear and nonlinear population models using the Gibbs sampler. Applied Statistics, 1994; 43: 201-221.

White D. B., Walawander C. A., Tung Y. and Grasela T. H. An Evaluation of Point and Interval Estimates in Population Pharmacokinetics using NONMEM analysis. Journal of Pharmacokinetics and Biopharmaceutics, 1991; 19 (1): 87-112.

Whiting B., Kelman A. W., and Grevel J. Population pharmacokinetics: Theory and clinical application. (linical Pharmacokinetics, 1986; 11:387-401.

Wolfinger R. D. Laplace's approximation for nonlinear mixed effects models Biometrika, 1993; 80: 791-795.

Wu E. Y., Wilkinson II J. M. and Shetty B. V. High-performance liquid chromatographic method for the determination of nelfinavir, a novel HIV-1 protease inhibitor, in human plasma. Journal of ('hromatography B. Biomedical Applications, 1997; 695: 373-380.

Wu E. Y., Sandoval T. M., Zhang K. E., Grettenberger H. M., Hee B. R., Lee C. A., Webber S. and Shetty B. V. Cytochrome P450 Isoforms involved in the Metabolism of 
Nelfinavir Mesylate, an HIV-1 Protease Inhibitor. $5^{\text {th }}$ International ISSX Meeting, Cairns, Australia, October 25-29, 1998; Abstract 110.

Yuen G. J., Anderson R., Sandoval T., Wu E., Shetty B. V. and Kerr B. M. The Pharmacokinetics (PK) of Nelfinavir (N) Administered Alone and with Rifampin (Rif) in Healthy Volunteers. Clinical Pharmacology and Therapeutics, 1997; 61 (2): 147, Abstract Pl-40.

Yuen G. J., Drusano G. L., Forrest A., Plaisance K. and Caplan E. S. Prospective use of optimal sampling theory: Steady-state ciprofloxacin pharmacokinetics in critically ill trauma patients. ('linical Pharmacology and Therapeutics, 1989; 46: 451-457.

Zhang, M. H., Pithavala Y. K., Lee C. A., Lillibridge J. H., Wu E. Y., Sandoval T. M., Daniels R. G. and Kerr B. M. Apparent Genetic Polymorphism in Nelfinavir Metabolism Evaluation of Clinical Relevance. $12^{\text {ih }}$ International Symposium on Microsomes and Drug Oxidations, Montpelier, France, 20-24 July, 1998; Abstract 264. 